UNIVERSIDAD DE SALAMANCA

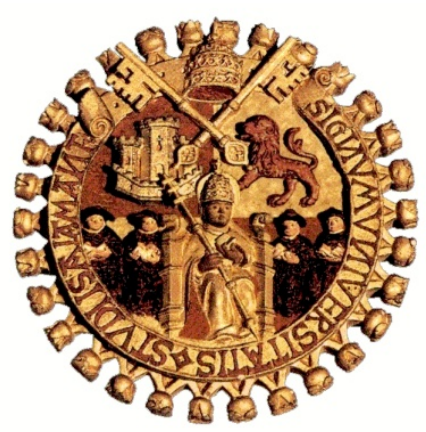

INSTITUTO UNIVERSITARIO DE BIOLOGIA MOLECULAR

Y CELULAR DEL CANCER

DEPARTAMENTO DE MEDICINA

\title{
ANÁLISIS DE POLIMORFISMOS DE GENES RELACIONADOS A LA AUTOFAGIA EN PACIENTES CON COLITIS ULCEROSA
}

\author{
YULIANA MÓNICA JAMANCA POMA
}

\author{
TESIS DOCTORAL
}

DIRECTORES

Prof. Dr. Antonio Rodríguez Pérez

Dra. Alejandra Fernández Pordomingo

TUTOR

Prof. Dr. Rogelio González Sarmiento 
DR. D. ANTONIO RODRÍGUEZ PÉREZ, JEFE DE SERVICIO DE APARATO DIGESTIVO DEL HOSPITAL UNIVERSITARIO DE SALAMANCA Y PROFESOR ASOCIADO DEL DEPARTAMENTO DE MEDICINA DE LA UNIVERSIDAD DE SALAMANCA,

DRA. $\mathrm{D}^{\mathrm{a}}$. ALEJANDRA FERNÁNDEZ PORDOMINGO, MEDICO LICENCIADO ESPECIALISTA DEL SERVICIO DE APARATO DIGESTIVO DEL HOSPITAL UNIVERSITARIO DE SALAMANCA,

\section{CERTIFICAN:}

Que el trabajo titulado: "Análisis de polimorfismos de genes relacionados a la autofagia en pacientes con colitis ulcerosa", que presenta la Licenciada en Medicina, Dña. Yuliana Mónica Jamanca Poma, ha sido realizado bajo nuestra dirección en el Departamento de Medicina y reúne, a nuestro juicio, los requisitos necesarios para que sea presentado ante el tribunal correspondiente y optar al título de "Doctor" por la Universidad de Salamanca.

Y para que así conste y a los efectos oportunos, expiden el presente certificado en Salamanca a del 2017.

Dr. D. Antonio Rodríguez Pérez Dra. $D^{a}$. Alejandra Fernández Pordomingo 
El presente trabajo ha sido desarrollado en la Unidad de Medicina Molecular USAL-IBSAL y financiado por una ayuda de la Gerencia Regional de Salud de la Junta de Castilla y León, referencia GRS 1043/A/14. 


\section{AGRADECIMIENTOS}

En estas líneas quisiera expresar mi más sincero agradecimiento a todas aquellas personas que han contribuido de una manera $u$ otra a la finalización de este proyecto.

Debo agradecer de manera especial y sincera al Dr. Antonio Rodríguez Pérez por su apoyo y confianza no sólo en el desarrollo de esta tesis, sino también en mi formación como especialista.

A la Dra. Alejandra Fernández Pordomingo quisiera agradecerle su estrecha colaboración en muchas de las tareas realizadas, su completa disposición en todo momento así como paciencia a la hora de las correcciones.

Al Dr. Rogelio González Sarmiento por su disponibilidad, colaboración y por darme las facilidades para el desarrollo de la tesis.

Para todos los miembros de Unidad de Medicina Molecular USALIBSAL, en especial a Ricardo Usategui Martin; por su colaboración y paciencia en el desarrollo del trabajo de laboratorio y a Javier Martin Vallejo, del Departamento de Estadística de la Facultad de Medicina de la Universidad de Salamanca por su gran ayuda en el análisis estadístico.

Así mismo agradezco mis compañeros del Servicio de Digestivo del HUS, que de alguna forma han apoyado este proyecto.

Agradezco a mi familia, porque a pesar que no están presentes físicamente, siempre me han hecho sentir su apoyo incondicional. A Juan y a mi hijo Alejandro, por ser mi principal motivación. 


\section{ÍNDICE DE CAPÍTULOS}

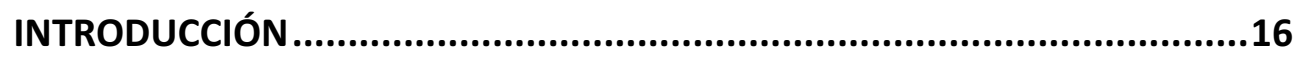

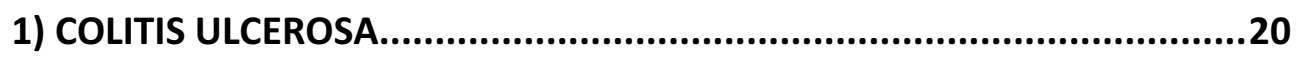

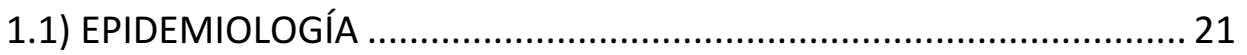

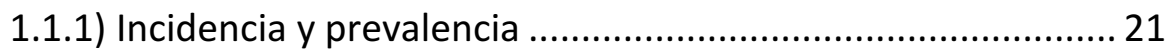

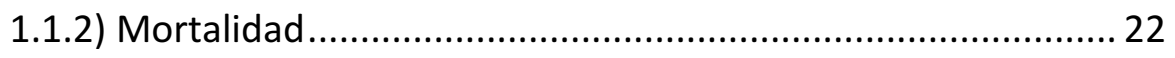

1.1.3) Características demográficas................................................. 23

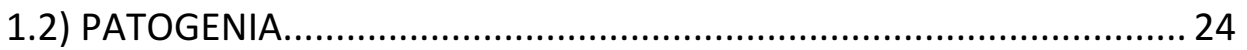

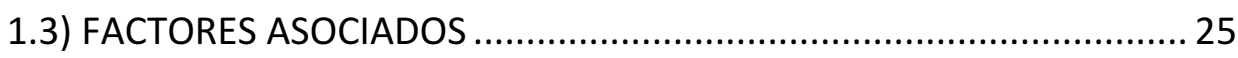

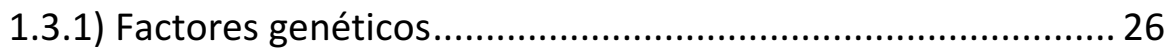

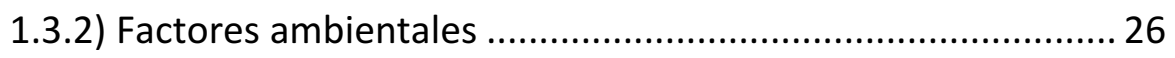

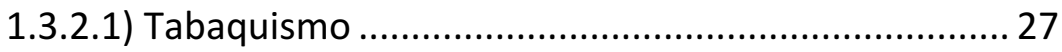

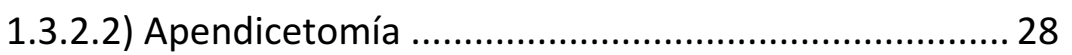

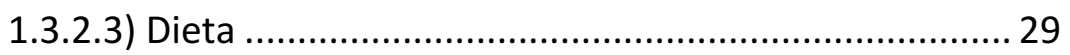

1.3.2.4) Vitamina D ........................................................... 29

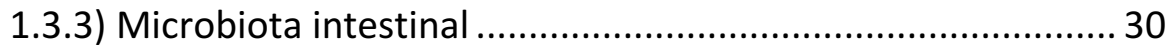

1.3.3.1) Disbiosis en la Ell .................................................. 32

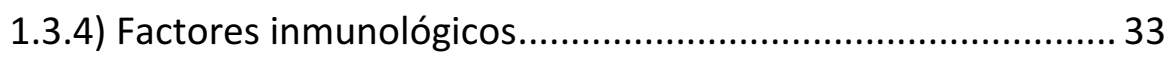

1.3.4.1) Respuesta inmune innata ....................................... 34

1.3.4.2) Respuesta inmune adaptativa ................................. 40

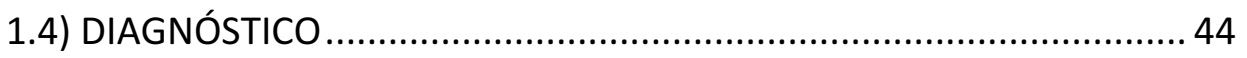

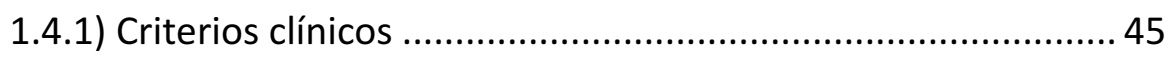

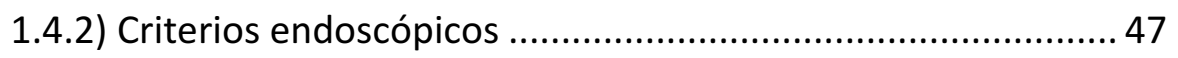

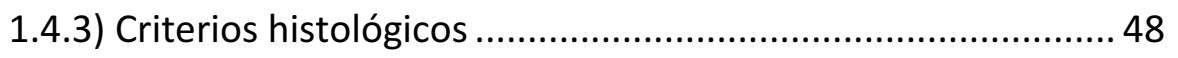

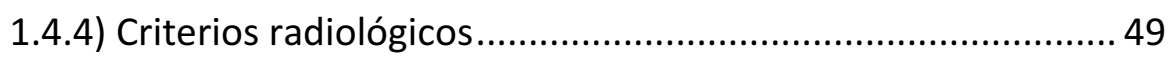

1.5) CLASIFICACIÓN DE LA COLITIS ULCEROSA ...................................... 49

1.6) EVALUACIÓN DE LA ACTIVIDAD DE LA ENFERMEDAD ..................... 51

1.6.1) Índices de actividad clínica ................................................. 51

1.7) DEFINICIÓN DE ALGUNAS VARIABLES ANALIZADAS ........................55

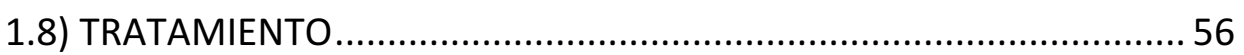




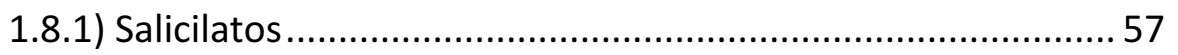

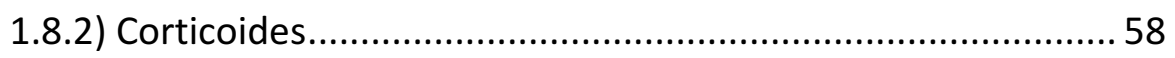

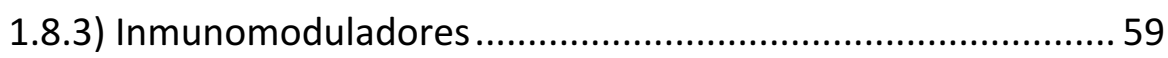

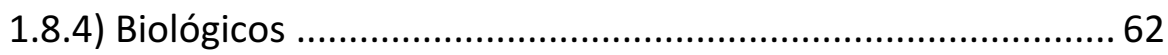

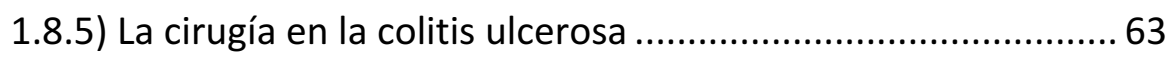

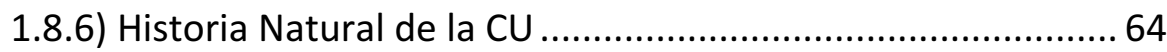

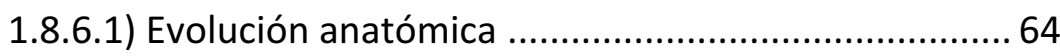

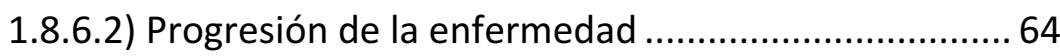

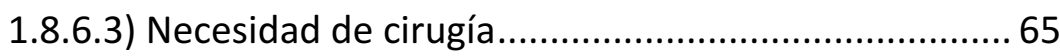

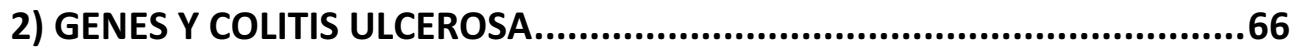

2.1) GENES RELACIONADOS CON LA INFLAMACIÓN ...............................69

2.1.1) CTLA4 (Cytotoxic T-lymphocyte antigen 4) .............................69

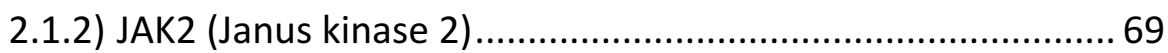

2.1.3) STAT3 (Signal transducer and activator of transcription 3)...69

2.1.4) TNFA (Factor de necrosis Tumoral alpha) .............................. 70

2.1.5) OCTN1 (SLC22A4) y OCTN2 (SLC22A5) ................................. 70

2.1.6) MDR1 (Multidrug-resistant transporter-1) ........................... 71

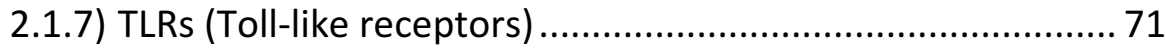

2.1.8) CAM (moléculas de adhesión celular) .................................. 72

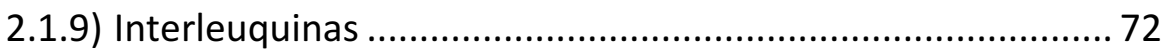

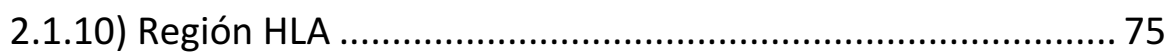

2.2) GENES QUE REGULAN LA BARRERA INTESTINAL .......................... 76

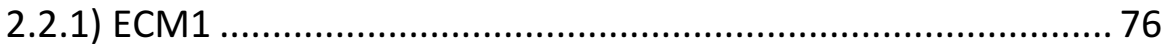

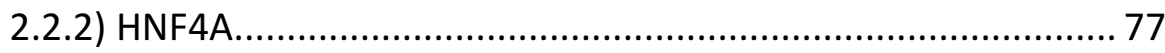

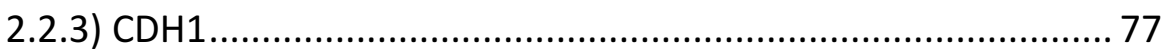

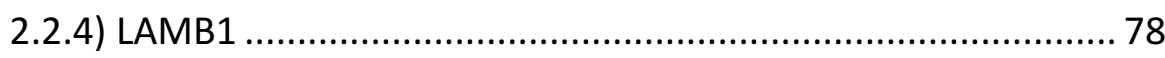

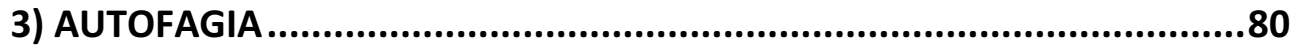

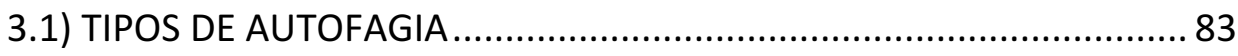

3.2) SEÑALIZACIÓN DE LA MAQUINARIA DE AUTOFAGIA ......................84

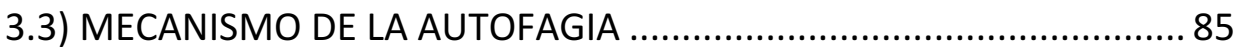


3.4) REGULACIÓN DE LA AUTOFAGIA ............................................... 88

3.5) GENES RELACIONADOS CON LA AUTOFAGIA (ATG) ..................... 89

3.6) AUTOFAGIA EN LA RESPUESTA INMUNITARIA ............................ 90

3.6.1) Autofagia en la inmunidad innata ................................... 91

3.6.2) Autofagia en la inmunidad adaptativa .............................. 91

3.6.3) Autofagia y presentación antigénica .................................. 92

3.6.3.1) Autofagia y presentación antigénica en MHC clase I 93

3.6.3.2) Autofagia y presentación antigénica en MHC clase II

93

3.7) AUTOFAGIA Y HOMEOSTASIS INTESTINAL ................................ 94

3.8) AUTOFAGIA Y MICROBIOTA INTESTINAL .................................... 95

3.9) ROL DE LA AUTOFAGIA EN LA INFLAMACIÓN............................... 95

3.10) AUTOFAGIA, ROL ANTIMICROBIANO..................................... 97

4) AUTOFAGIA EN LA Ell ..............................................................100

4.1) AUTOFAGIA COMO DIANA TERAPÉUTICA ............................... 103

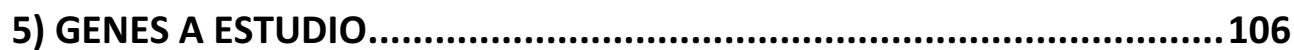

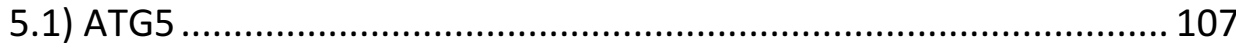

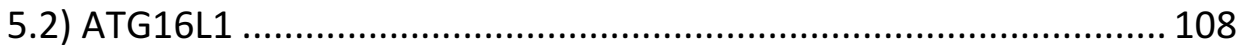

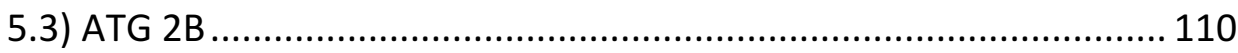

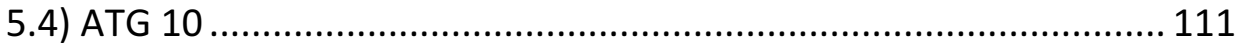

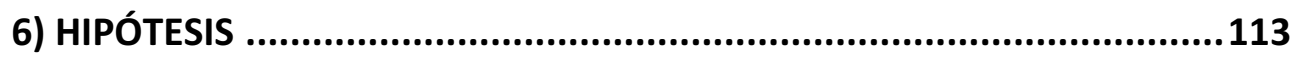

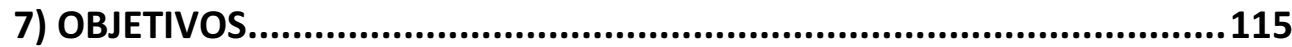

8) MATERIAL Y MÉTODOS............................................................117

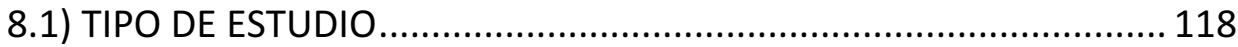

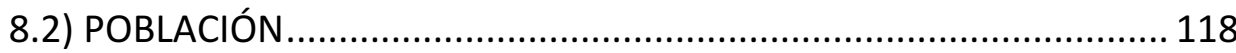

8.3) RECOGIDA Y PROCESADO DE LAS MUESTRAS ............................ 119

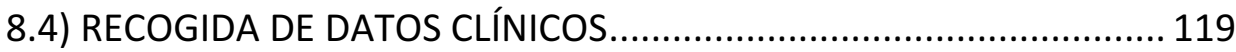

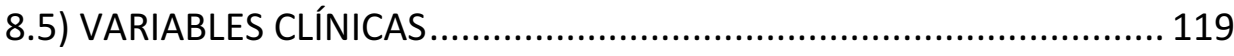




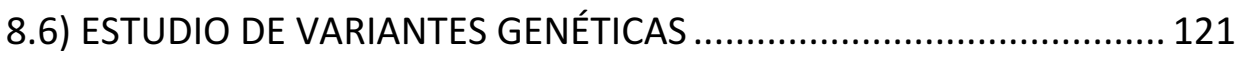

8.6.1) Metodología del análisis de polimorfismos ........................ 121

8.6.2) Aislamiento de ADN y genotipado del polimorfismo ........... 122

8.6.3) Discriminación alélica mediante PCR con sondas TaqMan . 122

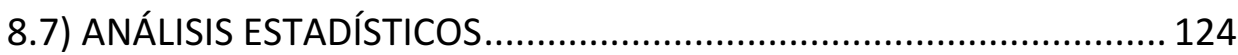

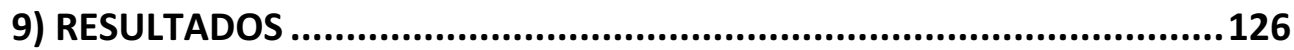

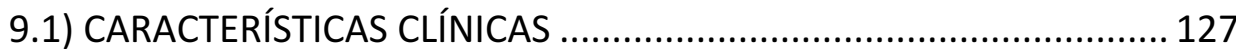

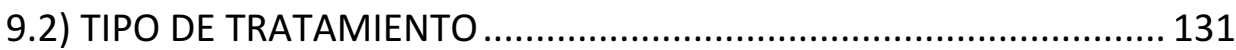

9.3) ASOCIACIÓN ENTRE VARIABLES CLÍNICAS ..................................... 136

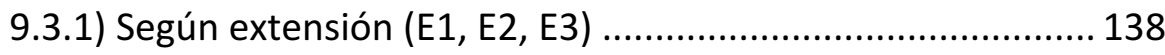

9.3.2) Según gravedad (S1, S2, S3) ........................................... 141

9.4) ESTUDIO DE POLIMORFISMOS …………………...................... 144

9.4.1) Comparación de polimorfimos con grupo control

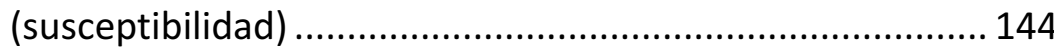

9.4.2) Asociación entre polimorfismos y variables clínicas ............ 147

9.4.3) Asociación entre el genotipo ATG16L1, la variante alélica y susceptibilidad a la enfermedad ....................................... 150

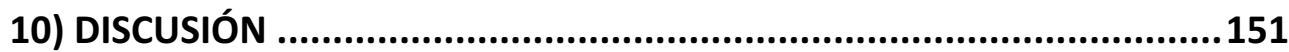

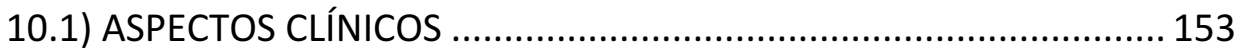

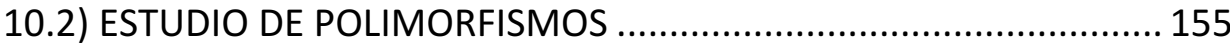

10.3) ESTUDIO DE VARIABLES CLÍNICAS Y POLIMORFISMOS................. 159

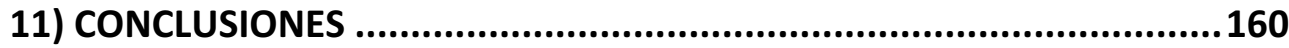

12) LIMITACIONES

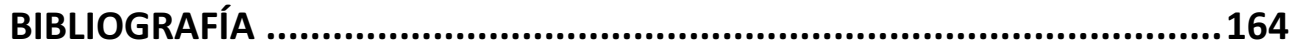

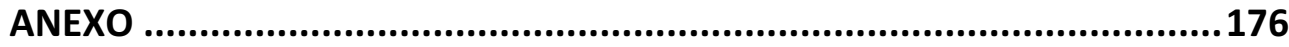




\section{ÍNDICE DE TABLAS}

Tabla 1. Criterios diagnósticos de Lennard-Jones ...................................... 45

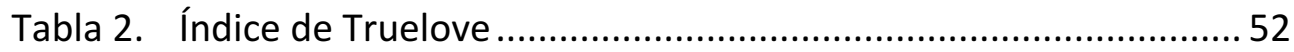

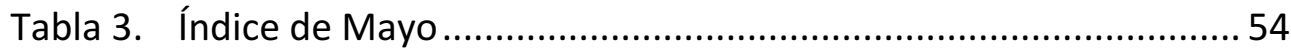

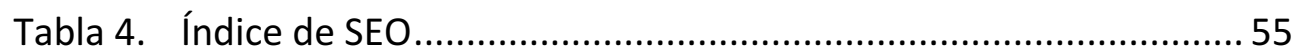

Tabla 5. Fármacos en la Ell y sus acciones en la modulación de la autofagia 61

Tabla 6. Fármacos en la CU según grado de recomendación y niveles de

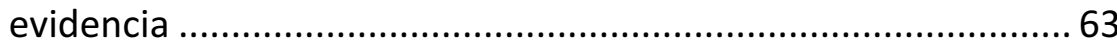

Tabla 7. Proteínas ATG y características funcionales ................................. 82

Tabla 8. Polimorfismos de los genes relacionados con la autofagia analizados en este estudio ....................................................... 124

Tabla 9. Características generales de los pacientes ................................ 130

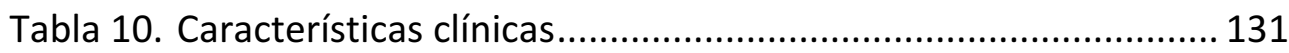

Tabla 11. Tratamiento recibido y respuesta ............................................ 136

Tabla 12. Asociación entre la edad al diagnóstico y variables clínicas .......... 138

Tabla 13. Asociación entre edad al diagnóstico y el uso de corticoides ......... 138

Tabla 14. Asociación entre la extensión y las variables clínicas................. 139

Tabla 15. Asociación entre la gravedad y variables clínicas........................ 143

Tabla 16. Asociación entre hábito tabáquico y el tratamiento ................... 144

Tabla 17. Distribución genotípica entre pacientes y controles en el estudio

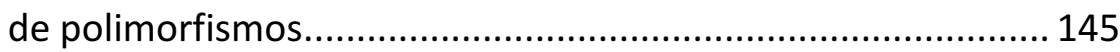

Tabla 18. Análisis y estimación del OR del gen ATG2B ............................ 146

Tabla 19. Estudio alélico del gen ATG2B ................................................ 146

Tabla 20. Análisis del gen ATG2B según el modelo dominante y recesivo147

Tabla 21. Asociación entre el género y el gen ATG2B .............................. 147

Tabla 22. Análisis del género y el gen ATG2B ………............................. 148

Tabla 23. Asociación del gen ATG2B y las variables clínicas ...................... 149

Tabla 24. Análisis del gen ATG16L1 entre pacientes con CU y EC.............. 150 


\section{ÍNDICE DE FIGURAS}

Figura 1. Mapa global de la incidencia de la Ell................................... 24

Figura 2. Respuesta al daño intestinal entre individuos susceptibles y resistentes .......................................................................... 25

Figura 3. Factores asociados a la patogenia de la Ell ............................. 25

Figura 4. Mecanismo de defensa de la mucosa intestinal........................ 36

Figura 5. Hipótesis del mecanismo patogénico en la Ell ......................... 43

Figura 6. Patofisiología de la Colitis Ulcerosa.................................... 43

Figura 7. Tratamiento actual de la Ell y las vías que modulan la autofagia 62

Figura 8. Genes asociados a la Ell ........................................................... 68

Figura 9. Factores genéticos asociados a la inflamación en la CU............76

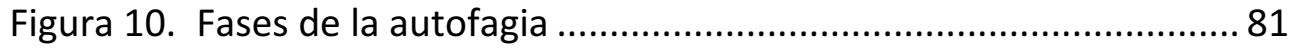

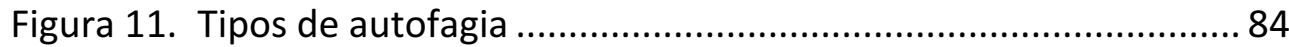

Figura 12. Formación del autofagosoma.......................................... 87

Figura 13. Mecanismos de regulación de la autofagia ............................. 89

Figura 14. Procesos inmunológicos asociados a la autofagia.................... 99

Figura 15. Asociación entre mutaciones de los reguladores de la autofagia y la EC 105

Figura 16. Representación de los resultados de discriminación alélica ... 123

Figura 17. Distribución de la edad al diagnóstico según la clasificación de Montreal

Figura 18. Distribución de las edades al diagnóstico y al registro............ 128

Figura 19. Distribución según la presencia de antecedentes familiares de ElI

Figura 20. Distribución según hábito tabáquico....................................... 129

Figura 21. Respuesta a corticoides............................................. 132

Figura 22. Porcentaje de pacientes que recibieron tratamiento con AZA 132

Figura 23. Porcentaje de pacientes con respuesta a AZA 133 
Figura 24. Porcentaje de pacientes que recibieron infliximab ............... 133

Figura 25. Indicación del tratamiento con infliximab.......................... 134

Figura 26. Porcentaje de pacientes que respondieron a infliximab ........ 134

Figura 27. Porcentaje de pacientes intervenidos quirúgicamente........... 135

Figura 28. Indicación del tratamiento quirúrgico................................ 135

Figura 29. Presencia de MEI según extensión ..................................... 139

Figura 30. Pacientes con corticoides según extension .......................... 140

Figura 31. Pacientes con Azatriopina según extension ............................ 140

Figura 32. Uso de Ciclosporina según extension ................................... 140

Figura 33 Cirugía según extension............................................... 141 


\section{ABREVIATURAS}

ADN

AMP

ATG

ATG16L1

ATP

ATG8 / LC3 y ATG12 Sistemas de conjugación ubiquitina like

CEP

CCR

CAM

CARD

$C D$

$\mathrm{CR}$

$\mathrm{CDH} 1$

CTLA4

CU

$\mathrm{CP}$

DSS

EC

E1,2,3 like

ECAI

ECM1

EGF

EII

EP
Ácido Desoxirribonucleico

Adenosina monofosfato

Genes relacionados al proceso de autofagia

"Autophagy related 16-like 1"

Adenosín trifosfato

Colangitis esclerosante primaria

Cáncer colorrectal

Moléculas de adhesión celular

"Caspase-recruitment domain"

Corticodependencia

Corticoresistencia

Gen que codifica cadherina 1

Gen que codifica antígeno 4 del linfocito $T$ citotóxico

Colitis ulcerosa

Células plasmáticas

Dextrano sulfato de sodio

Enfermedad de Crohn

Sistemas enzimáticos análogos de la enzima conjugadora de ubiquitina

Escherichia coli adherente e invasiva

Gen que codifica proteína de la matriz extracelular

Factor de crecimiento epidérmico

Enfermedad inflamatoria intestinal

Enfermedad de Paget 


$\begin{array}{ll}\text { EPA } & \text { Enfermedad perianal } \\ \text { FC } & \text { Fosfatidilcolina } \\ \text { FIP200 } & \begin{array}{l}\text { Proteína de } 200 \text { kDa que interactúa con la familia } \\ \text { de las quinasas de adhesión focal }\end{array} \\ \text { GCS } & \text { Glucocorticoides } \\ \text { GWAS } & \text { Estudios de asociación genómica } \\ \text { HGF } & \text { Factor de crecimiento de hepatocitos } \\ \text { HLA } & \text { Complejo mayor de histocompatibilidad } \\ \text { HSV-2 } & \text { Herpes simple virus-2 } \\ \text { HNF4A } & \text { El factor nuclear 4 alfa de hepatocito } \\ \text { IFN-Gamma } & \text { Interferón gamma } \\ \text { IFN- } 3 & \text { Interferón beta } \\ \text { IL } & \text { Interleucina } \\ \text { IRGM } & \text { Proteína de la familia M de la GTPasa relacionado } \\ \text { con la inmunidad } \\ \text { ICAM-1 } & \text { Molécula de adhesión celular intercelular } \\ \text { JAK2 } & \text { Quinasa de c-Jun en la región N-terminal } \\ \text { LAMB1 } & \text { "laminin, beta-1" } \\ \text { LAMP-2a } & \text { Receptor asociado a la proteína de membrana } \\ \text { LC3 } & \text { lisosomal tipo 2A } \\ \text { LLC } & \text { Proteína asociada a microtúbulos de cadena ligera 3 } \\ \text { LPS } & \text { Leucemia linfocítica crónica } \\ \text { MadCAM-1 } & \text { Lipopolisacaridos } \\ \text { MHC } & \text { Molécula de adhesión celular adresina de la mucosa } \\ \text { MAP } & \text { Moléculas del complejo principal } \\ \text { MEI } & \text { Mycobacterium avium subespecie paratuberculosis } \\ & \end{array}$


MSI

MNV

MARN

mTOR

miRNAs

miR-130a

MDR1

NF-KB

NKT

NOD

NLRs

OCTNS

OR

PAS

PCR

PE

PAMPS

PECAM-1

Pgp

PI3K

PMG

PRR

PUFA

RE

ROS

STAT

SNP
Inestabilidad de microsatélites

Norovirus murino

Ácido Ribonucleico mensajero

Diana de rapamicina en mamíferos

micro ARN

Micro ARN-130a

MDR1 "Multidrug resistance protein 1"

Factor nuclear kappa B

Células T naturales asesinas

"Nucleotide-binding oligomerization domain"

Receptores citosólicos similares al NOD

"Organic cation transporter"

"Odds ratio"

Estructura preautofagosomal

Reacción en cadena de la polimerasa

Fosfatidiletanolamina

Patrones moleculares asociados a patógenos.

Molécula de adhesión celular endotelial de plaquetas

P-glicoproteína 1

Fosfatidilinositol 3-quinasa

Polimorfismos genéticos

receptores que reconocen Patrones

ácidos grasos poliinsaturados

Retículo endoplásmico

Especies de reactivas de oxígeno

"Signal transducer and activator of transcription"

Polimorfismos de nucleótido único 
TAP

TJ

TLR

Treg

TNF

VPS34

ubl

5-ASA
Transportador de péptidos antigénicos

Uniones intercelulares

Receptores semejantes a TOLL

Treguladora

Factor de necrosis tumoral

Phosphatidylinositol 3-kinase, Catalytic Subunit Type 3

Sistemas de conjugación similar a ubiquitina

Ácido 5- aminosalicilato 


\section{INTRODUCCIÓN}


El conocimiento de la secuencia del genoma humano, completado en 2003 [1], junto con la disponibilidad de los métodos de genotipado y secuenciación del DNA, han llevado a la rápida expansión de la lista de variantes genéticas comunes que contribuyen a la susceptibilidad y a la progresión de la enfermedad, así como a la variabilidad en la respuesta al tratamiento.

Las diferencias en las secuencias de DNA son consecuencia de mutaciones que se acumulan a lo largo de la evolución de la especie. Entre ellas están los denominados polimorfismos genéticos que son los responsables en parte de la variabilidad genética entre individuos. Un polimorfismo es considerado como tal cuando la frecuencia de uno de sus alelos en la población es superior al 1\%. Algunos polimorfismos se pueden encontrar dentro de los genes y pueden influir en la susceptibilidad a padecer la enfermedad y en la respuesta al tratamiento, mientras que otros que se encuentran fuera de los genes tienen un efecto neutral [2]. Los polimorfismos de nucleótido único (SNP) representan la forma más abundante de la variación genética y son responsables de gran parte de la variación fenotípica heredable observada en las poblaciones humanas [3].

A partir de los datos generados del estudio de los polimorfismos se han logrado entender parcialmente los mecanismos de susceptibilidad a ciertas enfermedades, entre ellas la Enfermedad Inflamatoria Intestinal (EII).

La Ell se ha convertido en un problema de salud pública debido al aumento de su incidencia, a que su naturaleza prolongada ejerce importantes efectos en la calidad de vida y productividad de estos pacientes, y a los costes que conllevan los distintos tratamientos [4].

La Ell engloba a un grupo de trastornos inflamatorios crónicos que afectan al tracto gastrointestinal y están marcados por episodios de brotes 
y remisión. La Enfermedad Crohn (EC) y la Colitis Ulcerosa (CU) son las dos principales formas de presentación. Ambas comparten características patogénicas y epidemiológicas similares, siendo distinguibles por la clínica, los hallazgos endoscópicos, radiológicos e histológicos.

La EC es una inflamación intestinal crónica transmural que puede afectar cualquier segmento del tracto gastrointestinal con carácter discontinuo desde la boca hasta el ano. Sus complicaciones más frecuentes a largo plazo son las estenosis y la formación de fístulas [5]. En la CU la inflamación es continua y limitada al colon, suele empezar en el recto y extenderse proximalmente. Su presentación clínica típica incluye diarrea sanguinolenta, dolor abdominal, urgencia y tenesmo. Ambas entidades se pueden acompañar de manifestaciones extraintestinales (MEI) [6], que pueden preceder a la enfermedad intestinal o presentarse años después.

La etiología de la Ell es aún desconocida; la hipótesis más aceptada es que factores ambientales, genéticos y la microbiota intestinal se combinan para iniciar y perpetuar la inflamación crónica en el tracto gastrointestinal.

Los avances en el análisis genético de la Ell han generado nuevos conocimientos sobre las susceptibilidades genéticas y los mecanismos subyacentes de su patogenia. La influencia de la genética en la etiología de la Ell fue inicialmente demostrada por datos epidemiológicos en diferentes etnias, datos de agregación familiar, concordancia en gemelos y asociación con síndromes genéticos. Estas observaciones identificaron el gen NOD2 como factor de riesgo de Ell en el 2001 [7]. Desde entonces se han identificado múltiples locus asociados con la susceptibilidad a padecer la enfermedad, entre los que se encuentran los genes ligados a un proceso celular común llamado autofagia [8].

La autofagia es un importante proceso homeostático de degradación intracelular que consiste en la encapsulación de los componentes celulares 
citosólicos en vesículas de doble membrana para su degradación lisosomal, y posterior reciclaje.

Desde el descubrimiento de los genes relacionados con la autofagia (ATG) en la década de 1990, ha habido una proliferación de estudios sobre las funciones fisiológicas y patológicas de la autofagia en una variedad de modelos murinos y recientemente han surgido pruebas directas de la conexión entre la disfunción de genes ATG y enfermedades humanas. Un número creciente de estudios han demostrado mutaciones en los genes ATG en enfermedades inflamatorias, neurodegenerativas, infecciosas, y en el cáncer [9].

En la patogénesis de la Ell la respuesta inmune adaptativa juega un rol primordial y según recientes estudios la respuesta inmune innata es igualmente importante en la inducción de la inflamación intestinal [10]. La autofagia cumple funciones a distintos niveles de la respuesta inmune y una alteración en este proceso provocaría una pérdida de la homeostasis intestinal con la consiguiente inflamación.

Múltiples estudios han logrado determinar la asociación entre autofagia y EC; sin embargo, aún no está claro el papel que desempeña en CU. Este conocimiento sería un importante progreso en la comprensión de los mecanismos patogénicos de la enfermedad, especialmente en términos de utilidad y validez clínica.

El presente estudio pretende dilucidar si polimorfismos de genes implicados en la autofagia tienen un papel en la susceptibilidad a padecer CU. 


\section{1) COLITIS ULCEROSA}


La CU es una enfermedad intestinal inflamatoria crónica que se caracteriza por la inflamación de la mucosa del colon. Pertenece al grupo de Ell junto a la EC y fue descrita por primera vez por Samuel Wilks en el año 1859 como una colitis idiopática. La CU se caracteriza por una inflamación continua de la mucosa del colon que se extiende desde el recto a partes más proximales del colon [6], afectando al recto en un $95 \%$ de los casos y algunas veces al íleon terminal, denominándose "ileitis por reflujo". La enfermedad se presenta típicamente en la tercera década de la vida, aunque hay un segundo pico de edad entre los 60 y 70 años. Se caracteriza por fases de remisión y periodos de actividad, durante los cuales los síntomas más frecuentes son la diarrea sanguinolenta y el dolor abdominal.

\section{1) EPIDEMIOLOGÍA}

\subsection{1) Incidencia y prevalencia}

En los últimos años se ha observado un incremento en la incidencia de la Ell a nivel mundial, hecho que se ha observado también en países en vías de desarrollo, siendo considerada en la actualidad una enfermedad global [11]. En el norte de Europa y América, la incidencia de la CU aumentó substancialmente en los inicios y tercio medio del siglo XX, estabilizándose posteriormente. En la actualidad, las tasas tienden a estabilizarse en áreas de alta incidencia previa, mientras que continúan subiendo en áreas de baja incidencia como Europa del sur, Asia, y países en vías de desarrollo.

La incidencia de la CU varia entre $0.5-31.5$ por 100,000 personas/año dependiendo de la población estudiada [12]. Se estima una incidencia anual de CU entre 0-19.2 por 100,000 en América del Norte y 0.6-24.3 por 100,000 en Europa, y una prevalencia de $37.5-248.6$ por 100,000 y 4.9-505 por 100,000, respectivamente [11]. La prevalencia en países en vías de desarrollo parece haber cambiado en los últimos años; las publicaciones muestran un número creciente de casos en países de América del sur, Asia 
y el sur de Europa $[11,13,14]$, estabilizándose o incluso disminuyendo en países de América del Norte y Europa occidental. España es uno de los países donde se han realizado mayor número de estudios epidemiológicos; no obstante la mayoría de ellos son estudios retrospectivos y hospitalarios. Según estudios prospectivos, las áreas de mayor incidencia en España son Galicia, Navarra y Asturias. En el estudio Epicom, donde la única población española participante fue Vigo, se describe una incidencia de 21.4 por 100000/año entre pacientes mayores de 15 años (10.8 para EC, 9.4 para $\mathrm{CU})$, siendo considerada una de las mayores descritas en la población española [15].

\subsection{2) Mortalidad}

En los últimos años la mortalidad de los pacientes con $\mathrm{CU}$ ha cambiado; desde 1950 se observa un descenso de la mortalidad a pesar del incremento en la incidencia, justificado por el desarrollo de nuevos tratamiento médicos, la optimización de técnicas quirúrgicas [16] y por la disminución de muertes secundarias al CCR y otras enfermedades asociadas a la CU [17].

En un metaanálisis realizado por Jess et al, describe que el riesgo global de muerte en pacientes con CU no difiere de la población general, aunque existen subgrupos de pacientes que tienen mayor riesgo como los pacientes con diagnóstico reciente y pacientes con CU extensa [18]; a largo plazo, existe un mayor riesgo de muertes por causas relacionadas con la CU (enfermedad hepática, CCR) [19]. En la actualidad, la tasa de mortalidad de los pacientes con $\mathrm{CU}$ es similar al de la población general, evolución que podemos atribuir en parte al incremento en el uso de terapias inmunosupresoras. 


\subsection{3) Características demográficas}

Edad: A pesar del aumento de la incidencia de la $\mathrm{CU}$ en diferentes grupos etarios, el pico de incidencia de la CU es 30-40 años. Algunos estudios hablan de un segundo pico de edad entre los 60-70 años; aunque no existe consenso al respecto en la literatura [20]. La edad de inicio puede variar según área geográfica, siendo mayor la edad al diagnóstico en la población asiática comparada con países occidentales [21].

Género: La incidencia no parece estar influenciada por el género, aunque sí por la raza y la etnia $[4,11]$. La mayoría de estudios describen una mayor o igual frecuencia de $\mathrm{CU}$ entre géneros, particularmente en áreas de alta incidencia [22]. En la población pediátrica la distribución de EC y CU es diferente a la de los adultos, la EC predomina en varones y la CU en mujeres [20].

Países emergentes: Tradicionalmente la Ell ha sido considerada una enfermedad de occidente; sin embargo, estudios recientes ya describen un aumento de la incidencia de la Ell desde 1980 al 2003 en poblaciones de Asia, Japón, Hong Kong y Corea [4]. Este fenómeno estaría en relación a la occidentalización de los estilos de vida, cambios en los hábitos dietéticos, cambios ambientales como la industrialización y la mejora del saneamiento. En estas regiones las susceptibilidades genéticas difieren de la población blanca, siendo menos comunes las mutaciones del gen NOD2/CARD15[14]; también son distintos las características fenotípicas (curso clínico más leve que en poblaciones occidentales). El rápido aumento de la incidencia, paralelo a los cambios en el estilo de vida y el comportamiento, enfatizan el papel clave del medio ambiente en la patogénesis de la enfermedad [4]. 


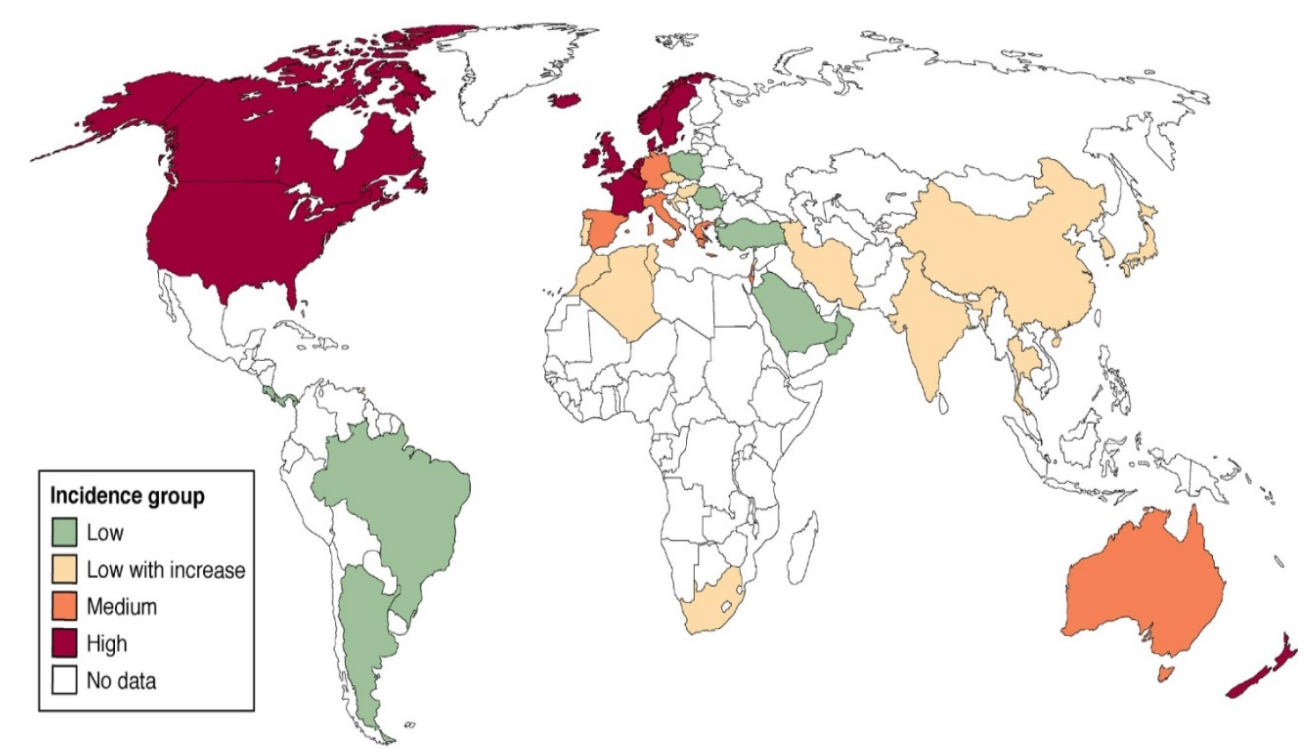

Figura 1. Mapa Global de la Incidencia de la Ell ${ }^{[20]}$

El mapa global de la enfermedad inflamatoria intestinal: rojo se refiere a la incidencia anual superior a $10 / 10^{5}$, de color naranja con la incidencia de 5-10/10 , verde con la incidencia de menos de 4/10 de color amarillo a la baja incidencia que está aumentando continuamente.

\section{2) PATOGENIA}

La etiopatogenia de la $\mathrm{CU}$ es aún desconocida. La hipótesis más aceptada es que la inflamación intestinal es producto de una disregulación de la homeostasis entre la microflora comensal, otros elementos ambientales y la capacidad de respuesta inmune en individuos genéticamente susceptibles. 


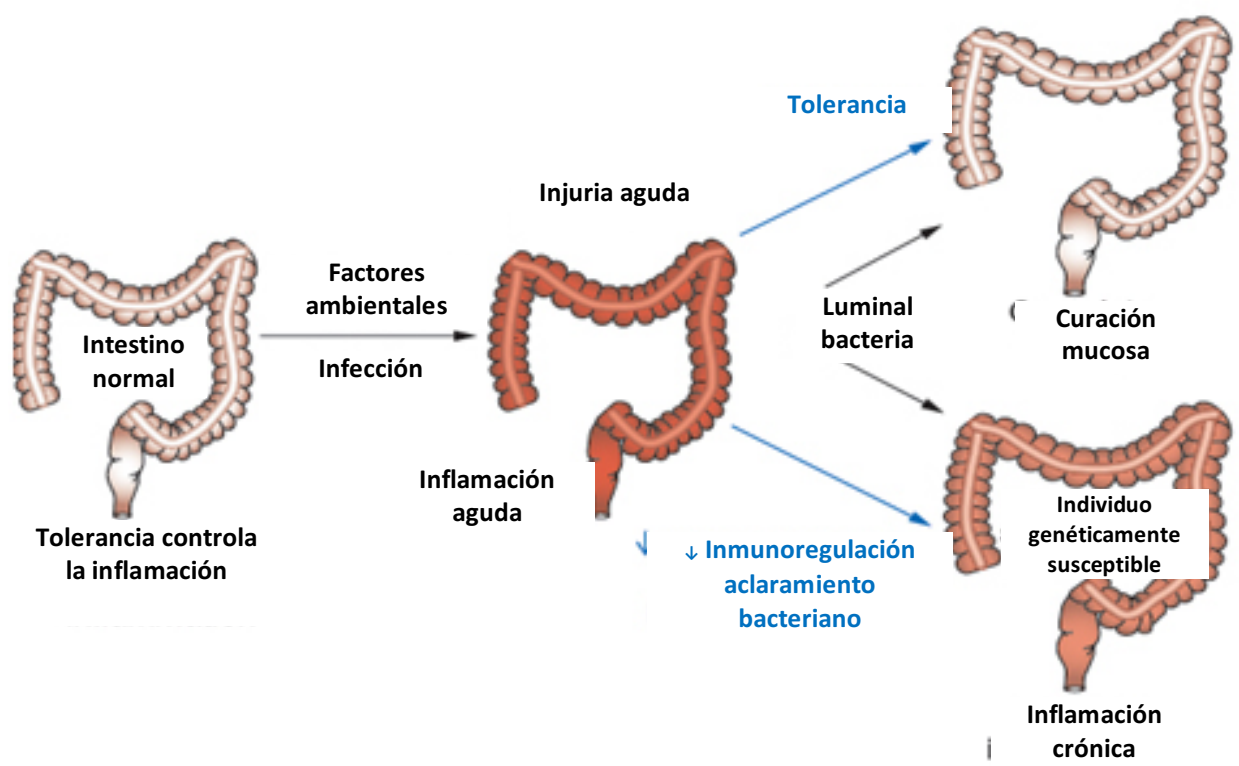

Figura 2. Respuesta al daño intestinal entre individuos susceptibles y resistentes ${ }^{[23]}$

\section{3) FACTORES ASOCIADOS}

Ell es una enfermedad compleja y multifactorial resultado de la intersección de la genética, el medio ambiente, la microbiota intestinal y la respuesta inmune, elementos que se combinan para dar lugar a la inflamación recurrente del intestino [24].

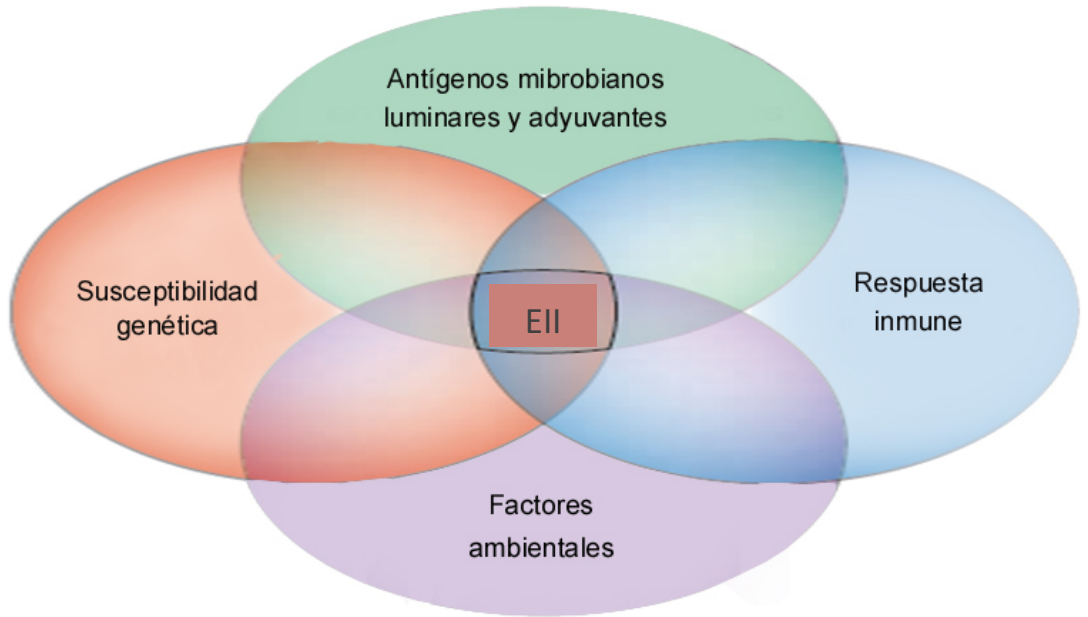

Figura 3. Factores asociados a la patogenia de la EII ${ }^{[23]}$ 


\subsection{1) Factores genéticos}

Los cimientos sobre el rol de la genética en la Ell se basan en estudios poblacionales, de agregación familiar y en gemelos. Todos estos estudios destacan el importante componente hereditario en la Ell. Según los estudios de agregación familiar los familiares de primer y segundo grado tienen 4 y 2 veces mayor riesgo, respectivamente, de desarrollar CU [25]. EI grado de concordancia para la EC entre gemelos monocigotos es del 20$50 \%$ y en gemelos dicigotos es del $10 \%$. El grado de concordancia en la CU es menor, $16 \%$ para monocigotos y $4 \%$ para dicigotos. A pesar de que la historia familiar es un factor de riesgo para el desarrollo de la enfermedad, no parece ser un factor pronóstico negativo [26-28].

Se han investigado una variedad de genes candidatos. Los más estudiados, desde un punto de vista epidemiológico han sido los polimorfismos del gen NOD2 (CARD 15), mostrándose como factor de riesgo independiente para la EC, pero no para la CU. En los últimos años, el gen ATG16L1, un gen asociado al proceso de autofagia, también ha demostrado su asociación con la EC.

\subsection{2) Factores ambientales}

El aumento de la incidencia y la aparición en poblaciones de bajo riesgo, proporcionan una fuerte evidencia que apoya el efecto del medio ambiente en el desarrollo la Ell [4]. Se han descrito un gran número de factores de riesgo ambientales asociados con la enfermedad: tabaquismo, alimentos, medicamentos, xenobióticos, factores geográficos, nivel socioeconómico, el estrés, la apendicectomía, la permeabilidad intestinal y la microbiota intestinal. Sin embargo, sólo hay evidencia epidemiológica fiable en cuanto al tabaquismo, la apendicectomía, y recientemente la microbiota intestinal y la dieta como factores implicados en la CU [29]. 
Teoría de la higiene: Esta teoría fue propuesta para explicar el aumento de incidencia de enfermedades autoinmunes en países desarrollados, asociándose de forma inversa al riesgo de EC o de CU: el número de hermanos, el número de miembros de la familia, la toma de leche no pasteurizada, vivir en granjas o la exposición a mascotas [30]. Sin embargo, las medidas de higiene en los países en desarrollo, no han demostrado asociación inversa como en Occidente $y$, de hecho, se han asociado a un mayor riesgo de CU. Un estudio realizado en el norte de la India no proporcionó evidencias definitivas para apoyar la hipótesis de la higiene y más bien atribuyó la creciente incidencia de $\mathrm{CU}$ en esa región a medidas sanitarias inadecuadas u otros factores aún no identificados[31].

\subsubsection{1) Tabaquismo}

La asociación entre el tabaco y la CU fue descrito por primera vez en 1982 por Harries et al, quienes observaron una baja frecuencia de fumadores entre pacientes con CU comparado con controles saludables. El tabaquismo constituye un factor de riesgo para la EC, por el contrario, el tabaquismo activo tendría un efecto protector sobre la CU [32]. Está demostrado que el tabaquismo protege contra el desarrollo de la CU y tendría un impacto en el inicio y en el curso de la enfermedad, asociándose a un inicio tardío, un curso leve y menor necesidad de inmunosupresión y cirugía [33, 34]; pero no parece tener impacto sobre la respuesta a tiopurinas ni en la progresión de la enfermedad en pacientes corticodependientes [35]. También podría influir en el fenotipo al inicio y en el curso de la enfermedad, con el desarrollo de EC en lugar de CU en una proporción de fumadores, lo que explicaría, en parte, el aparente efecto protector del tabaquismo en la CU.

El abandono del tabaco aumenta el riesgo de desarrollar CU y este incremento puede ser observado tras el primer año hasta los 10 años 
posteriores. Además, los pacientes con CU establecida tienen mayor riesgo de presentar brotes [36]. A pesar de la clara evidencia de un vínculo entre el tabaquismo y la Ell, los mecanismos que median estos efectos siguen sin estar claros; el tabaco podría tener efectos a nivel de la microbiota intestinal, la integridad del epitelio intestinal, el sistema inmunológico y, potencialmente, la susceptibilidad epigenética [34]. El efecto sobre la microbiota intestinal se ve reflejado en un aumento de Firmicutes y Actinobacteria y con una disminución de Bacteroides tras el abandono del tabaco. Sobre el sistema inmune desdesencadenaría una alteración de la respuesta inmune innata y adquirida, lo que podría explicar el efecto del abandono del tabaquismo en la CU $[34,37]$. Se ha propuesto que la nicotina y su metabolito son los responsables del efecto sobre la CU, pues tendría funciones a nivel de la permeabilidad e inflamación intestinal; también actuaría sobre el tono del musculo liso y la función endotelial de la microvasculatura intestinal a través de la producción de óxido nítrico [38, 39].

A pesar que el tabaquismo es el factor asociado más consistente, las variaciones en la susceptibilidad según género y etnia sugieren una compleja interacción genético-ambiental.

\subsubsection{2) Apendicetomía}

Al igual que el tabaquismo, la apendicectomía demuestra un efecto divergente sobre la EC y la CU. La apendicetomía temprana (antes de los 20 años) se asocia a una reducción en el riesgo de desarrollar CU. La asociación entre la apendicectomía y la CU ha sido objeto de un intenso escrutinio, con la esperanza de que pueda conducir a la identificación de los mecanismos patogénicos importantes. Una hipótesis es que las alteraciones en la respuesta inmune de la mucosa intestinal que llevan al desarrollo de apendicitis o a la apendicectomía protegerían del desarrollo 
de CU [40]. Varios estudios de casos-controles y de cohortes han demostrado una asociación fuerte y consistente[41]. En un metaanálisis, Koutroubakis et al concluyeron que la apendicectomía reducía el riesgo de desarrollar CU en un 69\% de los casos [42].

\subsubsection{3) Dieta}

Se ha descrito una asociación inversa entre la ingesta de fibra y la EC. La fibra soluble (a partir de frutas y verduras) es metabolizada por las bacterias intestinales a ácidos grasos de cadena corta que inhiben la transcripción de mediadores proinflamatorios [43]. Además, la fibra ayudaría a mantener la integridad de la barrera epitelial y reduciría la translocación de E. coli a través de las placas de Peyer "in vitro" en pacientes con EC [44]; la ingesta de fibra procedente de frutas ha demostrado una reducción del riesgo de EC, pero no de CU [45]. Por otra parte, la dieta grasa, particularmente la grasa saturada podría tener un efecto perjudicial en la Ell. El alto consumo de ácidos grasos poliinsaturados omega-6 (omega-6 PUFA) y bajo consumo de PUFA omega 3 (o un alto $n-6: n-3$ ) se ha asociado a un mayor riesgo tanto de CU como de EC, justificado por la presencia de variantes genéticas en las enzimas CYP4F3 y FADS2 implicadas en el metabolismo de ácidos grasos, como lo demuestra un estudio en población pediátrica [46].

\subsubsection{4) Vitamina $D$}

La vitamina D podría tener un papel en la patogénesis y curso de la Ell. En ratones deficientes de 1,25-dihidroxi vitamina D3 (1,25 (OH) 2D3) o del receptor de la vitamina $D$ se observa un mayor riesgo de colitis y la administración de 1,25 (OH) 2D3 aminora esta inflamación y suprime la expresión de genes pro inflamatorios [47]. 


\subsection{3) Microbiota intestinal}

Los pacientes con Ell muestran una disbiosis en su microbiota luminal, que consiste en una reducción en la diversidad microbiana comparada con individuos sanos [48, 49]; sin embargo, no está claro si el daño tisular es el resultado de una respuesta inmune anormal a una microbiota normal o de una respuesta inmune normal contra una microbiota anormal [50]. En la EC, la microbiota se caracteriza por una falta relativa de Firmicutes $y$ Bacteroidetes, y una sobre-representación de enterobacterias, mientras que en la CU existiría una reducción de Clostridium spp. y un aumento de Escherichia coli (E. coli) [51]

La microbiota intestinal es parte de lo que llamaríamos "exposoma endógeno". Se estima que hay unas 500 a 1.000 especies bacterianas diferentes en todo el intestino humano. Se ha calculado el número de unidades formadoras de colonias entre $10^{13}$ a $10^{14}$, superando el número de células humanas en un factor de 10. La flora bacteriana entérica en su conjunto es esencial para el desarrollo y la función normal del intestino: nos protege de patógenos entéricos, desempeña un papel en la adquisición de la energía y los nutrientes de nuestra dieta, y su interacción con la mucosa intestinal es crucial en la regulación y la activación del sistema inmunológico [52].

La microbiota intestinal humana es dinámica y está sometida a una evolución temporal continua, tanto en cantidad como en calidad, desde el nacimiento hasta la edad adulta; esta evolución se ve influenciada por el genoma y los componentes de la dieta. La composición de la microbiota adquiere diversidad en los primeros años de desarrollo, se estabiliza en el adulto y disminuye en los ancianos. El período más crítico de esta evolución ocurre en periodos tempranos de la vida, cuando la microbiota se expone a una cada vez más rica variedad de alimentos, medicamentos, xenobióticos, etc., y se modifica en consecuencia [29]. 
En el intestino sano predominan los filum Firmicutes y Bacteroidetes, que contribuyen a la producción de sustratos metabólicos epiteliales; por el contrario, el estado de enfermedad está asociado a un incremento del género de bacterias Enterobacteriaceae, Fusobacteriaceae, Pasteurellaceae y Bifidobacteriaceae. Además, se ha descrito una reducción de un tipo de bacterias de la familia Ruminococcaceae, en particular Faecalibacterium con función protectora relacionada con la habilidad de fermentar la fibra dietética para producir ácidos grasos de cadena corta, que son fuente de energía para las células epiteliales del colon[50].

La función de los virus eucariotas presentes en el tracto gastrointestinal en condiciones de homeostasis aún no está bien establecida. En un estudio se ha demostrado que la infección por norovirus murino (MNV) de ratones libres de gérmenes o tratados con antibióticos restauró la morfología intestinal y la función de los linfocitos sin inducir inflamación ni enfermedad manifiesta, pudiendo remplazar la función beneficiosa de las bacterias comensales en el intestino [53].

La interacción entre los hongos y las bacterias en el tracto gastrointestinal son relevantes en la Ell. Diversas especies de hongos son parte de la microbiota intestinal normal, pero esta diversidad se incrementa en pacientes con EC [54] y parece que existen diferencias en la microbiota fúngica en la mucosa inflamada respecto a la sana; estos cambios en la composición de la microbiota intestinal fúngica pueden estar asociados con el grado de inflamación de la mucosa [55].

La microbiota intestinal está influenciada por factores ambientales y sus cambios serían paralelos al desarrollo socioeconómico. El abandono del tabaco se asociaría a un aumento en la cantidad de bacterias con efecto protector, como Firmicutes y Actinobacteria, y una disminución de Bacteroidetes [37]. Los cambios en los hábitos dietéticos en relación al desarrollo socioeconómico, como la elevada ingesta de alimentos 
procesados con alto contenido de azúcar y grasa, serían los causantes de los cambios epidemiológicos de la Ell en países emergentes ya descritos. Es verdad que los estudios genéticos proporcionan información sobre los mecanismos de la enfermedad, pero la influencia ambiental sobre la microbiota puede ser el factor esencial en el desarrollo de la enfermedad $[50]$.

En condiciones normales, el sistema inmunitario intestinal mantiene el equilibrio entre la tolerancia a la flora comensal y los antígenos de la dieta, así como la capacidad de respuesta adecuada a patógenos entéricos. La CU parece ser el resultado de una ruptura en el balance homeostático entre la inmunidad del huésped y la microflora entérica, lo que lleva a una respuesta inmune aberrante contra la flora comensal no patogénica [56]. Los estudios en seres humanos apoyan la importancia de la microflora intestinal no sólo en la patogénesis de la enfermedad sino también en la gravedad de la inflamación y el fenotipo (CU vs EC) [57].

\subsubsection{1) Disbiosis en la Ell}

En la actualidad, no está claro cuáles son los factores que inician o mantienen el proceso inflamatorio en la CU. La infecciones con frecuencia son los causantes de los brotes en pacientes con Ell ya establecida, siendo el más común la infección por Clostridium difficile, al que se asocia una elevada mortalidad y morbilidad [58].

Grandes estudios epidemiológicos han abordado el interrogante sobre la existencia de un evento gatillo que conduzca a la disbiosis en la CU. En un estudio realizado en España, la incidencia estimada de desarrollar EC y CU fue significativamente elevado en pacientes con un episodio identificable de gastroenteritis aguda. Para la cohorte control sin un episodio de gastroenteritis, la incidencia de la Ell se calcula en 29,7 / 100.000 personas-año, pero aumentó a 68,4 / 100.000 personas-años para 
los pacientes con un episodio anterior de infección intestinal bacteriana. En este estudio, el patógeno bacteriano causante de la infección entérica más frecuente fue Campylobacter spp., seguido por Salmonella spp. y Shigella spp [59]. Las bacterias patógenas iniciarían el proceso inflamatorio en la CU con un episodio de gastroenteritis aguda, debilitando el revestimiento intestinal a través de la producción de altas concentraciones de ácido butírico; este defecto ofrecería a las bacterias acceso al sistema inmune de la mucosa intestinal, lo que resultaría en una inflamación descontrolada y disbiosis [52]. Los argumentos en contra de la supuesta asociación entre los agentes patógenos infecciosos y la Ell son la falta de transmisibilidad, la excelente respuesta a la inmunosupresión y la mala respuesta a los antibióticos.

\subsection{4) Factores inmunológicos}

El sistema inmune ha evolucionado como protección contra una amplia gama de agentes infecciosos. En los vertebrados, el sistema inmunológico lo conforman la respuesta inmune innata y la adaptativa. El sistema inmune innato es la primera línea de defensa y ofrece una respuesta de protección inmediata contra las infecciones y también ayuda a iniciar la respuesta inmune adaptativa.

La mucosa gastrointestinal está expuesta continuamente a antígenos de los alimentos y a antígenos bacterianos de la flora microbiana residente. El lumen intestinal representa la vía de entrada de microorganismos patógenos que pueden inducir daño tisular; en este sentido, el sistema inmune intestinal se enfrenta a la delicada tarea de proporcionar una respuesta inmune rápida y eficaz contra bacterias patógenas mientras mantiene la tolerancia hacia antígenos de los alimentos y de bacterias comensales, lo que se logra gracias a una muy eficiente barrera epitelial y un sistema inmune intestinal especializado y complejo; cualquier alteración 
y su perpetuación resulta en respuestas inflamatorias aberrantes que conducen a la inflamación intestinal crónica, como ocurre en la Ell [10]

\subsubsection{1) Respuesta inmune innata}

La respuesta inmune innata representa la primera línea de defensa contra los patógenos. A diferencia de la respuesta inmune adaptativa, es inespecífica y no confiere inmunidad de larga duración (de memoria). La homeostasis intestinal requiere un control de la respuesta inmune innato a la microbiota; este proceso de reconocimiento contribuye a la tolerancia y cuando el proceso está mal regulado, sobreviene la inflamación.

El sistema inmune innato se compone de la barrera epitelial, macrófagos, monocitos, neutrófilos, células naturales asesinas (células NKT), eosinófilos y basófilos; todo ello actúa en conjunto para iniciar la inflamación mediante la secreción de citoquinas, quimiocinas y agentes antimicrobianos, la fagocitosis de las células infectadas y microorganismos, la presentación de antígenos, y la activación del sistema inmune adaptativo [60].

\section{Barrera intestinal}

Cubierta por una capa mucosa, es la primera línea de defensa del sistema inmune de la mucosa, ya que proporciona una separación física entre las células inmunes del huésped y microorganismos luminales, además de sintetizar péptidos antimicrobianos [61].

La barrera mucosa protege la superficie del tracto intestinal de la adhesión y la invasión por microorganismos luminales. La colonización intestinal aumenta de proximal a distal y llega a $10^{11}-10^{12}$ organismos por gramo de contenido luminal en el colon. Para evitar una adherencia perjudicial y la invasión de microorganismos, la mucosa intestinal está equipada de diversos mecanismos de protección específicos e 
inespecíficos, constituyendo colectivamente una compleja y eficaz barrera [62].

La barrera mucosa intestinal está compuesta por secreciones luminales, células del epitelio intestinal, sistemas de transporte de membrana responsables del paso transepitelial de diferentes moléculas, y el compartimiento del estroma por debajo de la capa epitelial. La barrera intestinal tiene que ser permeable a los nutrientes y macromoléculas, que son importantes para el crecimiento y el desarrollo $y$, al mismo tiempo, tiene que evitar la entrada de microorganismos y macromoléculas perjudiciales, lo que se consigue por mecanismos fisiológicos extremadamente complejos. Por un lado, las propiedades estructurales y funcionales del epitelio limitan la cantidad de antígenos que llegan a la superficie del epitelio; por otro lado, células especializadas del epitelio (células M) y las células dendríticas presentan los antígenos luminales a las células del sistema inmune de la mucosa, garantizando de este modo inmunovigilancia permanente [63].

Las uniones intercelulares (TJ) situadas en el extremo apical del espacio intercelular lateral se consideran clave en la regulación del movimiento paracelular de fluidos y solutos. El daño en la barrera epitelial conduce a un aumento de la permeabilidad, posiblemente debido a la regulación defectuosa de las uniones celulares provocado por la acción de la IL13 [64], lo que permite una mayor absorción de antígenos luminales; sin embargo, no está claro si esta disfunción precede a la CU o es resultado de la inflamación (Figura 4). 


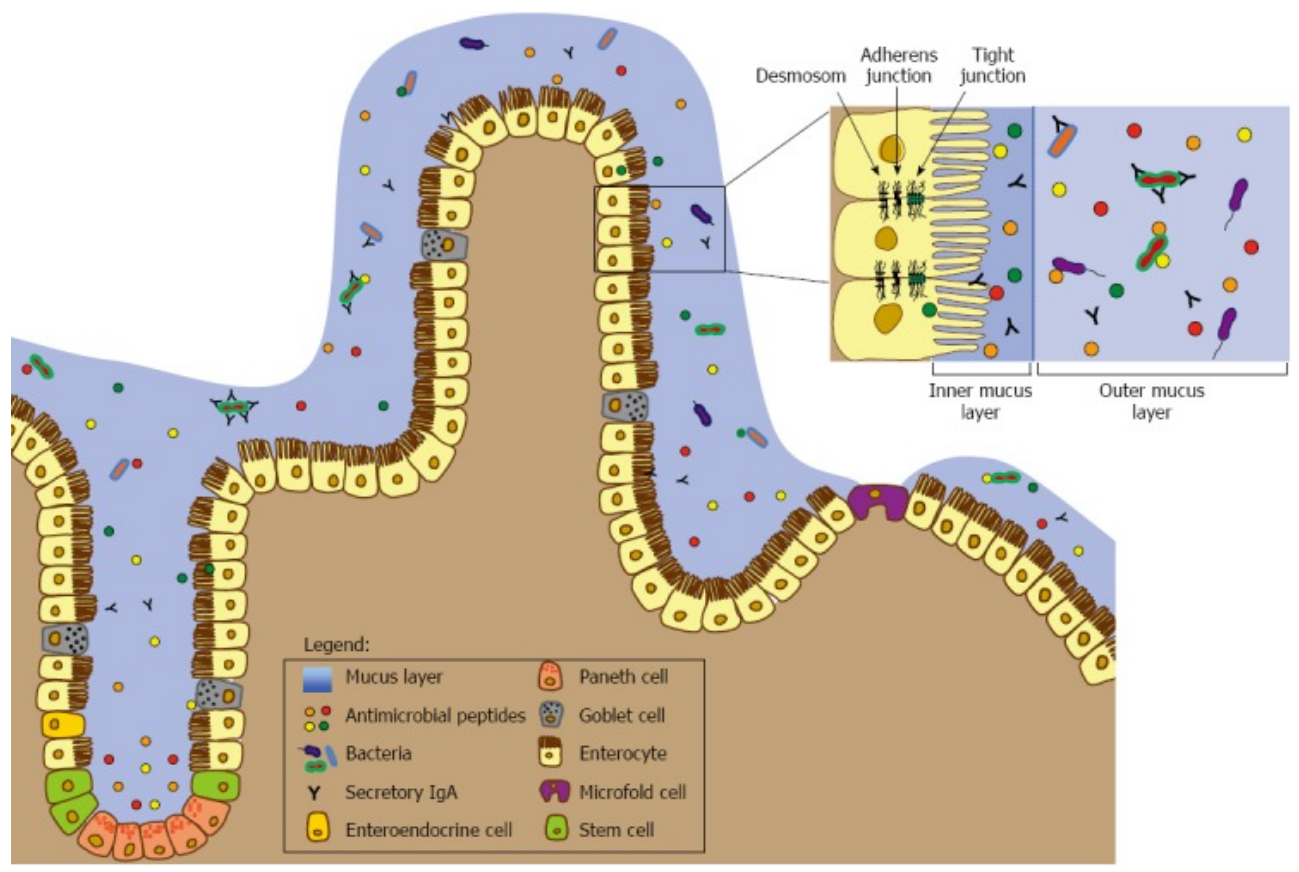

Figura 4. Mecanismo de defensa de la mucosa intestinal sana ${ }^{\text {[62] }}$

Componentes de la barrera intestinal

Capa de moco intestinal: El tracto gastrointestinal está cubierto por una capa de moco que protege el epitelio de antígenos luminales y proporciona lubricación para avanzar el bolo. Una barrera de moco bien desarrollado es la primera línea de defensa contra una variedad de patógenos entéricos. Aparte de su función de protección, también tiene capacidad de lubricación y es importante para mantener la superficie de la mucosa hidratada. Se compone de proteínas, carbohidratos, lípidos y también contiene una elevada cantidad de agua[62]. Se organiza en un capa interior firme y una capa exterior menos densa; la capa interior es generalmente estéril, mientras que la capa exterior parece ser más permeable y está habitada por bacterias comensales que encuentran 
nutrientes importantes en los glicanos de mucina [10, 62]. La superficie exterior de moco ofrece un medio para que las cepas probióticas crezcan y construyan capas protectoras, evitando la acumulación bacteriana y la formación de microcolonias en la superficie colorrectal. La inflamación tiene lugar sólo después de que la barrera mucosa se haya roto. La CU existe por un debilitamiento en la barrera intestinal, debido a la infiltración de las bacterias del intestino, el reclutamiento resultante de neutrófilos y la formación de abscesos crípticos [63].

Papel del moco en la CU: La producción y la secreción de moco es un proceso continuo. La renovación rápida de la barrera de moco impide el contacto microbiano con las células epiteliales. La alteración de la barrera de moco es un factor predisponente para la aparición temprana de daño celular epitelial en la colitis inducida. La MUC2 es la mucina más importante en el intestino grueso y es secretada por las células caliciformes; se le atribuye un papel importante en el mantenimiento de la función fisiológica del colon. Se ha observado que una variante en el gen MUC2, confiere susceptibilidad a desarrollar colitis espontánea[60]. Otro componente del moco es la fosfatidilcolina $(\mathrm{FC})$, que representa más del $70 \%$ de los fosfolípidos totales dentro de la capa de moco intestinal. En pacientes con CU la sulfatación de las mucinas está significativamente reducida, el contenido de FC se ve reducido hasta un $70 \%$, se reduce el número de células caliciformes y disminuye el espesor de moco [62].

El epitelio gastrointestinal: El epitelio gastrointestinal es una monocapa de células columnares unidas por uniones intercelulares circunferenciales estrechas que forman una barrera selectivamente permeable al contenido luminal, evitando la entrada de solutos no deseados, microorganismos, y antígenos luminales.

La capa epitelial muestra un equilibrio estricto entre la proliferación celular y la muerte celular, con el fin de mantener la barrera intestinal. Es 
importante destacar que si la muerte de las células del epitelio no está estrictamente regulada, podría resultar en un defecto de barrera con la subsiguiente inflamación e invasión microbiana. En este sentido, distintos estudios han demostrado que la proliferación epitelial y el recambio celular están acelerados en la Ell, lo que se demuestra por los elevados niveles de muerte celular programada en pacientes con EC y CU. En la Ell se observan los tres tipos de muerte celular programada: la apoptosis, la autofagia y la necrosis [65].

El epitelio intestinal cumple las funciones de absorción, secreción y digestión. Hay cuatro tipos principales de células epiteliales: enterocitos de absorción, las células caliciformes productoras de moco, las células enteroendocrinas y las células de Paneth productoras de antimicrobiano y factor de crecimiento celular.

Además de ser una barrera física, el epitelio intestinal contribuye a la defensa del huésped con la producción de péptidos antimicrobianos (defensinas entre otros), limitando así la invasión bacteriana. Estos agentes pueden ser producidos constitutivamente 0 ser inducidos por el reconocimiento de los componentes bacterianos [10]. En muestras de colon de pacientes con CU se ha observado una mayor producción de betadefensinas, pero no está claro si este aumento es inducido en respuesta a los microorganismos, a las citoquinas inflamatorias o a ambos [66].

El epitelio comunica las células inmunes de la lámina propia y la microbiota del lumen del intestino vía patrones de reconocimiento molecular, como son los receptores Toll (TLR) y los receptores citosólicos similares al NOD (NLRs) [60].

Defectos en la integridad epitelial contribuirían a la patogénesis de la Ell al permitir el libre paso de organismos a través de la capa epitelial, incitando una respuesta inmune. Recientemente se han descrito genes que 
cumplen un papel en la integridad de la barrera epitelial; entre los que se encuentran: el factor de transcripción HNF4A, que regula el complejo conjunto de la unión apical; $\mathrm{CDH} 1$, que codifica la E-cadherina, un componente principal de uniones adherentes y un mediador clave de la comunicación intercelular del epitelio, y LAMB1, una laminina expresada en la membrana basal del epitelio intestinal, lo que podrían conferir susceptibilidad específica a CU.

\section{Reconocimiento del antígeno}

Los antígenos activan la respuesta inmune innata a través de la interacción con los macrófagos y las células dendríticas. Las células dendríticas pueden enviar dendritas fuera del epitelio para identificar bacterias y otros antígenos en el lumen para luego presentarlos a las células B y las células T en la lámina propia conduciendo a la activación de las respuestas inmunitarias adaptativas. Las células dendríticas expresan una amplia gama de receptores de reconocimiento microbianos, incluyendo receptores de tipo Toll (TLR) y los receptores similares a NOD. EI papel principal de la señalización TLR es proporcionar defensa contra distintos patógenos y protección contra lesiones epiteliales, lo que contribuye a la homeostasis intestinal y al mantenimiento de la barrera epitelial. Las células epiteliales intestinales normales expresan principalmente TLR3 y TLR5, mientras que TLR2 y TLR4 están escasos o ausentes [67]; por el contrario, en pacientes con CU la expresión de TLR4 se incrementa sustancialmente en las células del epitelio y de la lámina propia intestinal. Los polimorfismos en TLRs pueden producir susceptibilidad a las infecciones entéricas o cambiar la capacidad de la respuesta inmune adaptativa para ser tolerante a las bacterias comensales. La activación de TLRs desencadena respuestas inmunitarias innatas y adaptativas que conducen a la activación del factor de transcripción factor nuclear kappa B (NF-kB) y otros factores de transcripción que son 
importantes en la activación de la cascada inflamatoria [68]. En los pacientes con $\mathrm{CU}$, se incrementa el número de células dendríticas activadas y también su capacidad estimuladora, lo que se correlaciona con la actividad de la enfermedad, lo que sugiere un papel importante de estas células en el inicio y perpetuación de la inflamación [69].

\subsubsection{2) Respuesta inmune adaptativa}

La respuesta inmune adaptativa se compone de linfocitos $\mathrm{T}$ y $\mathrm{B}$ que al activarse generan respuestas efectoras (citoquinas y anticuerpos). A diferencia de la respuesta inmune innata, el sistema inmune adaptativo es altamente específico y confiere inmunidad de larga duración[60].

Normalmente los componentes del sistema inmune adaptativo cooperan entre sí con las moléculas y células del sistema inmune innato para montar una respuesta inmune efectiva que es capaz de eliminar los patógenos invasores. Los principales actores de la respuesta inmune adaptativa son los linfocitos $T$. Las células Th0 pueden llegar a ser activados, o bien diferenciarse en Th1, Th2 o Th17. Éste es un proceso esencial que contribuye a la eliminación de patógenos específicos. Las células Th1 son esenciales en la eliminación de patógenos intracelulares; las Th2 en la eliminación de parásitos y mediación en las reacciones alérgicas y las células Th17 puede contribuir a la eliminación de las bacterias extracelulares y hongos. Una disregulación en la respuesta de células T puede llevar al inicio de la inflamación por una liberación excesiva de citoquinas y quimiocinas que tiene múltiples efectos patogénicos a nivel tanto de la respuesta inmune innata como adaptativa.

\section{Células Th1 y Th2 en la Ell}

En base principalmente a los niveles de citoquinas derivadas de células T detectadas en la mucosa en pacientes con Ell, varios estudios han asociado EC y CU a diferentes subtipos de respuestas inmunes pro- 
inflamatorias. Se cree que una anormal respuesta inmune Th1 causa la inflamación intestinal en la EC. Las células Th1 son inducidos por la IL-12, produciendo altas cantidades de IFN- $\gamma$. En contraste, la respuesta de células T dominante en la CU parece ser Th2 (IL- 4 , IL5 e IL- 13 ), las células NKT y las células T reguladoras, un subconjunto inmuno-modulador de células CD4 + [70] .

El perfil de las células $\mathrm{T}$ en la $\mathrm{CU}$ ha sido difícil de caracterizar: clásicamente se ha considerado que la CU tenía un perfil Th2; sin embargo, se ha observado que las concentraciones de IL-4 e IL-5, que están normalmente elevadas en la respuesta Th2, son variables en muestras de tejidos de pacientes con CU. Recientemente se ha descrito una respuesta Th2 atípica, mediada por NKT que secretan IL-13 y que jugarían un papel central en un modelo murino de colitis. La IL 13 es de particular importancia, ya que ejerce funciones citotóxicas contra las células epiteliales, incluyendo la inducción de la apoptosis y la alteración de la composición de proteínas de unión celular [71]. En pacientes con CU se han encontrado grandes cantidades de IL13 en la lámina propia, por lo que esta citocina sería uno de los principales mediadores en la patología intestinal de la CU. Esto se acompaña de un aumento en la expresión de la molécula de unión claudin-2, que conduce al desarrollo de la función de barrera deteriorada para los pequeños cationes que podría ser la responsable de la diarrea en la CU [63]. Según estas observaciones el bloqueo de la IL-13 podría proporcionar un nuevo enfoque para el tratamiento de la CU; además, en la CU se producen anormalidades en la inmunidad adaptativa humoral con un desproporcionado aumento de anticuerpos IgG1 [72].

Recientemente se han delineado linajes de células helper, incluyendo las células Th17, que producen la citocina proinflamatoria IL-17, con efectos pleiotrópicos como la inducción de citoquinas proinflamatorias y la expresión de quimioquinas que ocasionan infiltración y daño tisular [73]. 
La producción de citoquinas proinflamatorias, tales como interleuquina-1 $\beta$, interleucina-6, factor de necrosis tumoral $\alpha$ (TNF-a) y factor de necrosis tumoral como ligando (TL1A), están aumentados en pacientes con Ell y no permite discriminar entre CU y EC (Figura 5).

\section{El reclutamiento celular}

El tránsito de células efectoras desde la circulación a la mucosa intestinal se lleva a cabo por un mecanismo altamente selectivo que involucra la interacción con el endotelio vascular, la diapédesis a través de la pared vascular y la migración a la lámina propia. El reclutamiento de leucocitos a la mucosa inflamada se produce por la liberación de factores quimiotácticos, tales como CXCL8 (que está regulada positivamente en los pacientes con $\mathrm{CU})$, importante para la amplificación de la respuesta inflamatoria. Las células $T$ que contienen la integrina $\alpha 4 \beta 7$ se unen a las moléculas de adhesión celular presentes en el endotelio vascular de los vasos sanguíneos de la mucosa (MadCAM-1), promoviendo la adhesión de leucocitos y la extravasación en el tejido, perpetuando así el ciclo de la inflamación. MAdCAM-1, a través de la interacción con la integrina $\alpha 4 \beta 7$, media la localización de linfocitos en el tejido linfoide intestinal durante inflamación (Figura 6). Los anticuerpos contra MAdCAM-1, contra su ligando $\alpha 4 \beta 7$ (en el caso de vedolizumab) o específicamente contra la subunidad $\beta 7$ de la integrina (en el caso de etrolizumab), previenen el reclutamiento de linfocitos y reducen la gravedad de la inflamación del colon [56]. 


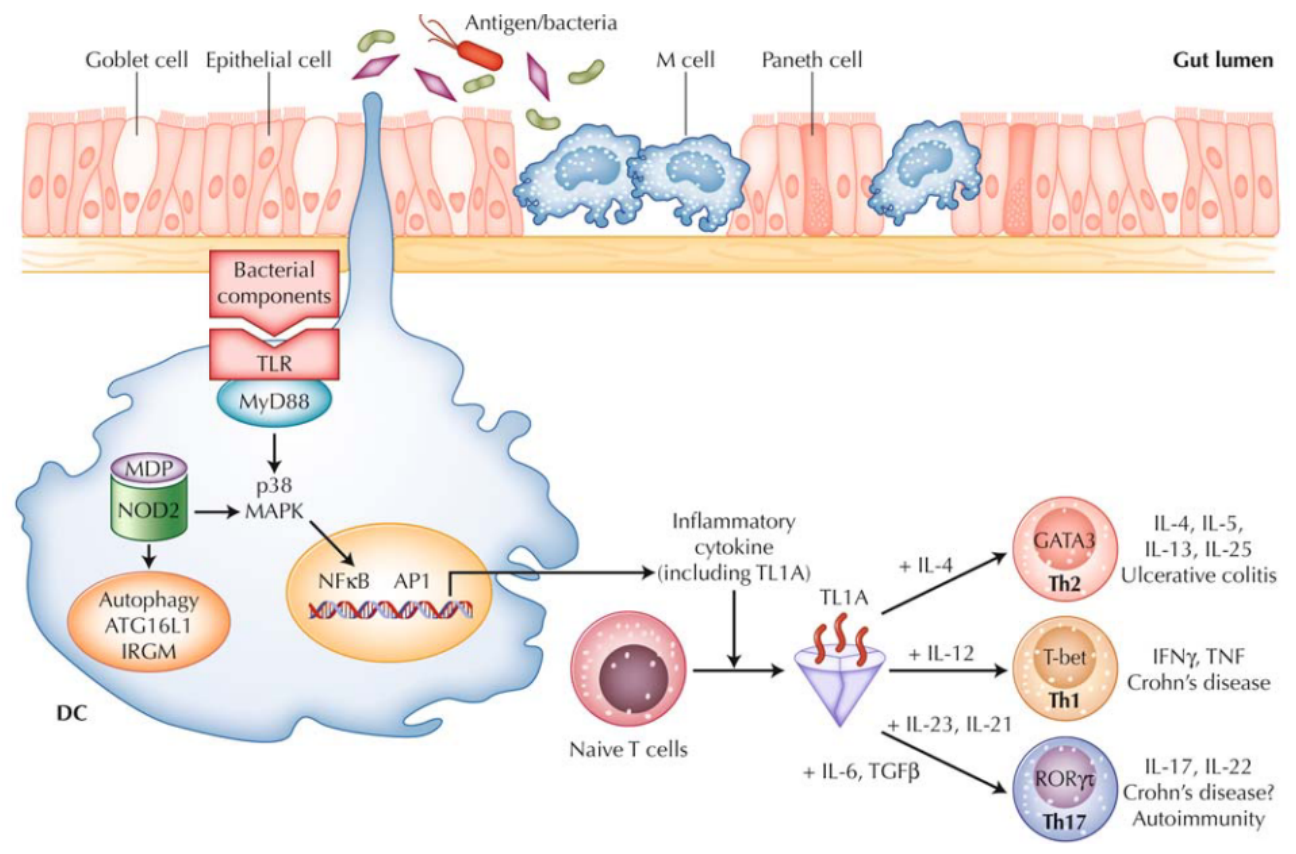

Figura 5. Hipótesis del Mecanismo Patogénico en la Ell ${ }^{\text {[70] }}$

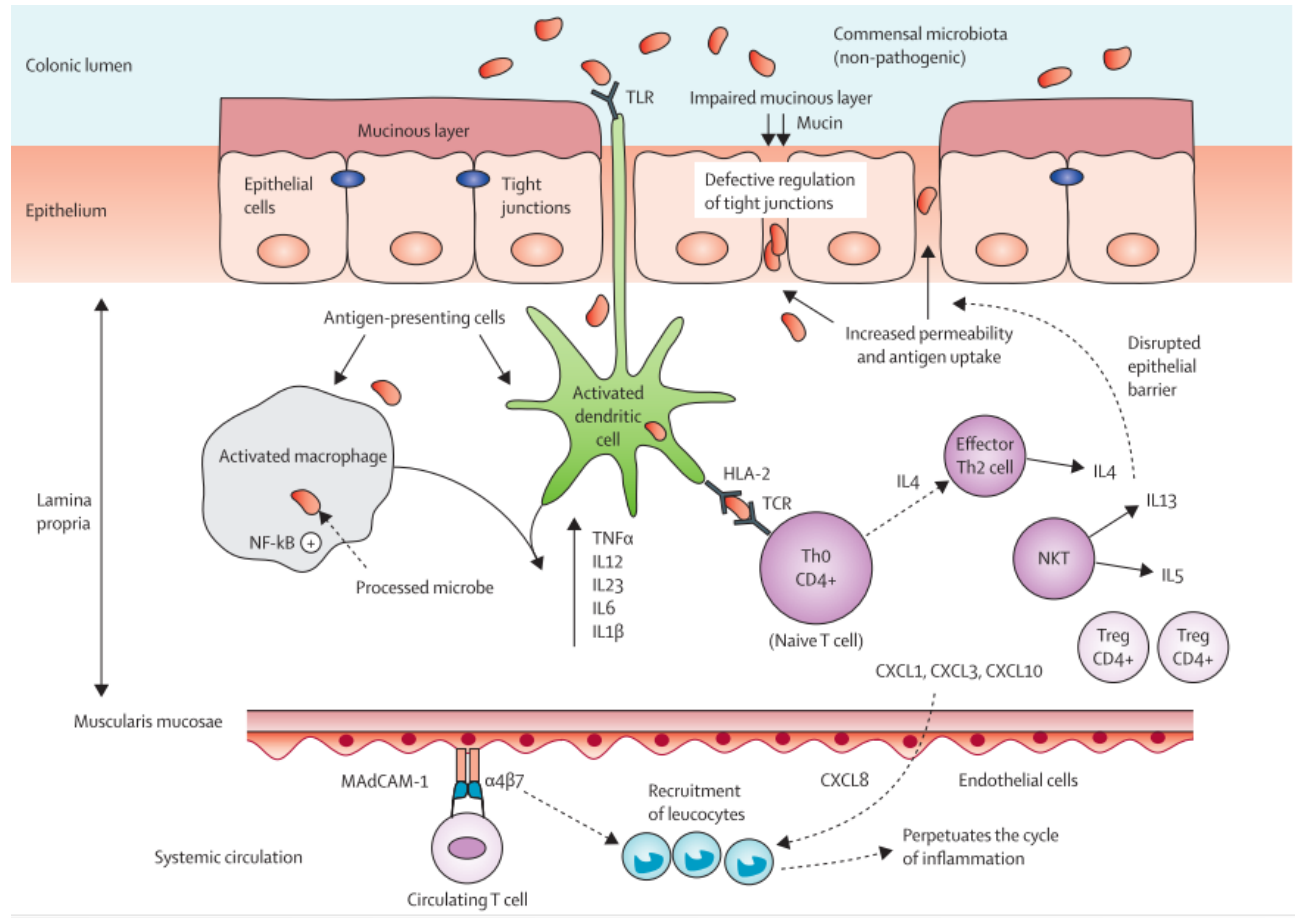

Figura 6. Patofisiología de la Colitis Ulcerosa ${ }^{[56]}$ 


\section{4) DIAGNÓSTICO}

En la actualidad no existe un único criterio patognomónico que defina la Ell. El diagnóstico se establece en función de una combinación de criterios clínicos, endoscópicos, histológicos y radiológicos, siendo necesario descartar otras formas de colitis agudas o crónicas.

El diagnóstico se basa, entre otras cosas, en una minuciosa historia clínica, la existencia de antecedentes familiares con Ell y la presencia o el antecedente de manifestaciones extraintestinales (MEI) típicas: afectación articular (artropatía periférica o axial, con frecuencia espondilitis o sacroileítis); ocular (uveítis, epiescleritis); cutáneomucosa (pioderma gangrenoso, eritema nodoso, aftas orales recurrentes) o hepática (colangitis esclerosante primaria, pericolangitis). También se debe tener en cuenta la posible asociación con otras enfermedades de origen inmune (enfermedad celiaca, vasculitis, etc.).

En los años 80 se establecieron los criterios de Leonnard-Jones para el diagnóstico de la CU y la EC (tabla 1). Se requiere la presencia de al menos 2 criterios para el diagnóstico, aunque en muchos casos es la evolución de la enfermedad lo que nos dará el diagnóstico definitivo [74]. 


\begin{tabular}{|l|l|}
\hline \multirow{4}{*}{$\begin{array}{l}\text { Criterios } \\
\text { clínicos }\end{array}$} & $\begin{array}{l}\text { Rectorragia } \\
\text { Diarrea crónica (aunque en un 10\% de los casos puede haber } \\
\text { estreñimiento) }\end{array}$ \\
\cline { 2 - 2 } Dolor abdominal \\
Manifestaciones extraintestinales
\end{tabular}

Tabla 1. Criterios diagnósticos de Lennard-Jones

Fuente: Lennard-Jones, J.E., Classification of inflammatory bowel disease. Scand J Gastroenterol Suppl, 1989

\subsection{1) Criterios clínicos}

Clásicamente, la CU se presenta con diarrea con sangre, dolor abdominal, urgencia y tenesmo. La enfermedad suele comenzar gradualmente y progresa durante varias semanas. Como resultado, el paciente presenta pérdida de peso y en los casos más graves afectación sistémica[75].

La rectorragia es uno de los síntomas más frecuentes en la CU. Las características de la hemorragia varían según la localización de la enfermedad. Los pacientes con proctitis suelen presentar sangre fresca 
separada de las heces o bien heces formadas con hebras de sangre; a menudo presentan pujos y tenesmo rectal. Cuando la enfermedad se extiende en sentido proximal se presenta con diarrea sanguinolenta.

La diarrea se manifiesta como deposiciones frecuentes y de poca cuantía, típica de la diarrea por lesión del colon. En la fisiopatología de la diarrea de la CU intervienen varios mecanismos, pero la absorción insuficiente de sal y agua es el factor predominante. La diarrea es común, pero no siempre está presente en la CU, pues las formas distales de CU (proctitis, proctosigmoiditis) pueden cursar con estreñimiento, dando lugar a cuadros de dolor abdominal (localizado en hemiabdomen derecho) que pueden malinterpretarse como brotes de actividad. Sin embargo, el dolor abdominal no suele ser un síntoma destacado. Puede haber dolor abdominal cólico intenso y continuo en cuadros graves de la enfermedad.

La enfermedad de actividad moderada o grave puede asociarse a síntomas sistémicos como pérdida de peso, febrícula o fiebre, malestar general e hiporexia. Un $15 \%$ de los pacientes pueden debutar con complicaciones como hemorragia digestiva baja, perforación colónica o megacolon tóxico.

Signos clínicos: los pacientes con enfermedad leve o moderada muestras pocos signos físicos anormales. Sin embargo, la mayoría los pacientes con una $\mathrm{CU}$ grave presentan taquicardia, fiebre, postración y pérdida de peso. El dolor abdominal suele hacerse difuso y moderado. La colitis fulminante se presenta con distensión abdominal, ausencia de ruidos intestinales y datos de irritación peritoneal.

Manifestaciones extraintestinales: $\mathrm{La} \mathrm{CU}$ se asocia con manifestaciones extraintestinales que pueden afectar a la piel, las articulaciones, los ojos y el hígado, entre otros órganos. 
El eritema nodoso y el pioderma gangrenoso son las lesiones cutáneas más frecuentes. El eritema nodoso sigue un curso paralelo a la enfermedad luminal, mientras que el pioderma gangrenoso es independiente.

La artritis es la manifestación extraintestinal más común y puede ser periférica o axial (espondilitis anquilosante y sacroileítis).

La colangitis esclerosante primaria se asocia también a la CU, es ligeramente más común en varones y en pacientes con afectación extensa de la enfermedad. Tiene un curso progresivo que puede resultar en hipertensión portal y cirrosis, y es un factor de riesgo para el desarrollo de colangiocarcinoma y cáncer de colon.

Otras condiciones también han sido asociadas con la $\mathrm{CU}$, incluyendo uveítis, escleritis, neuritis óptica, osteoporosis, psoriasis, depresión, síndrome de Sweet y estomatitis aftosa.

\subsection{2) Criterios endoscópicos}

Típicamente, la mucosa mostrará una afectación de carácter continuo en los distintos segmentos colónicos. La CU en fase de actividad presenta una apariencia granular, pérdida del patrón vascular, eritema difuso, microulceraciones (o incluso úlceras de gran tamaño en casos graves), exudado y hemorragia espontáneos o al roce del endoscopio. La gravedad de las lesiones endoscópicas suele correlacionarse con el grado de actividad de la enfermedad. La afectación macroscópica de la mucosa en la mayoría de los casos no tratados (> 90\%) es difusa y continua (sin áreas interlesionales aparentemente sanas), y afecta siempre desde el recto en sentido proximal. Los hallazgos endoscópicos pueden modificarse en relación con el tratamiento recibido. Se han descrito variantes atípicas como la indemnidad rectal, la afectación parcheada cecal o periapendicular y la denominada "ileitis por reflujo" (aunque no está claro que sea ésa su patogenia). 
La actividad inflamatoria puede ser leve (mucosa de superficie granujienta con edema, eritema, pérdida de brillo, ausencia de visualización de vascularización submucosa), moderada (microulceraciones, friabilidad al roce, exudado fibrinoso) o grave (úlceras mayores de $5 \mathrm{~mm}$, confluentes, profundas, sangrado espontáneo). En casos de CU de larga evolución, en periodos de inactividad inflamatoria o quiescencia la mucosa muestra un aspecto atrófico, con secuelas cicatriciales, la luz puede presentar tubulización, disminución de la haustración, acortamiento de la longitud del colon o estenosis, y es frecuente la presencia de pseudopólipos inflamatorios y puentes de mucosa respetada.

\subsection{3) Criterios histológicos}

Durante los brotes agudos de actividad, la mucosa presenta un importante infiltrado inflamatorio compuesto por linfocitos y células plasmáticas, junto a neutrófilos que aparecen predominantemente en las criptas, formando microabscesos crípticos muy característicos, pero no patognomónicos. Las criptas presentan distorsión estructural, con disminución de sus ramificaciones y del número de células caliciformes. Durante las fases de remisión, disminuye o desaparece el infiltrado inflamatorio y los abscesos crípticos, y se recupera el número de células caliciformes; sin embargo, las criptas suelen continuar mostrando distorsión arquitectural.

No se ha determinado el número de alteraciones necesarias para el diagnóstico de $\mathrm{CU}$, aunque se establece con la existencia de plasmacitosis basal, aumento celular intenso, difuso y transmucoso de la lámina propia y ensanchamiento de la mucosa o alteraciones de la arquitectura criptal. En las dos primeras semanas tras el inicio de los síntomas pueden no presentarse los hallazgos típicos de CU. La biopsia en la enfermedad 
quiescente o ya tratada puede ser normal o persistir alguna de las alteraciones descritas [76].

\subsection{4) Criterios radiológicos}

En el enfoque inicial puede resultar de utilidad la realización de una radiografía simple de abdomen que podría detectar signos indirectos como tubulización, acortamiento de la luz colónica o pérdida de haustración. Resulta imprescindible en la valoración inicial de un brote grave por sospecha de perforación, dilatación colónica $(\geq 6 \mathrm{~cm})$ o de asas de intestino delgado. En la enfermedad grave el margen luminal del colon se hace irregular y edematoso, el engrosamiento de la pared del colon se ve a menudo en una radiografía simple y pueden detectarse signos pronósticos como los islotes de mucosa, la distensión del intestino delgado y la dilatación del colon. También es útil para detectar la presencia de material fecal; el colon inflamado raramente contiene heces y no hay material fecal cuando se afecta todo el colon. Las técnicas con mayor resolución de imagen, como la resonancia magnética abdominal (RMN) o la tomografía axial computarizada (TAC), pueden aportar información que sugiera una Ell y sus complicaciones; sin embargo, en ausencia de gravedad, las técnicas endoscópicas suelen precederlas en el estudio inicial.

\section{5) CLASIFICACIÓN DE LA COLITIS ULCEROSA}

Las características clínicas de la CU, su curso evolutivo y pronóstico, dependen de la extensión de las lesiones y de la actividad o gravedad de las mismas.

La CU se clasifica de acuerdo al grado de extensión y gravedad según la clasificación de Montreal [77]. 
Extensión: La extensión de la enfermedad tiene importantes implicaciones pronósticas y terapéuticas. Dependiendo de los segmentos colónicos involucrados, la enfermedad puede ser clasificada como proctitis, colitis izquierda o pancolitis. La extensión debe evaluarse en el momento del diagnóstico, pues de ello depende la elección apropiada de tratamientos y la vía de administración, además de tener implicaciones pronósticas a corto y largo plazo de seguimiento [56].

Gravedad: La gravedad de la enfermedad se basa en hallazgos clínicos, como el número de deposiciones diarias y la presencia (o ausencia) de signos sistémicos de inflamación, como fiebre y taquicardia.

Según la clasificación de Montreal, la CU se clasifica,

Según la extensión (E):

E1: proctitis ulcerosa con extensión limitada a recto. Su límite proximal sería distal a la unión rectosigmoidea.

E2: colitis izquierda o distal. Se extendería al recto y colon distal al ángulo esplénico.

E3: extensa o pancolitis. La colitis se extendería a tramos más proximales al ángulo esplénico.

Según la gravedad (S):

SO: colitis en remisión. No hay síntomas de la enfermedad.

S1: colitis leve. 4 o menos deposiciones al día con sangre, sin fiebre, leucocitosis, taquicardia, anemia ni aumento de VSG.

S2: colitis moderada. Criterios intermedios entre leve y grave. Sin signos o con signos mínimos de afectación sistémica.

S3: colitis grave. 6 o más deposiciones al día con sangre, fiebre, leucocitosis, taquicardia, anemia, aumento de VSG y signos de afectación sistémica grave. 
La localización más frecuente de la CU varía según las distintas regiones geográficas. La colitis izquierda fue más frecuente en estudios realizados en Francia (colitis extensa: 19,1\%; colitis izquierda: 52,3\%; proctitis: $28,7 \%$ ) y Portugal (colitis extensa: 28\%; colitis izquierda: 52\%; proctitis: $21 \%$ ). En Asia y Brasil, parece que más pacientes tienen procesos inflamatorios limitados a la mucosa del recto. La extensión de la CU influye en el curso clínico y el pronóstico de la enfermedad. Los pacientes con colitis extensa son más propensos a ser sometido a terapias más intensivas o incluso a colectomía. La extensión de la enfermedad puede variar con el tiempo; en los pacientes con proctitis o colitis izquierda, el proceso inflamatorio puede progresar a segmentos más proximales del colon. Este fenómeno puede requerir una mayor vigilancia clínica e incluso cambios en el régimen terapéutico [78].

\section{6) EVALUACIÓN DE LA ACTIVIDAD DE LA ENFERMEDAD}

La evaluación de la actividad de la enfermedad es importante para la toma de decisiones. Se han ideado varios instrumentos para la evaluación estandarizada de la actividad de la enfermedad en la CU, aunque ninguno se acepta de forma universal.

\subsection{1) Índices de actividad clínica}

Índice de Truelove-Witts, es el índice de actividad clínica más utilizado en el que se incluyen cuatro variables clínicas y dos de laboratorio; es sencillo, fiable y fácil de usar en la práctica clínica diaria[79]. Distingue entre enfermedad en remisión y con actividad, diferenciándose entre actividad leve o grave, pudiéndose considerar moderada una situación intermedia. La forma semicuantitativa de este índice es el Truelove-Witts modificado, que incluye, además, otras variables como los niveles de albúmina, leucocitos y potasio. No es un índice válido en las proctitis, ni da 
un valor cuantitativo a la actividad, pero se recomienda su uso a la hora de plantearse el ingreso hospitalario. En él se basan las clasificaciones de actividad de la CU de Montreal, de la European Crohn's and Colitis Organisation (ECCO) y del American College of Gastroenterology (ACG). En realidad, este índice no ha sido validado formalmente en ningún estudio.

\begin{tabular}{|c|c|c|}
\hline Variable & Leve & Grave \\
\hline No deposiciones & $>6$ & $>4$ \\
\hline Sangre en deposiciones & $++/+++$ & $+/-$ \\
\hline Hemoglobina (g/l) & Anemia no grave & $\mathrm{Hb}<75 \%$ \\
\hline Temperatura & No fiebre & $>37,5$ \\
\hline Taquicardia & Ausente & $>90 \mathrm{lpm}$ \\
\hline VSG (mm/1 h. .) & $<30$ & $>30$ \\
\hline
\end{tabular}

Tabla 2. Índice de Truelove

Leve: Si hay < 4 deposiciones al día con o sin sangre, sin signos de toxicidad sistémica, es decir, temperatura $<37,5$ 으, frecuencia cardíaca $<90$ lpm, VSG $<30 \mathrm{~mm} / \mathrm{h}$ y $\mathrm{Hb}>10,5 \mathrm{~g} / \mathrm{dl}$.

Moderada: si el paciente tiene $>4$ deposiciones al día con escasos signos de toxicidad sistémica.

Grave: Si tiene > 6 deposiciones al día con sangre y signos de toxicidad como fiebre (temperatura $>37,50 \mathrm{C}$ ), taquicardia (frecuencia cardíaca $>90$ lpm), elevación de la VSG (> $30 \mathrm{~mm} / \mathrm{h})$ o anemia $(\mathrm{Hb}<10,5 \mathrm{~g} / \mathrm{dl})$.

Fulminante: Si el paciente tiene > 10 deposiciones al día, sangrado persistente, signos de toxicidad, distensión e hipersensibilidad abdominal, necesidad de transfusiones y dilatación colónica. Este último apartado se diferencia solo en la clasificación del ACG. En realidad, la colitis fulminante sería una descripción retrospectiva de pacientes con colitis grave que requirieron colectomía 
En la actualidad no se dispone de ningún índice clínico de actividad de referencia, por lo que es preciso conocer varios. Entre los más importantes podemos citar:

Índice de Actividad (Al, Activity Index) o de Seo: Se basa en síntomas y datos de laboratorio: número de deposiciones, sangre en las heces, albúmina, hemoglobina y VSG, es de cálculo más complejo [80].

Índice Simple Activity Index (índice de Walmsley): Incluye el número de deposiciones, deposiciones nocturnas, urgencia, estado general y la presencia de manifestaciones extradigestivas [81]

Índices de Lichtiger y de Ho: Son útiles en pacientes graves, y valoran la respuesta a la ciclosporina. Entre sus variables incluyen el dolor abdominal, los datos de peritonismo y la dilatación colónica [82].

Índice de la clínica Mayo o UCDAI (Ulcerative Colitis Disease Activity Index): elaborado por un conjunto de datos clínicos y endoscópicos que incluyen el número de deposiciones, la cantidad de sangre en las heces y la actividad endoscópica, así como la valoración global del médico. El subíndice endoscópico es el más utilizado en la práctica clínica. El índice de Mayo predice la corticorrefractariedad de un brote grave de CU en caso de no existir mejoría a los 3 y 5 días del inicio del tratamiento. Este índice se utiliza en numerosos trabajos en los que se valora la respuesta a tratamientos, pero empleando puntuaciones distintas y más o menos estrictas para definir la respuesta clínica, la remisión clínica o endoscópica [83]. 


\begin{tabular}{|c|c|c|c|c|}
\hline Variables & \multicolumn{2}{|c|}{ Puntuación } & \multicolumn{2}{|c|}{ Puntos } \\
\hline 1. Frecuencia de deposiciones & & & \multicolumn{2}{|c|}{$=\ldots \ldots \ldots \ldots \ldots$} \\
\hline Normal para el paciente & \multicolumn{2}{|c|}{0} & & \\
\hline 1-2 más que lo habitual & \multicolumn{2}{|r|}{1} & & \\
\hline 3-4 más que lo habitual & \multicolumn{2}{|r|}{2} & & \\
\hline$>5$ más de lo habitual & \multicolumn{2}{|r|}{3} & & \\
\hline 2. Hemorragia rectal & & & \multicolumn{2}{|c|}{$=\ldots \ldots \ldots \ldots \ldots$} \\
\hline Ninguna & \multicolumn{2}{|c|}{0} & & \\
\hline Algunas trazas de sangre & \multicolumn{2}{|r|}{1} & & \\
\hline Sangre evidente en la mayoría de & \multicolumn{2}{|r|}{2} & & \\
\hline \multicolumn{5}{|l|}{ las deposiciones } \\
\hline Solo sangre & \multicolumn{2}{|c|}{3} & & \\
\hline 3. Hallazgos sigmoidoscópicos & & & \multicolumn{2}{|c|}{$=\ldots \ldots \ldots \ldots \ldots$} \\
\hline Normal o enfermedad & \multicolumn{2}{|r|}{0} & & \\
\hline Eritema, leve friabilidad & \multicolumn{2}{|r|}{1} & & \\
\hline Eritema marcado, friabilidad & \multicolumn{2}{|r|}{2} & & \\
\hline \multicolumn{5}{|l|}{ Evidente } \\
\hline Hemorragia espontánea & \multicolumn{2}{|r|}{3} & & \\
\hline 4. Evaluación global del médico & & & \multicolumn{2}{|c|}{$=\ldots \ldots \ldots \ldots \ldots$} \\
\hline Normal & \multicolumn{2}{|r|}{0} & & \\
\hline Enfermedad leve & \multicolumn{2}{|r|}{1} & & \\
\hline Enfermedad moderada & \multicolumn{2}{|r|}{2} & & \\
\hline Enfermedad grave & \multicolumn{2}{|r|}{3} & & \\
\hline Valoración global del índice de Mayo & Síntomas & Endoscopia & Médico & Suma \\
\hline Leve & $1-3$ & 1 & 1 & 3 a 5 \\
\hline Moderado & $3-6$ & $1-2$ & 2 & 6 a 10 \\
\hline Grave & $>6$ & $>2$ & 3 & $>10$ \\
\hline
\end{tabular}

Tabla 3. Índice de Mayo 


\begin{tabular}{|l|c|}
\hline \multicolumn{1}{|c|}{ Variable } & Valoración \\
\hline No de deposiciones & $\times 13=$ \\
$\leq 4=1$ & \\
\hline $5-7=2$ & \\
\hline$\geq 8=3$ & \\
\hline Sangre en heces & $\times 60=$ \\
\hline No o poca $=0$ & $=$ Hemoglobina (g/dl) \\
\hline Presente $=1$ & $\times 15=$ \\
\hline VSG (mm/h) $0,5=$ Total A (sumatorio previos) & $=$ \\
\hline V $\times$ 4= Albúmina (g/dl) & $=\ldots \ldots . .$. \\
\hline Total B (sumatorio previos) & Puntuación \\
\hline Índice de actividad SEO; total A- total B + 200 & $<150$ \\
\hline Valoración índice de SEO & $>220$ \\
\hline Remisión o actividad leve & \\
\hline Moderado-grave & \\
\hline Grave & \\
\hline
\end{tabular}

Tabla 4. Índice de SEO

\section{7) DEFINICIÓN DE ALGUNAS VARIABLES ANALIZADAS}

Remisión: resolución completa de los síntomas y cicatrización mucosa en la endoscopia [84].

Respuesta: mejora clínica y endoscópica, según cual sea el índice de actividad usado. 
Recaída: exacerbación de los síntomas en un paciente con CU establecida tras haberse alcanzado la remisión, bien de forma espontánea o tras el tratamiento médico.

Corticodependencia: pacientes con una de las 2 características siguientes: imposibilidad de disminuir la dosis de corticoides por debajo de $10 \mathrm{mg} / \mathrm{día}$ de prednisona (o equivalente) tras 3 meses de inicio del tratamiento corticoideo o recaída dentro de los primeros 3 meses de haber suspendido los corticoides.

Corticorresistencia: actividad clínica a pesar del tratamiento durante 4 semanas con dosis plenas $(0,75 \mathrm{mg} / \mathrm{kg} /$ día de prednisolona o $1 \mathrm{mg} / \mathrm{kg} /$ día de prednisona, o equivalente). En el contexto de un brote grave, la gran mayoría de los clínicos definirían la corticorresistencia como la falta de respuesta clínica tras la administración de corticoides a dosis plena por vía intravenosa durante 7 días. Es más, hay una tendencia creciente a situar la definición en 5 o incluso 3 días. A los efectos de nuestro estudio utilizaremos el concepto de un mes para los brotes leves o moderados y de 7 días para los graves [85].

Reservoritis: inflamación del reservorio ileal creado para mantener la continuidad intestino-ano tras una colectomía total, comportándose en muchos pacientes como una enfermedad crónica [85].

\section{8) TRATAMIENTO}

Los objetivos del tratamiento de la CU han evolucionado desde el tratamiento de los síntomas y la inducción de la remisión clínica a objetivos más estrictos, incluyendo mantenimiento de la remisión libre de esteroides, la prevención de hospitalización y cirugía, curación mucosa y mejora en la calidad de vida [56]. 
El tratamiento de la CU se compone principalmente de ácido 5-amino salicilato (5-ASA), antibióticos, corticoides, terapias inmunomoduladoras y terapias biológicas, de manera que el abordaje quirúrgico se reserva para casos de mal control. El éxito del tratamiento depende de varios factores como el uso y la indicación correcta (inducción vs mantenimiento), la optimización de la dosis y la máxima adhesión al tratamiento.

El tratamiento debe adaptarse a la actividad de la enfermedad (leve, moderada, grave), al comportamiento y grado de extensión (proctitis, colitis izquierda o pancolitis), las complicaciones extraintestinales, la aparición de efectos adversos y la relación coste-efectividad[56].

En las últimas décadas se han producido avances significativos en cuanto al arsenal terapéutico con el que contamos en la CU, fundamentalmente con el uso de inmunosupresores y fármacos biológicos. Sin embargo, continúa habiendo muchas incógnitas en cuanto al mecanismo de acción de los fármacos con los que contamos en el momento actual. En los últimos años se ha avanzado hacia la caracterización de sus efectos, con la modulación de vías de señalización inmunorreguladora que a menudo están vinculados directa o indirectamente a la autofagia [86] (tabla 5).

\subsection{1) Salicilatos}

Los aminosalicilatos son fármacos que contienen en su estructura molecular la molécula del ácido 5- aminosalicílico (5-ASA o mesalazina), donde el componente activo y responsable de la actividad antiinflamatoria es la mesalazina. La sulfapirina actúa como un transportador y es el responsable de los efectos adversos. Los 5 - ASA presentan efectos antinflamatorios a través de la regulación de sistemas antioxidantes; la inhibición de la motilidad leucocitaria, la activación de leucotrienos y plaquetas; además de ejercer un potente efecto inhibidor sobre la 
activación de NFkB , TNFa , IL- 1 y TGF ; la formación de óxido nítrico y la prevención de daño mitocondrial. Muchas de estas actividades podrían afectar directa o indirectamente a la autofagia.

El 5-ASA por sí solo, administrado por vía oral, es inactivo, ya que se ve afectado por el pH ácido del estómago y no llega al intestino, que es el sitio de acción. Es por ello que se han desarrollado diversos preparados y sistemas de liberación controlada.

Podemos distinguir dos tipos de moléculas: por un lado los profármacos, que consisten en distintos dímeros entre el ácido 5-ASA y diferentes portadores inertes que impiden la absorción en tramos proximales del tubo digestivo; $y$, por otro lado, las formulaciones de liberación controlada, en las que el 5-ASA está protegido por excipientes (fórmulas multimatriz $\mathrm{MMX}$ ), que permiten llegar al fármaco a puntos concretos del tubo digestivo[87].

La eficacia del tratamiento parece ser directamente proporcional a la dosis empleada. Dado que el 5-ASA administrado por vía oral presenta concentraciones rectales inferiores a las del colon derecho, excepción hecha de las formulaciones $\mathrm{MMX}$, el tratamiento tópico en forma de supositorios, espumas o enemas que libera el fármaco directamente en el colon distal también es de utilidad en esas localizaciones más distales [88].

Son el tratamiento de primera elección y eficaces para inducir la remisión en los pacientes con CU leve-moderada, Puede ser administrados vía oral o tópica en forma de supositorios o enemas[6]. Se recomienda el uso de salicilatos orales para la inducción de la remisión del paciente con brote leve-moderado de CU a dosis mínima de 2,4 g/día y probablemente óptima superior a $3 \mathrm{~g}$ /día en una dosis única diaria [85]. La dosis mínima efectiva para mantener la remisión es de $1 \mathrm{~g}$ al día [84]. 


\subsection{2) Corticoides}

El mecanismo de acción de los corticoides es multifactorial: bloquea la vía del ácido araquidónico mediante la inhibición de la fosfolipasa A2, actúa inhibiendo la función leucocitarias y de las citoquinas proinflamatorias y se ha descrito además que la vía mTORC1 y la autofagia jugarían un papel importante en la respuesta al tratamiento con corticosteroides [86].

Según las recomendaciones de las distintas guías de práctica clínica, en los pacientes con CU que no responden a los salicilatos, los corticoides serán los fármacos de primera elección[84] .

La administración de corticoides sistémicos se ha relacionado con la aparición de numerosos efectos secundarios. La prevalencia y gravedad de su aparición depende fundamentalmente de la dosis y duración del tratamiento. Aumentan el riesgo de infecciones y se los ha considerado como los principales responsables de la aparición de osteopenia y osteoporosis en estos pacientes. En las formas distales, como alternativa a los corticoides clásicos podemos utilizar los corticoides de acción tópica con eficacia similar y buen perfil de seguridad, como el dipropionato de beclometasona, que está indicado actualmente en la CU distal leve a moderada de forma concomitante a los salicilatos en pacientes que previamente no han respondido a ellos.

Los corticoides son el principal agente terapéutico, ya sea oral o parenteral, en los brotes de CU moderados a graves para inducir la remisión. No se deben usar como mantenimiento y la dosis recomendada de prednisona es de 1g/ $/ \mathrm{kg} /$ día o su equivalente de $0.8 \mathrm{~g} / \mathrm{Kg} / \mathrm{día}$ de metilprednisolona. 


\subsection{3) Inmunomoduladores}

Disponemos en la actualidad de tres familias diferentes de fármacos inmunomoduladores: tiopurinas (azatioprina y mercaptopurina); metotrexato y calcineurínicos (ciclosporina y tacrolimus).

De los diversos inmunomoduladores, los más usados son azatioprina y 6-mercaptopurina, análogos de las purinas que interfieren con el metabolismo de los ácidos nucleicos y ejercen efectos tóxicos sobre las células linfoides.

Aunque el tratamiento médico de los pacientes con CU ha avanzado mucho en las últimas décadas, entre un 20-30 \% de los pacientes requieren antes o después una colectomía [89] y es en este escenario donde los fármacos inmunosupresores tienen un importante papel, tanto en los pacientes con CU corticodependiente como en los corticorrefractarios.

Algunos de estos fármacos se emplean en los pacientes con Enfermedad Inflamatoria Intestinal desde hace más de 15 años, inicialmente de forma empírica. Actualmente su eficacia está plenamente demostrada en algunas situaciones clínicas. En la tabla 6 resumimos los fármacos en la CU según los niveles de evidencia y grado de recomendación recogidos en el consenso elaborado por la Organización Europea de Crohn y Colitis (ECCO) [84]. 


\begin{tabular}{|c|c|}
\hline Fármaco & Evidencia de la modulación de la autofagia \\
\hline Corticosteroides & $\begin{array}{l}\text { - Induce la autofagia sobreexpreanndo inhibidores } \\
\text { mTORC1 en el músculo esquelético in vivo, mioblastos y } \\
\text { linfocitos. } \\
\text { - Dexametasona induce autofagia en linfocitos T } \\
\text { - Inhibición de la autofagia en monocitos humanos } \\
\text { infectados con Aspergillus Fumigatus }\end{array}$ \\
\hline Aminosalicilatos & $\begin{array}{l}\text { - Sulfasalazina reduce la autofagia por la inhibición de la vía } \\
\text { NFkB en un modelo murino } \\
\text { - Sulfasalazina induce la muerte celular autofagica en } \\
\text { carcinoma oral de celulas escamosas }\end{array}$ \\
\hline Tiopurinas & $\begin{array}{l}\text { - La autofagia es activada en hepatocitos tratados con } \\
\text { tiopurinas } \\
\text { - La autofagia se ve incrementada en las celulas epiteliales } \\
\text { de un modelo animal de colitis por la rápida conversión } \\
\text { de tioguanina a su metabolito activo }\end{array}$ \\
\hline Inmunomoduladores & $\begin{array}{l}\text { - La citotoxicidad producida por la ciclosporina induce la } \\
\text { autofagia como un proceso de supervivencia en celulas de } \\
\text { glioma maligno, células renales; y tacrolimus induce } \\
\text { autofagia en ratones en lineas celulares de la microglia y } \\
\text { en meduloblastomas }\end{array}$ \\
\hline Biológicos & $\begin{array}{l}\text { - Anti-TNF pueden inducir reactivación de la TB, al menos } \\
\text { parcialmente debido a la disminución de la autofagia } \\
\text { - TNF induce la autofagia de fibroblastos sinovial de } \\
\text { pacientes con artritis reumatoide, en musculo } \\
\text { esquelético, celulastrofoblasticas, celulas vasculares en } \\
\text { arterioesclerosis y macrófagos en ratones }\end{array}$ \\
\hline
\end{tabular}

Tabla 5. Fármacos en la Ell y sus acciones en la modulación de la autofagia ${ }^{[86]}$ 


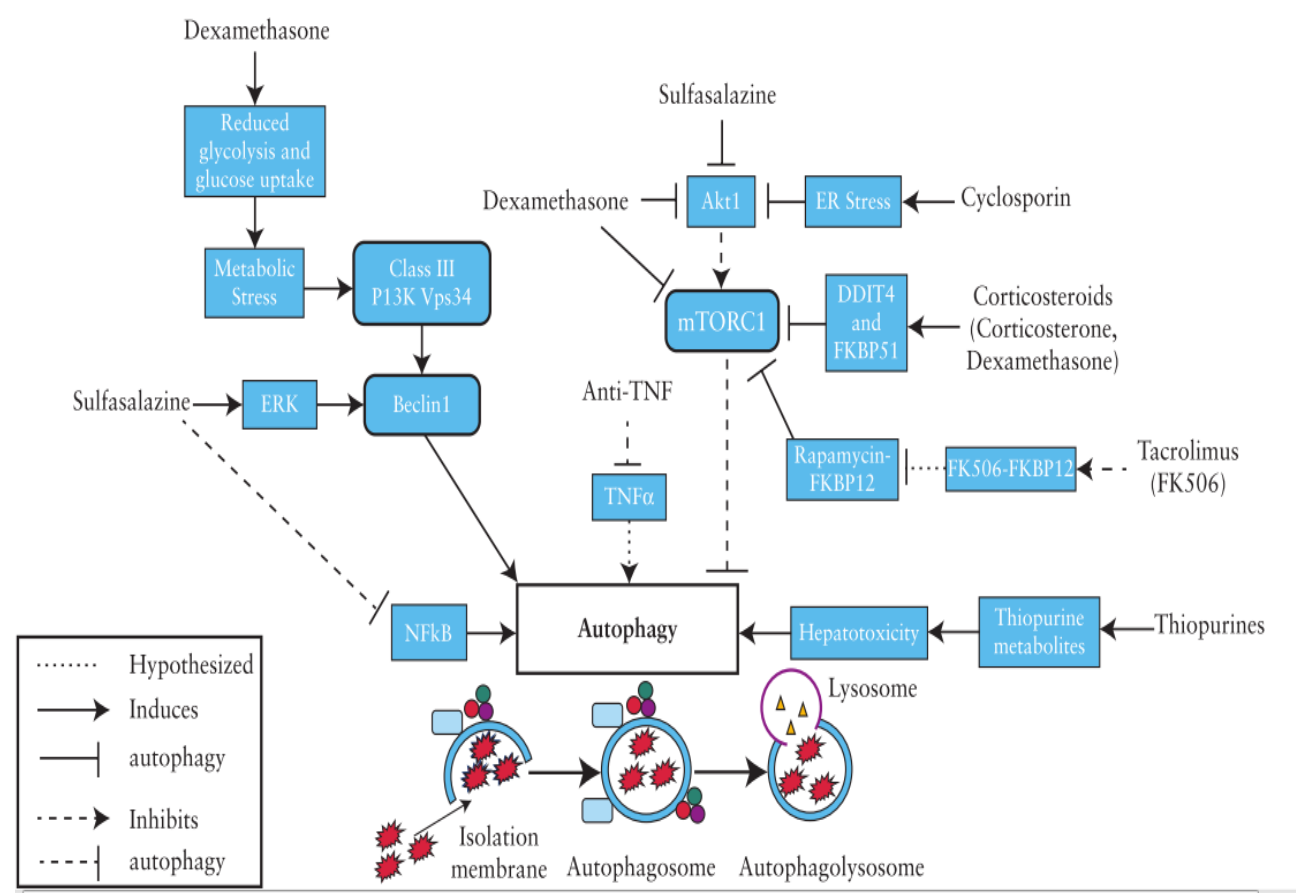

Figura 7. Tratamiento actual de la Ell y las vías que modulan la autofagia ${ }^{[86]}$

\subsection{4) Biológicos}

Las terapias biológicas se centran en los anticuerpos monoclonales dirigidos contra proteínas específicas implicados en la patogénesis de la enfermedad inflamatoria crónica. En la Ell se emplea principalmente anticuerpos frente al factor de necrosis tumoral (TNF) (infliximab, adalimumab, certolizumab, golimumab), además de otros de reciente aprobación o en vías de desarrollo dirigidos contra otras dianas: integrinas (natalizumab, vedolizumab) o interleucina (IL) -12 / 23 (ustekinumab), entre otros [90].

El diluvio de estudios que siguieron a su aprobación proporcionó evidencia de que esta clase de fármacos podría inducir la remisión clínica sostenida en una cohorte de pacientes, además de evitar la necesidad 
crónica de esteroides, el reducir el número de hospitalizaciones y potencialmente, evitar la cirugía.

En distintos estudios se ha concluido que infliximab es eficaz en el tratamiento de pacientes con CU moderada-grave refractaria a corticoides y/o inmunomoduladores para inducir remisión, respuesta clínica, fomentar la cicatrización mucosa y reducir la necesidad de colectomía a corto plazo [84].

\begin{tabular}{|c|c|c|c|}
\hline Fármaco & Indicación & $\begin{array}{c}\text { Nivel de } \\
\text { evidencia }\end{array}$ & $\begin{array}{l}\text { Grado de } \\
\text { recomendación }\end{array}$ \\
\hline \multirow{3}{*}{$\begin{array}{c}\text { Azatioprina/ } \\
\text { Mercaptopurina }\end{array}$} & $\begin{array}{c}\text { Inducción a la remisión en brote } \\
\text { moderado corticorrefractario }\end{array}$ & $1 b$ & B \\
\hline & $\begin{array}{l}\text { Mantenimiento en } \\
\text { corticodependencia }\end{array}$ & $1 a$ & A \\
\hline & $\begin{array}{l}\text { Mantenimiento tras inducción } \\
\text { con ciclosporina }\end{array}$ & $1 b$ & C \\
\hline Metotrexato & \multicolumn{3}{|c|}{ No indicación } \\
\hline Ciclosporina & $\begin{array}{c}\text { Inducción a la remisión en brote } \\
\text { grave corticorrefractario }\end{array}$ & $1 b$ & C \\
\hline Tacrolimus & $\begin{array}{l}\text { Inducción a la remisión en brote } \\
\text { grave corticorrefractario }\end{array}$ & $1 b$ & C \\
\hline
\end{tabular}

Tabla 6. Fármacos en la CU según grado de recomendación y niveles de evidencia

\subsection{5) La cirugía en la colitis ulcerosa}

Aunque la base del tratamiento de la CU es médico, en el transcurso de la enfermedad alrededor de un $20-30 \%$ de los pacientes van a requerir cirugía [89].

La cirugía urgente está indicada en los pacientes con CU grave que no responden al tratamiento médico o en situaciones que suponen un riesgo vital como el megacolon tóxico. Las indicaciones más frecuentes de cirugía 
electiva son la refractariedad al tratamiento médico, la intolerancia al tratamiento de mantenimiento a largo plazo y la aparición de displasia o cáncer colorrectal. Aunque la mortalidad está asociada a los brotes graves, ésta ha disminuido al menos del $1 \%$ en las últimas décadas [17]. Hay que tener en cuenta que un retraso en la cirugía puede aumentar el riesgo postoperatorio de complicaciones y las tasas de mortalidad [91]

\subsection{6) Historia Natural de la CU}

\subsubsection{1) Evolución anatómica}

La CU afecta al recto y colon y se extiende de forma continua a tramos proximales. Las lesiones son generalmente difusas y superficiales. Ulceraciones profundas se observan sólo en pacientes con enfermedad grave. De acuerdo con un estudio prospectivo en el momento de la presentación, la inflamación se limita al recto, en un tercio de los pacientes; a colon distal a la flexura esplénica y al recto en otro tercio, y es proximal al ángulo esplénico en el tercio restante. Una afectación extensa (pancolitis) se observa en el $25 \%$ de los pacientes[92].

\subsubsection{2) Progresión de la enfermedad}

El curso de la CU se caracteriza por brotes que se alternan con períodos de remisión; una minoría de pacientes puede tener una actividad continua. La gravedad de los brotes y su respuesta al tratamiento varían y son difíciles de predecir; con el tiempo, la actividad de la enfermedad tiende a disminuir. En un estudio de una cohorte danesa que no recibió tratamiento inmunosupresor, el $40 \%-50 \%$ de los pacientes estaban en remisión prolongada después de unos años, y la proporción con la enfermedad activa cada año disminuyó gradualmente a aproximadamente el 30\%; cerca de un tercio de los pacientes no tenían recurrencia en los 10 años tras el primer brote a pesar de la gravedad del primer brote; en los 
pacientes con una presentación grave en los que se evitó la colectomía, tendían a tener un curso más benigno de la enfermedad durante el siguiente año [89]

\subsubsection{3) Necesidad de cirugía}

La necesidad de colectomía varía alrededor del 20\% - 30\% después de 25 años; la probabilidad de colectomía es mayor durante el primer año después del diagnóstico, llegando al 10\% en algunos estudios. La extensión y la gravedad de los síntomas en el momento del diagnóstico son los mejores predictores de colectomía [89]. Ciclosporina e infliximab, son tratamientos eficaces en aquellos cuadros graves que no responden a los esteroides y pueden retrasar o prevenir la colectomía en la mayoría de los pacientes. La cirugía no puede ser considerada como un tratamiento definitivo en pacientes a los que se realiza un reservorio ileoanal, pues hasta un $10 \%$ de éstos presenta reservoritis refractaria a los antibióticos considerada como una recurrencia de la enfermedad inflamatoria y pudiendo incluso requerir terapias inmunosupresoras, biológicas e incluso la exéresis del reservorio [93]. 


\section{2) GENES Y COLITIS ULCEROSA}


Desde hace varias décadas los estudios poblacionales han demostrado que el factor genético contribuye en la patogenia de la Ell. Es conocido que la población judía Ashkenazi tiene más riesgo de padecer la enfermedad; además, se ha comprobado una elevada agregación familiar pues el riesgo de padecer la enfermedad en familiares afectos está aumentado de 8 a 10 veces. El riesgo de $\mathrm{CU}$ en familiares de primer y segundo grado se multiplica por 4 y 2 respectivamente [26]. También se observó que existe una concordancia importante entre gemelos, siendo mayor para los gemelos monocigotos con EC (20-50\%) que para los gemelos dicigotos (10\%); en la CU el grado de concordancia es menor, tanto en gemelos monocigotos como dicigotos (16\% y $4 \%$ respectivamente).

En 2002 se identificó el primer gen asociado a la Ell: NOD2 fue el primer gen identificado que confiere susceptibilidad para la EC; desde entonces se inició una nueva era en el estudio de las bases genéticas de la Ell. Estudios de asociación genética (GWAS) y metaanálisis han identificado mediante análisis bioinformáticos sofisticados muchos SNPs asociados a la $\mathrm{CU}$, lo que ha permitido conocer y profundizar en aspectos de su naturaleza poligénica de su patogenia y de potenciales dianas terapéuticas. Mediante estos estudios se han identificado hasta 163 locus asociados a la Ell, de los cuales 110 se asocian a ambas enfermedades: 30 son específicos de la EC y 23 de la CU [94], lo que sugiere una contribución genética similar a la predisposición de la enfermedad en ambos casos, así como rutas fisiopatológicas comunes (Figura 8). Recientemente en un estudio de asociación trans-étnica de Ell, en se han descrito otros 38 locus [95]; por lo que hasta el momento existen 200 locus asociados a la Ell.

La identificación con éxito de las variantes genéticas asociadas a enfermedades complejas como la Ell ha planteado la posibilidad de un enfoque más personalizado para su manejo clínico. En este sentido ya que están realizando estudios de asociación entre el genotipo (NOD2, MHC, y 
MST1) y tres subfenotipos de Ell según la localización (enfermedad de Crohn ileal, enfermedad de Crohn colónica y la Colitis Ulcerosa) con el objetivo de comprender aún más las relaciones biológicas entre ambas enfermedades [96].

Como ya hemos descrito, en la patogenia de la CU existe una alteración de la barrera intestinal; estudios de asociación genética han identificado genes implicados asociados a este defecto como ECM1, CDH1, HNF4A y LAMB1 que pueden conferir susceptibilidad específica a padecer CU. Curiosamente, el locus $\mathrm{CDH} 1$ representa la primera asociación genética con la susceptibilidad al cáncer colorrectal familiar [97].

Aunque los loci de susceptibilidad para CU han incluido principalmente los genes que regulan la función de barrera del epitelio intestinal, hay pruebas recientes de que distintas variantes de HLA están involucrados en el desarrollo de la CU, así como otros alelos de riesgo que codifican citoquinas y mediadores inflamatorios, incluyendo el factor de necrosis tumoral (TNF), ILs y los receptores de IL (IL1R2, IL8RA / RB, IL7R) [98].

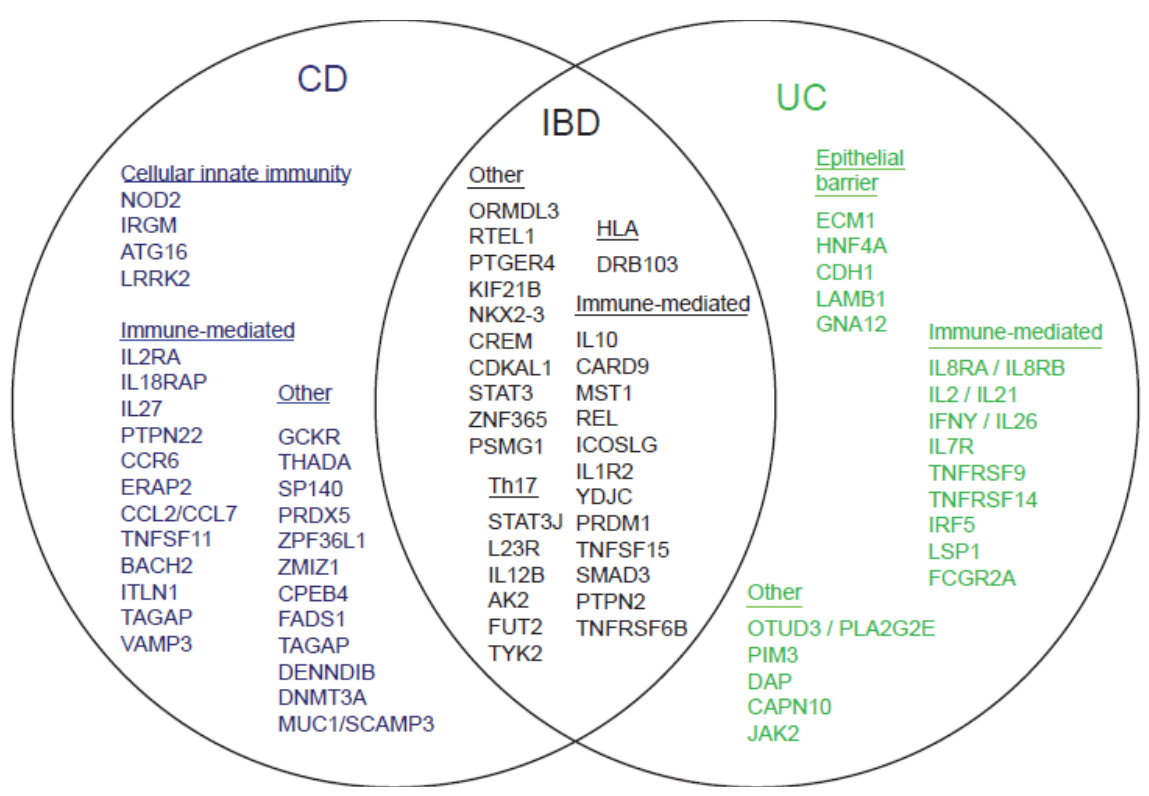

Figura 8. Genes asociados a la Ell ${ }^{[99]}$ 


\section{1) GENES RELACIONADOS CON LA INFLAMACIÓN}

\subsection{1) CTLA4 (Cytotoxic T-lymphocyte antigen 4)}

El gen CTLA4 se localiza en la región cromosómica 2 q33 y codifica un receptor expresado por las células $T$ activadas. Es un inhibidor importante de la activación de las células T y podría contribuir a la tolerancia periférica. CTLA4 es un gen candidato de susceptibilidad para la CU, ya que actúa como un regulador negativo de la activación de células $\mathrm{T}$ y monocitomacrófago [97]. Se han descrito varios polimorfismos genéticos del gen CTLA4. Su asociación ha sido descrita en una población china donde los genotipos A / G + G / G en la posición -1661 y la frecuencia del alelo $G$ fueron estadísticamente superiores en los pacientes con $\mathrm{CU}$ que en los controles sanos.

\subsection{2) JAK2 (Janus kinase 2)}

Se encuentra en la región cromosómica 9p24.1 y es un miembro importante de la familia de las tirosina quinasas. JAK2 y la señal de transductor y activador de la transcripción 3 (STAT3) forman parte de la vía de señalización de la IL23 / IL23-R, que desempeña un papel central en las respuestas inflamatorias innata y adaptativa a múltiples niveles en la mucosa intestinal [100]. Estudios de GWAS han identificado varios polimorfismos del gen JAK2 asociados a la CU. En dos poblaciones del Reino Unido y los Países Bajos se ha demostrado asociación de los SNPs rs10758669 y rs10974944 de la JAK2 con la CU [97]; un metaanálisis europeo también encontró asociación del SNP rs10758669 de JAK2 con CU y con EC y otro estudio en población asiática describe una asociación exclusiva del polimorfismo rs10758669 con la CU [100].

\subsection{3) STAT3 (Signal transducer and activator of transcription 3)}

Gen localizado en el cromosoma 17q21 que codifica una proteína miembro de la familia de proteínas con función de transductor de señal y 
activador de la transcripción (STAT). Se activa en respuesta a citocinas y factores de crecimiento incluyendo interferones (IFNs), factor de crecimiento epidérmico (EGF), interleucina-5 (IL-5), IL-6 y factor de crecimiento de hepatocitos (HGF). Los miembros de la familia STAT son fosforilados por las quinasas asociadas a receptores $y$, a continuación, forman homo o heterodímeros que se translocan al núcleo celular donde actúan como activadores de la transcripción. STAT3 regula la expresión de una variedad de genes en respuesta a estímulos y, por lo tanto, juega un papel importante en varios procesos celulares, tales como el crecimiento celular y la apoptosis [97]. Uno de los SNPs asociados a la CU en población norteamericana es el rs12948909.

\subsection{4) TNFa (Factor de necrosis Tumoral alpha)}

Tiene un importante papel patogénico en la Ell por su capacidad de causar alteración de la barrera intestinal y es el responsable de daño tisular. El factor de necrosis tumoral (TNF) - $\alpha$ se eleva en la sangre, heces y mucosa de los pacientes con CU. Estos hallazgos, junto con la eficacia del tratamiento anti-TNF para la CU, corroboran la importancia de TNF- $\alpha$ en la patogénesis de la enfermedad. Se ha demostrado en una cohorte europea de pacientes con CU que los portadores del alelo TNF 308A tienen mayor riesgo de enfermedad extensa y de necesitar una resección intestinal [97].

\subsection{5) OCTN1 (SLC22A4) y OCTN2 (SLC22A5)}

Son proteínas con una función multiespecífica en el transporte transmembrana de la carnitina y de cationes orgánicos [101]. Tienen un papel importante en el mantenimiento de la homeostasis intracelular y en la producción de energía celular. También podrían tener un papel en la modulación de la gravedad de la inflamación crónica en la CU. Las mutaciones en los genes que codifican OCTN podrían perjudicar el funcionamiento del OCTN y, como resultado, disminuir el transporte de 
carnitina, que es un cofactor esencial en la producción de energía celular mediada por el transporte de ácidos grasos de cadena larga a mitocondrias. En la mitocondria, los ácidos grasos se someten a beta-oxidación, y se ha demostrado que la inhibición de la oxidación de ácidos graso en el epitelio de la mucosa del colon se asocia con el desarrollo de CU [102]. En una cohorte italiana, se ha observado que pacientes homocigotos para la variante OCTN1 1672 T presentaban una asociación significativa con el riesgo de desarrollar CU.

\subsection{6) MDR1 (Multidrug-resistant transporter-1)}

El gen MDR1 se encuentra en el cromosoma 7q21; codifica la proteína transmembrana, P-glicoproteína 1 (Pgp), es un transportador ATP dependiente y se expresa en muchos tejidos normales como en las superficies epiteliales del intestino, conductos biliares, túbulos proximales de los riñones y el sistema nervioso central. Una de las mutaciones más significativas del gen MDR1 es el polimorfismo C3435T, que resulta en una disminución en la expresión del gen y de la actividad de Pgp. En un estudio en población alemana, las frecuencias del alelo $\mathrm{T}$ y genotipo TT del polimorfismo C3435T fueron mayores en pacientes con CU [97].

\subsection{7) TLRs (Toll-like receptors)}

Los componentes esenciales de la inmunidad innata son los Toll like receptores (TLRs). Estos receptores transmembrana reconocen los compuestos microbianos de bacterias, hongos y virus. Los TLRs se expresan en las células epiteliales intestinales y células inmunes en pacientes con Ell [97].

En un individuo sano, la señalización de TLRs impulsa mecanismos inmunes basales esenciales para la protección de la integridad de la barrera del huésped y mantener la homeostasis con la flora comensal; sin 
embargo, en un individuo susceptible, la señalización aberrante o disfuncional de TLR puede deteriorar esta homeostasis, contribuyendo así a la amplificación y perpetuación del daño tisular conduciendo a una inflamación crónica característico de la Ell [103]. Su asociación con la CU se realizó por primera vez con el polimorfismo de TLR4 Asp299Gly, posteriormente se encontró asociación significativa entre los portadores de la mutación Thr399 del gen TLR4 con la CU en una población caucásica.

\subsection{8) CAM (moléculas de adhesión celular)}

Son moléculas que median la extravasación de leucocitos y su acumulación en la mucosa intestinal inflamada. Este proceso es controlado por una familia de CAM incluyendo la molécula de adhesión celular intercelular (ICAM-1), la molécula de adhesión celular endotelial de plaquetas (PECAM-1), las selectinas (E, L, P y selectina) y la integrinas[97].

\subsection{9) Interleuquinas}

IL1: La interleucina 1 (IL-1) es una citoquina pro-inflamatoria que actúa a nivel de la proliferación celular, la diferenciación y la función de muchas células inmunocompetentes innatas y específicas. IL-1 representa dos formas estructuralmente distintas: IL-1 $\alpha$ e IL-1 $\beta$. Tanto para IL- $1 \alpha$ como para $\beta$, las propiedades más significativas y relevantes son la iniciación de ciclooxigenasa tipo 2 , óxido nítrico sintasa inducible y fosfolipasa $A 2$, que son producidas por varios tipos de células. El antagonista del receptor de IL-1 endógeno (IL-1Ra), un antagonista natural de IL-1, regula la homeostasis en el intestino normal. El aumento de la relación IL-1 / IL-1Ra es paralelo con la actividad de la colitis, mientras que la relación IL-1 / IL$1 \mathrm{Ra}$ permanece constante en la parte no afectada del colon y en los controles [104]. 
IL2: junto con el interferón-gamma (IFN- $\gamma$ ), es producida por linfocitos Th1 y estimula a los macrófagos, las células NK y las células T citotóxicas. Esta IL tiene un papel importante en el desarrollo de células Th1, Th2, Treg, y en la diferenciación Th17. La presencia de un gran número de células T activadas en la mucosa de pacientes con Ell sugiere que la IL-2 desempeñaría al menos algún papel en la estimulación de la inflamación. En un estudio se ha observado que el polimorfismo del gen IL2 podría tener un efecto modesto en la susceptibilidad a padecer CU [105]

IL6: es una citocina multifuncional, responsable de la regulación de la respuesta inmune, las respuestas de fase aguda, la hematopoyesis y la inflamación. En un estudio casos y controles se encontró una asociación positiva entre los niveles séricos de IL6 con la gravedad y extensión de la EII [106].

IL8: es miembro de la familia de las quimiocinas CXC y tiene dos receptores: CXCR1 (IL-8RA) y CXCR2 (IL-8RB). Las IL8RA/B son dos genes que codifican los dos receptores conocidos de la quimioquina IL-8, sintetizada entre otras estirpes por las células epiteliales intestinales y encargadas de la quimiotaxis de leucocitos polimorfonucleares. La expresión de IL-8RA está regulada al alza en macrófagos, linfocitos y células epiteliales intestinales de pacientes con CU [107].

En un estudio realizado en una población europea se analizó IL-8 T251A. La frecuencia del alelo mostró diferencias significativas comparando el grupo de CU con los controles; sin embargo, no se confirmó esta asociación en una cohorte china [108].

IL10: el gen está localizado en el cromosoma 1q32. La IL10 durante mucho tiempo ha sido conocida por sus propiedades antiinflamatorias. Es una citoquina reguladora y actúa como inhibidor del desarrollo de células Th1, macrófagos y sus productos (IL12, TNF e INFgamma). Se produce por 
muchas células como monocitos, células $T$, células $B$, células NK, macrófagos y células dendríticas (DCs). Evita la presentación de antígenos y la posterior liberación de citoquinas pro-inflamatorias, por lo que alivia al sistema inmunológico activado. En un GWAS, el polimorfismo rs3024505 mostró una asociación con la CU [109]; confirmado en otro estudio de asociación genética europeo [110]; al parecer una función defectuosa de la IL-10 jugaría un papel importante en la patogénesis de la CU.

IL12: es una interleucina que se produce naturalmente por las células dendríticas, los macrófagos y las células B-linfoblastoides en respuesta a la estimulación antigénica de patógenos bacterianos. Participa en la diferenciación de células T vírgenes en células Th1 y en las actividades de las células NKT y linfocitos T estimulando la producción de INFgamma por las mismas[111]. En una población alemana fueron investigados cuatro SNPs (rs3212227, rs17860508, rs10045431 y rs6887695) del IL- 12B, encontrándose asociación con la susceptibilidad a desarrollar CU con los polimorfismos rs10045431 y rs6887695 [112].

IL17: actúa sobre una variedad de células, las cuales responden regulando positivamente la expresión de citoquinas proinflamatorias, quimiocinas y metaloproteasas [113]. Está involucrado en el desarrollo de autoinmunidad, inflamación y tumores. En una cohorte japonesa de pacientes con CU, se analizó el polimorfismo rs2275913 de IL17A y rs763780 IL17F. Las frecuencias de los genotipos -197A / A y 7488T / T fueron significativamente mayor en los pacientes con $\mathrm{CU}$ que en los controles [114]

IL18: es producida por macrófagos y otras células; ésta, junto a la IL-12 participa en la inducción de la inmunidad mediada por células después de la infección, induce la expresión y síntesis de TNF, IL-1, el ligando de Fas, y varias quimiocinas [113]. Se han examinado varios polimorfismos del gen IL-18. En un estudio japonés el alelo $\mathrm{G}$ en 113 y el alelo T en 127 eran 
significativamente mayores en los pacientes con CU en comparación con los controles [115].

IL23: participa en la inmunidad innata y adaptativa al regular la función y expansión de células Th17. La IL-23 estimula a las células Th17 productoras de TNF $\alpha$, IL-17, IL-6, IL-22, GM-CSF y otros factores asociados con la inducción de la inflamación autoinmune. Entre los múltiples genes que se encuentran involucrados en la vía de señalización IL23/Th17 se encuentran el receptor de IL23, IL12B, JAK2, Tyk2 y STAT3. El gen IL23R fue descubierto originalmente como un gen de susceptibilidad para la EC; posteriormente, su importancia ha sido confirmado en la $\mathrm{CU}$, por lo que este gen parece conferir susceptibilidad a ambas enfermedades [110]. La IL 23 regula el equilibrio Th1 / Th17 en la CU, por tanto, su bloqueo es una diana terapéutica atractiva. En la actualidad, el ustekinumab, un anticuerpo monoclonal contra la subunidad p40 del receptor de IL23, es usado en el tratamiento de la EC. Un estudio reciente, demostró el incremento de la expresión de IL23R en biopsias de mucosa y en sangre periférica de pacientes con $\mathrm{CU}$, siendo su expresión mayor en enfermedad grave comparada con la enfermedad moderada o leve[116].

\subsubsection{0) Región HLA}

La región MHC en el cromosoma 6 abarca los genes HLA, conocida por codificar genes implicados en la regulación de la respuesta inmune a antígenos peptídicos endógenos y exógenos. La asociación más consistente con la CU ha sido con el alelo HLA DRB1 * 0103, una variante poco frecuente en la región HLA de clase II; curiosamente, es uno de los únicos factores genéticos que se ha asociado con las características fenotípicas de la enfermedad, siendo más frecuente en pacientes con enfermedad extensa, pacientes que no responden al tratamiento y aquellos con MEI. Se ha descrito la presencia del alelo HLA DRB1 * 0103 en el 15,8\% de las 
personas con colitis extensa en el momento de la cirugía y en $22,8 \%$ de un subgrupo de pacientes con MEI [110].

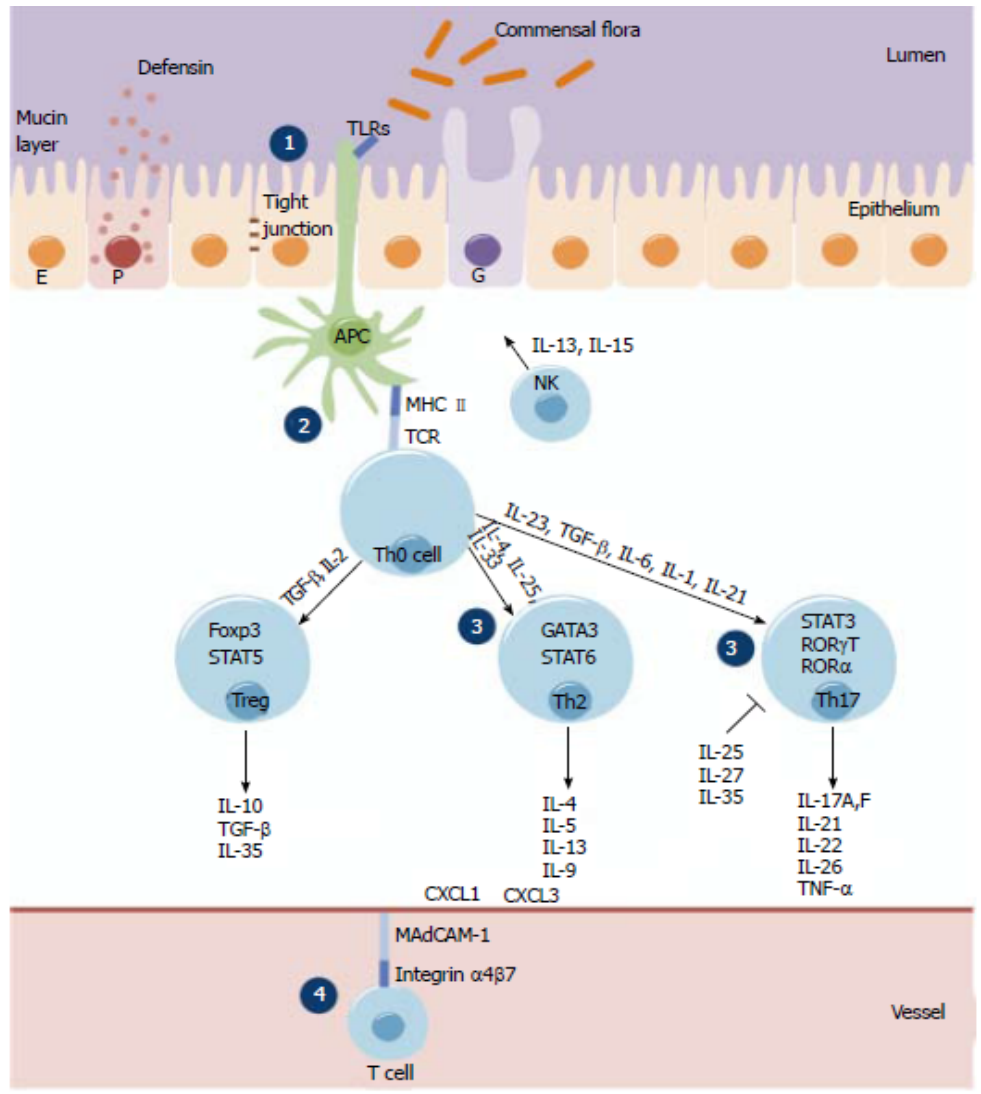

Figura 9. Factores genéticos asociados a la inflamación en la CU ${ }^{[97]}$

\section{2) GENES QUE REGULAN LA BARRERA INTESTINAL}

\subsection{1) ECM1}

Localizado en el cromosoma 1q21.2, codifica la proteína de la matriz extracelular 1 (ECM1). El gen ECM1 es un candidato plausible de susceptibilidad para la CU, se expresa en el epitelio de todo el intestino y se encarga de inhibir la metaloproteinasa 9 y de activar NFkB [110]. A nivel intestinal es posible que pueda tener un papel en la integridad y la función epitelial de la membrana basal. La membrana basal puede influir en el 
comportamiento de las células epiteliales mediante el control de su forma, la expresión génica, adhesión, migración, proliferación, y apoptosis. El gen ECM1 es necesario para el soporte estructural o funcional de la membrana basal y, por consiguiente, la capacidad del epitelio intestinal para formar una barrera efectiva [117].

\subsection{2) HNF4A}

Se localiza en el cromosoma $20 q 13$ y codifica el factor nuclear del hepatocito, que se expresa en hígado, páncreas e intestino. Tiene un rol crucial en el desarrollo del tracto gastrointestinal. HNF4A es un factor de transcripción nuclear que controla la expresión de múltiples genes. Desde una perspectiva funcional, es importante para la homeostasis del epitelio, la función celular, y la arquitectura celular en el hígado y el tracto gastrointestinal. En el tracto gastrointestinal es la proteína que controla la expresión de varios componentes de la unión célula-célula en el epitelio intestinal. En ratones, la pérdida de HNF4A conduce a aumento de la permeabilidad paracelular por el deterioro de las uniones célula-célula; lo que ratifica su papel crucial para la función de barrera de la mucosa intestinal. En humanos se ha observado una clara disminución de su expresión en muestras de pacientes con Ell. La asociación con la CU fue confirmada en una cohorte holandesa por Sommeren et al [118],

\subsection{3) $\mathrm{CDH} 1$}

El locus $\mathrm{CDH} 1$ en $16 \mathrm{q} 22$ comprende tres genes. CDH1 codifica la Ecadherina, una glicoproteína transmembrana y principal componente de las uniones adherentes, que juega un papel importante en la adhesión célula-célula. La pérdida de E-cadherina podría contribuir a la patogénesis de la Ell a través de la interrupción de los contactos célula-célula y el aumento de la permeabilidad intestinal. Curiosamente, diferentes bacterias son capaces de interrumpir estas adherencias celulares. La E- 
cadherina es un objetivo para la invasión intestinal por patógenos tales como Cándida albicans y Bacteroides fragilis. En el caso de B. fragilis, esto ocurre a través de la liberación de una toxina llamada fragilisin que escinde el dominio extracelular de la E-cadherina rompiendo así las uniones celulares.

En el epitelio intestinal normal la E-cadherina puede actuar en concierto con HNF-4A para mantener la integridad de la barrera. El descubrimiento $\mathrm{CDH} 1$ en la $\mathrm{CU}$ ha sido un hecho de gran relevancia, pues desde hace mucho tiempo la CU es factor de riesgo para el desarrollo de cáncer colorrectal y recientemente se ha asociado la metilación del promotor del locus CDH1 con displasia en pacientes con CU [110].

\subsection{4) LAMB1}

El locus fue identificado en una región del cromosoma 7q31. LAMB1 codifica la subunidad b1 laminina, una cadena ligera presente en los heterodímeros de laminina-1, laminina-2 y laminina 10. Las lamininas representan el componente glicoproteico predominante de la membrana basal, interactuando con integrinas para crear un sistema de adhesión celular en el epitelio intestinal. Estas proteínas están involucradas en múltiples funciones incluyendo la adhesión, migración, diferenciación y supervivencia.

No hay duda de que las variaciones genéticas juegan un rol importante en la patogénesis de la Ell. De hecho, estudios recientes muestran que el riesgo de desarrollar CU o EC aumenta en proporción directa al número de alelos de riesgo de cada paciente. En otras palabras, cuanto mayor es la carga de genes asociados a la Ell, mayor es el riesgo de manifestarla. Sin embargo, a pesar de todas las asociaciones genéticas descritas en la Ell; éstas sólo representan aproximadamente el $25 \%$ de todos los casos de enfermedad, y aunque se encontraran nuevas asociaciones, no 
aumentarían sustancialmente este porcentaje. Lo que puede explicar este " vacío genético " o " falta de heredabilidad" en la Ell es la posible interacción entre los genes de riesgo (interacción gen-gen o epistasis), la interacción entre genes y medio ambiente $o$, más probablemente una combinación de gen-gen y las interacciones gen-ambiente [29, 119].

No obstante, la CU al igual que la EC, parecen tener una base genética heterogénea por el gran número de genes implicados y el efecto aditivo de cada uno, por lo que actualmente el cribado genético no está indicado para evaluar el riesgo de CU [72]. 
3) AUTOFAGIA 
La autofagia (término derivado de las raíces griegas auto - uno mismo, y phagos - comer) [120], es un proceso homeostático fundamental presente en las células eucariotas desde la levadura hasta el humano [121] mediante el cual la célula degrada orgánulos, patógenos intracelulares, componentes dañados transformándolos y reciclándolos en elementos esenciales en procesos anabólicos [122]. Es un proceso necesario para el mantenimiento de la homeostasis celular después de la infección, el daño mitocondrial, o el estrés [60].

Fue descrita por primera vez en 1963 por Christian de Duve [123]. Desde entonces, estudios genéticos de levadura (predominantemente en saccharomices cerevisiae) han identificado más de 30 genes relacionados con el proceso de autofagia (ATG) (tabla 7).

Mediante este proceso las estructuras diana son secuestradas por vesículas de doble membrana llamadas autofagosomas, que se forman por la acción concertada de las proteínas relacionadas con la autofagia (ATG). Una vez formado el autofagosoma, se une al lisosoma para formar el autolisosoma, degradándose el contenido mediante la hidrolasa lisosomal $[124,125]$ (Figura 10).

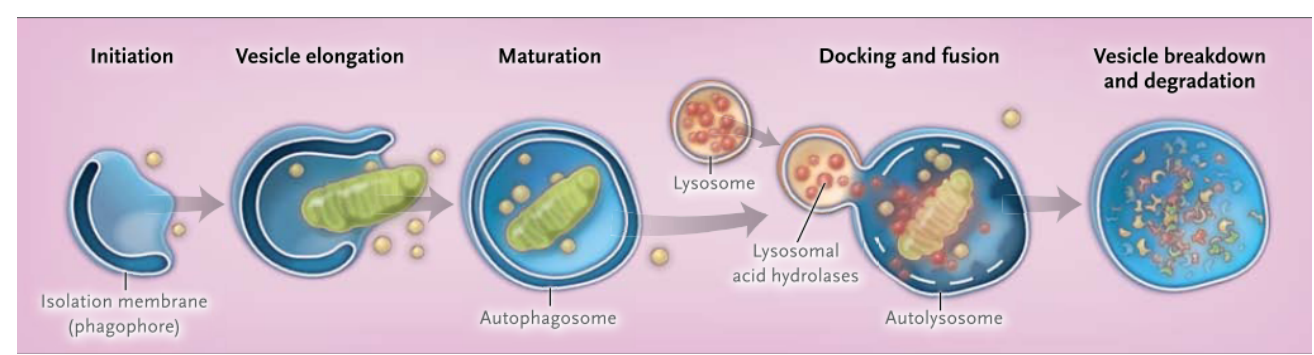

Figura 10. Fases de la autofagia ${ }^{[126]}$ 


\begin{tabular}{|c|c|c|}
\hline $\begin{array}{c}\text { ATG } \\
\text { proteins }\end{array}$ & $\begin{array}{l}\text { Mammalian } \\
\text { homologs }\end{array}$ & Functional changes \\
\hline Atg1 & ULK1/2 & Initiation of autophagy \\
\hline Atg2 & $\operatorname{Atg} 2 A / B$ & ATG18-interacting proteins \\
\hline Atg3 & Atg3 & $\begin{array}{l}\text { E2-like enzyme in Atg8 conjugation; } \\
\text { regulation of mitochondrial homeostasis }\end{array}$ \\
\hline Atg 4 & Atg4A-D & $\begin{array}{l}\text { Cysteine protease; activation as well as } \\
\text { delipidation of ATG8 }\end{array}$ \\
\hline Atg5 & Atg5 & $\begin{array}{l}\text { Autophagosome formation/elongation; } \\
\text { induction of apoptosis }\end{array}$ \\
\hline Atg6 & Beclin 1 & $\begin{array}{l}\text { Essential for autophagosome formation; } \\
\text { target for viral proteins to interfere with } \\
\text { autophagy function/efficacy }\end{array}$ \\
\hline Atg7 & Atg7 & $\begin{array}{l}\text { E1-like enzyme in Atg8 and Atg12 } \\
\text { conjugation }\end{array}$ \\
\hline Atg8 & $\mathrm{LC} 3 \mathrm{~A} / \mathrm{B} / \mathrm{C}$ & $\begin{array}{l}\text { Ubiquitin-like modifier; conjugation to } \\
\text { autophagosomal membrane; closure and } \\
\text { determination of size of autophagosome; } \\
\text { autophagy-independent functions }\end{array}$ \\
\hline Atg9 & Atg9A/B & $\begin{array}{l}\text { Transmembrane protein; possible } \\
\text { "membrane shuttle" }\end{array}$ \\
\hline Atg10 & Atg10 & E2-like inzyme in Atg12 conjugation \\
\hline Atg12 & Atg12 & Ubiquitin-like modifier \\
\hline Atg13 & Atg13 & Initiation of autophagy \\
\hline Atg14 & $\operatorname{Atg} 14 \mathrm{~L}$ & ER targeting of Vps34 complex \\
\hline Atg16 & Atg16L1/L2 & $\begin{array}{l}\text { Atg12- Atg5/ Atg16L1complex, essential for } \\
\text { autophagosome formation }\end{array}$ \\
\hline Atg17 & FIP-200 & Initiation of autophagy \\
\hline Atg18 & WIPI1-4 & $\begin{array}{l}\text { PI3P binding, possible functions in } \\
\text { omegasome formation and/or later stages } \\
\text { of autophagy }\end{array}$ \\
\hline
\end{tabular}

Tabla 7. Proteínas ATG y características funcionales ${ }^{[127]}$ 


\section{1) TIPOS DE AUTOFAGIA}

Se pueden distinguir tres formas de autofagia en base a la función celular y a la modalidad de transportar el contenido citoplasmático (cargo) hacia los lisosomas: La microautofagia, la autofagia mediada por chaperonas y la macroautofagia [123] (Figura 11).

Microautofagia: caracterizada por que los componentes citosólicos son directamente tomados por el lisosoma mediante invaginación de la membrana lisosomal.

La autofagia mediada por chaperonas: en este caso no se requiere la formación de vesículas intermedias. Las proteínas diana son incorporadas directamente a lisosomas de manera específica y dependiente de un complejo de translocación formado por proteínas chaperonas que son reconocidas por el receptor asociado a la proteína de membrana lisosomal tipo 2A (LAMP)-2A, provocando su desplegamiento y degradación.

Macroautofagia: Es el fenómeno más estudiado, se caracteriza por la formación de un compartimento de doble membrana, el autofagosoma, que engloba material citoplasmático. Una vez formado, el autofagosoma se fusiona con el lisosoma para formar un autolisosoma con actividad proteolítica. 


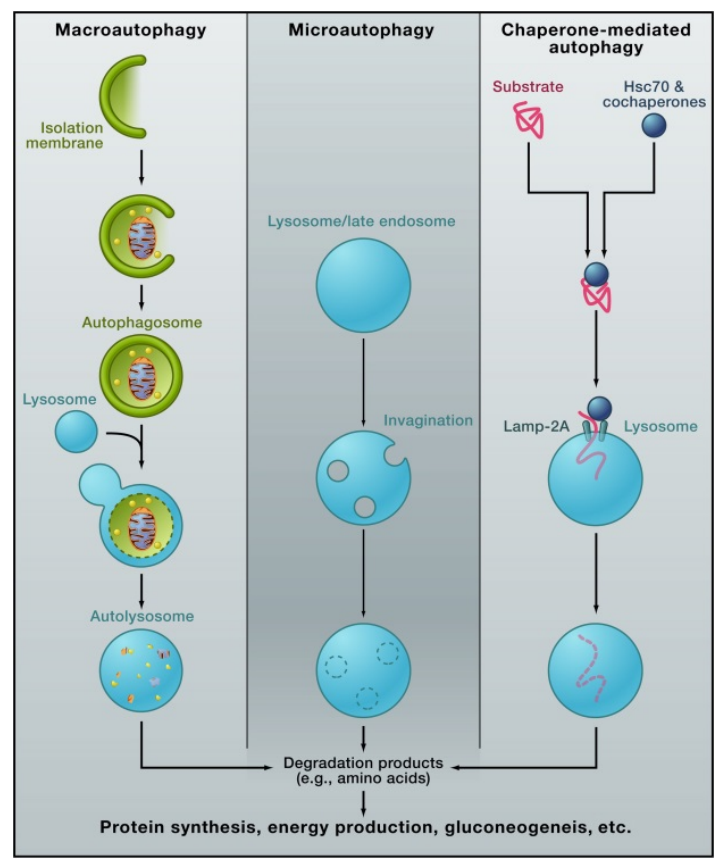

Figura 11. Tipos de autofagia ${ }^{[128]}$

De los tres tipos de autofagia, la macroautofagia es la mejor caracterizada y se la ha relacionado con la inmunidad adaptativa y con la inmunidad innata [120]. A partir de ahora se hará referencia a la macroautofagia con el término "autofagia".

\section{2) SEÑALIZACIÓN DE LA MAQUINARIA DE AUTOFAGIA}

En la formación del autofagosoma y su posterior unión a los lisosomas, las proteínas ATG deben ejercer su función. Así, podemos dividir estas proteínas en tres grupos funcionales dependiendo del papel que ejerzan en la maquinaria de la autofagia. 1) ATG9 y su sistema cíclico, que incluye ATG9, el complejo quinasa ATG1 (ATG1 y ATG13), ATG2 y ATG18; 2) el complejo PI3K-III (Vps34, Vps15, ATG6 (Vps30)/Beclina1 y ATG14; y 3) el sistema de proteínas similares a ubiquitina (ubiquitin-like) (Ubl), que incluye dos proteínas Ubl (ATG8/LC3 y ATG12), una enzima activadora (ATG7), dos análogos de la enzima conjugadora de ubiquitina (ATG10 y 
ATG3), una proteasa que modifica ATG8 (ATG4), la proteína diana de unión de ATG12 (ATG5) y ATG16.

\section{3) MECANISMO DE LA AUTOFAGIA}

El proceso de autofagia puede ser dividido en cuatro fases distintas: Inicicación, nucleación (formación del llamado fagosporo), elongación ( crecimiento y cierre del autofagosoma) y fusión del autofagosoma con el lisosoma para formar el fagolisosoma [123]. Como consecuencia del proceso se liberan aminoácidos y ácidos grasos, que serán reutilizados por la célula [121].

La maquinaria núcleo de la vía de la autofagia consta de cuatro complejos:

El complejo ULK (quinasa 1 tipo Unc 51): complejo formado por ULK1/2, ATG13, FIP200 y ATG101. Es el encargado de inducir la autofagia con la formación de la vesícula inicial. Inicia la nucleación de la membrana que permite el secuestro del material citoplásmico. Este complejo es regulado de forma negativa por mTORC con la fosforilación de ULK1/2 y ATG13 [125]

El complejo PI3K (fosfatidilinositol-3-quinasa): compuesto por Vps34, Vps15, ATG6/Beclina1 y ATG14 [125]. Es esencial para nucleación del fagóforo y para el reclutamiento de otras proteínas ATG. La familia de las fosfatidil inositol-3 quinasas (PI3P) de clase III, sobre todo la VPS34 (proteína de clasificación vacuolar 34 de humanos) y su unión a Beclina-1, es clave en la formación del fagosforo; Vps34 es la principal fuente de fosfatidil inositol-3- fosfato (PI3P) durante la autofagia. El complejo formado por WIPI1 (el homólogo en mamíferos de ATG18) con ATG2 y ATG9 de la membrana autofagosomal se une al fosfatidilinositol 3-fosfato generado, favoreciendo la curvatura y nucleación de la membrana. 
Sistemas de conjugación similar a ubiquitina (ubl): compuesta por dos sistemas de conjugación, el sistema de conjugación ATG12 y el sistema de conjugación LC3, importantes para la elongación y cierre del autofagosoma [129]. La membrana inicial contiene PI(3)P y ciertas proteínas ATG, incluidas las de los complejos de Beclina1 y ULK1. Esto produce el reclutamiento de otras proteínas ATG como LC3 y ATG12; ambas funcionan como proteínas "análogas a ubiquitina" y son conjugadas con otras mediante sistemas enzimáticos análogos de la enzima conjugadora de ubiquitina.

Sistema de conjugación ATG12: comprende dos enzimas, ATG7 y ATG10, que median la conjugación covalente de ATG12 con ATG5 para formar ATG12-ATG5. Ambos forman el complejo ATG12-ATG5/ATG16L1, que es esencial para la biogénesis del autofagosoma [125] .

El segundo sistema ubiquitina lo constituye LC3: que se une a la fosfatidiletanolamina (PE) en la membrana interna y externa del autofagosoma. LC3 es conjugado con ATG7 y ATG3. Finalmente es conjugado con fosfatidiletanolamina, para ello son necesarios ATG5ATG12, que presentan una actividad E3-like.

Una vez formados los autofagosomas se fusionan con lisosomas, dando lugar a los autofagolisosomas, donde el contenido citosólico se degrada [130]. Después de la formación del autofagosoma, varias proteínas ATG se reciclan en un proceso que implica a ATG9. (Figura 12) 


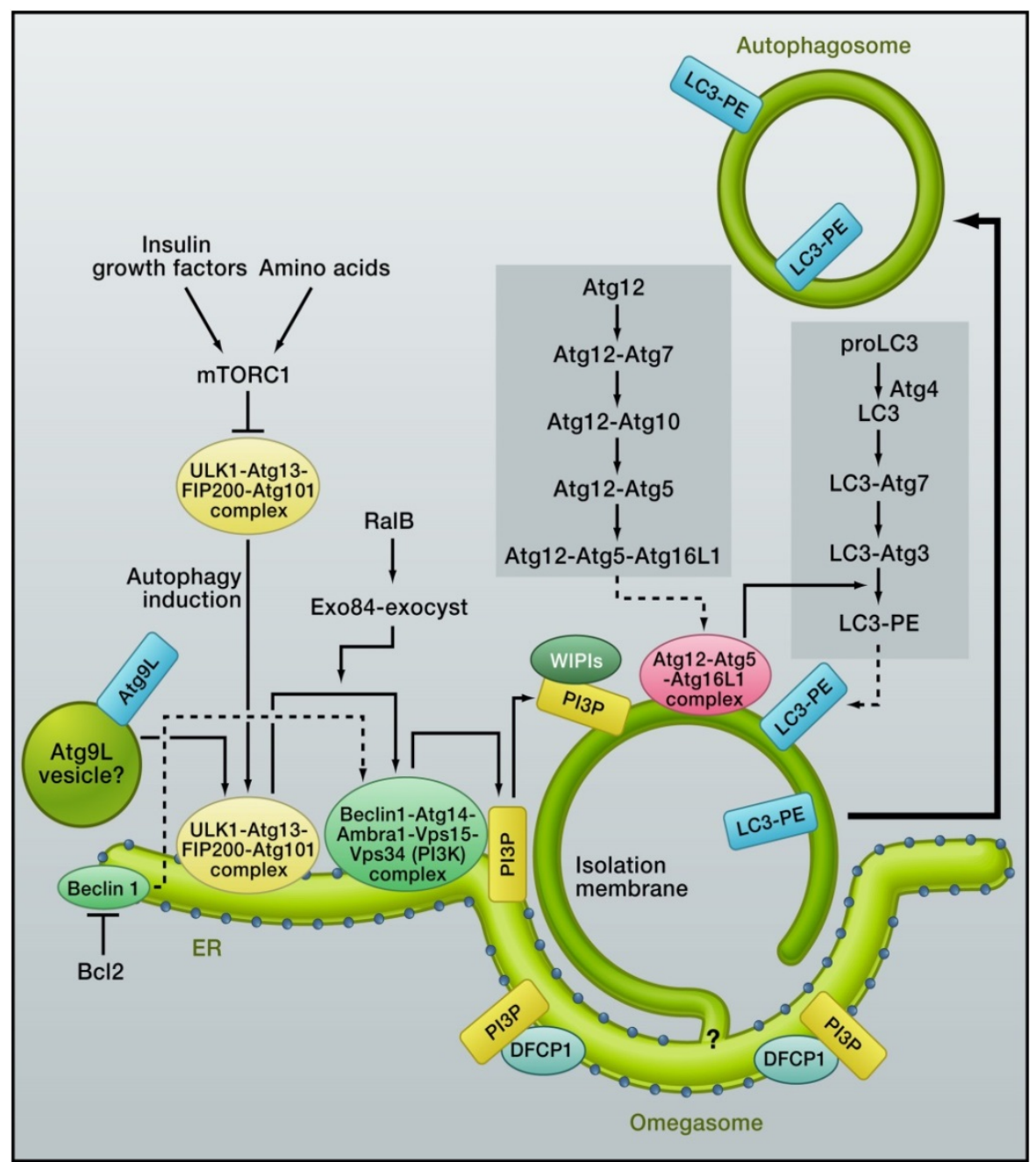

Figura 12. Formación del autofagosoma ${ }^{[128]}$

En resumen, la formación y expansión de la membrana autofagosomal es mediada por dos sistemas de conjugación proteicos similares a la ubiquitina: LC3 (ATG8) y ATG12. Inicialmente, el precursor LC3 es procesado por ATG4 a la forma madura de LC3 (LC3-I) y luego es modificado por ATG7 y ATG3, para generar LC3-II. El reclutamiento de LC3Il a la membrana de aislamiento creciente depende del sistema ATG12. ATG12 es activado por ATG7 y a continuación, es modificado ATG10 para, 
finalmente, unirse covalentemente con ATG5. El complejo ATG5 - ATG12 se asocia con ATG16L1 para iniciar la fase de elongación de la membrana de aislamiento mediante la unión a la lipidada LC3-II. Al término del autofagosoma, se disocia el complejo el ATG5 - ATG12 - ATG16L1 de la membrana autofagosomal exterior y se recicla junto con LC3. En la etapa de maduración, la fracción de LC3 atrapado en la parte luminal de la membrana autofagosomal se degrada y finalmente, una vía de reciclaje (que comprende ATG2 / ATG9 /ATG18) media el desmontaje del autofagosoma [123].

\section{4) REGULACIÓN DE LA AUTOFAGIA}

La formación del autofagosoma es altamente inducible. En condiciones basales la autofagia es inducida por una escasez de nutrientes celulares y regulada por varias señales fisiológicas, como el nivel de energía celular, la hipoxia y el estrés oxidativo[131]. El sensor nutricional mTORC1 es el principal complejo que la controla: la presencia de factores de crecimiento y nutrientes produce la activación de mTORC1, que inhibe la autofagia al bloquear la acción del complejo ULK:ATG13:FIP200 [131]. A la inversa, la escasez de nutrientes conduce a la inducción de la autofagia a través de la supresión mTORC1. Los inhibidores TORC1 / mTORC1 como rapamicina pueden inducir autofagia incluso en condiciones donde hay abundancia de nutrientes [121] (Figura 13). 


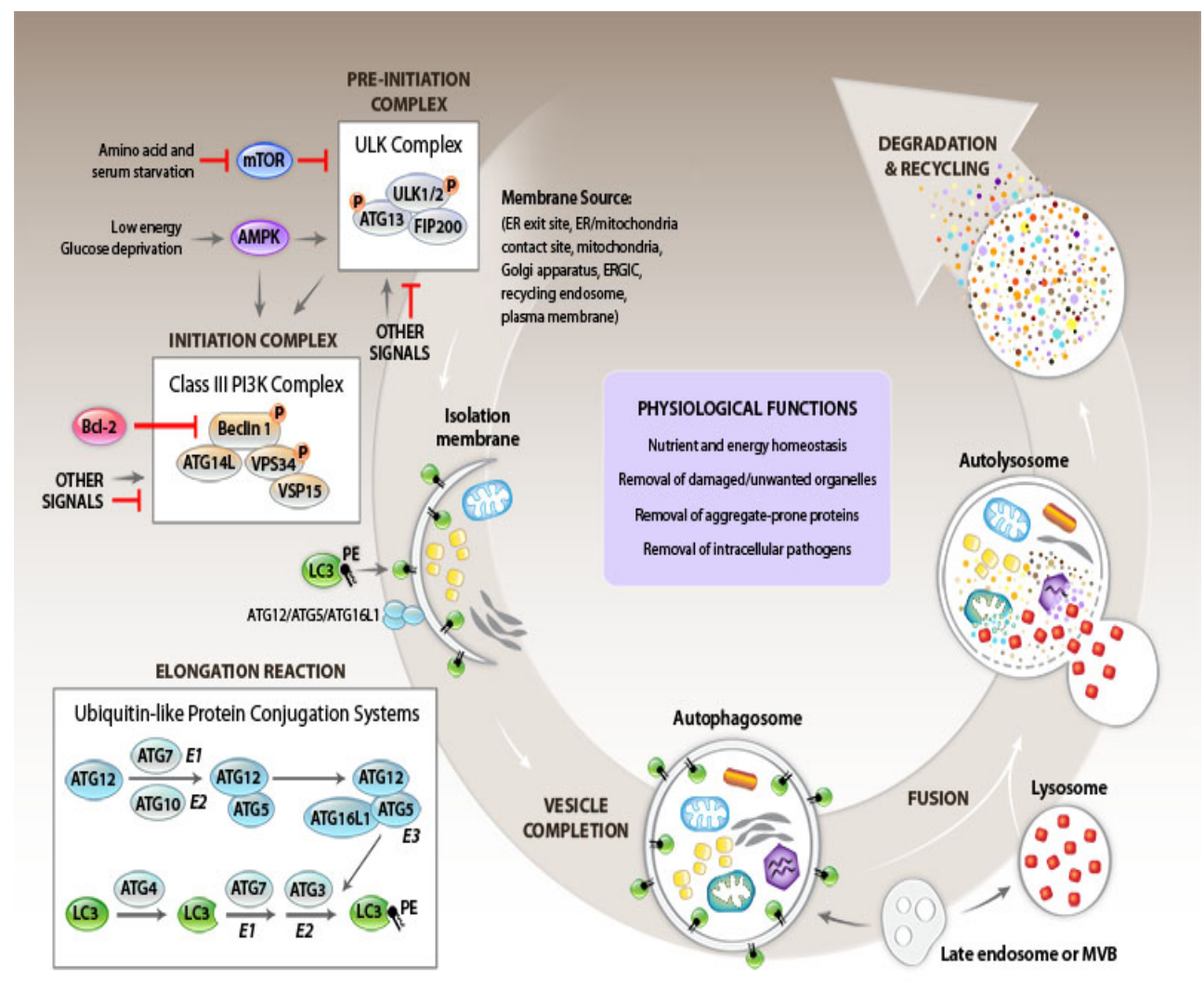

Figura 13. Mecanismos de regulación de la autofagia

\section{5) GENES RELACIONADOS CON AUTOFAGIA (ATG)}

Desde el descubrimiento de los genes relacionados con la autofagia (ATG) mediante estudios genéticos de la levadura en los años 1990 hasta la fecha, se han identificado más de 35 genes ATG en la levadura de los cuales 16 están presentes en los seres humanos (ATG2A, ATG2B, ATG3, ATG4A, ATG4B, ATG4C, ATG4D, ATG5, ATG6 (BECN1), ATG7, ATG9A, ATG9B, ATG10, ATG12, ATG16L1 y ATG16L2)[132].

En los organismos multicelulares, los genes de autofagia están íntimamente conectados a muchos procesos celulares fundamentales, tales como la embriogénesis, la regulación de la muerte celular, la proliferación celular, la inflamación y numerosas funciones inmunitarias innatas y 
adaptativas; en consecuencia, debido a estos efectos generalizados, perturbaciones en la autofagia se han asociado con numerosas enfermedades y procesos como la neurodegeneración, el cáncer, el envejecimiento y enfermedades autoinmunes tales como la (EII) [124, 131].

La autofagia juega un papel crítico en la eliminación de bacterias mediada por secuestro autofagosomal, degradación autolisosomal y en la regulación de la respuesta de citoquinas [60]. En estudios de asociación genética se han descrito que defectos en la autofagia confieren susceptibilidad a varias enfermedades autoinmunes e inflamatorias, en particular la Ell [133]

\section{6) AUTOFAGIA EN LA RESPUESTA INMUNITARIA}

La autofagia es un proceso metabólico crucial tanto en condiciones fisiológicas como patológicas, y puede ser considerado como uno de los mecanismos que "conecta" la respuesta inmunitaria innata con la adaptativa. La autofagia actúa en varias etapas de la respuesta inmune: en la resistencia a patógenos; en la producción de interferón de tipo I, en la presentación de antígeno, en la tolerancia y el desarrollo de los linfocitos, así como en la regulación negativa de la señalización de citoquinas y en la inflamación [134]. El papel específico de la autofagia en la inmunidad innata incluye la regulación del inflamasoma y la señalización PRR específico de la célula, así como el aclaramiento de cadáveres de apoptosis, un mecanismo para controlar la inflamación. En la inmunidad adaptativa, la vía de la autofagia es esencial para la presentación de antígenos, la selección de células $\mathrm{T}$ en el timo $\mathrm{y}$ el desarrollo, supervivencia $\mathrm{y}$ homeostasis de los linfocitos [127]. 


\subsection{1) Autofagia en la inmunidad innata}

La autofagia es la primera línea de defensa y protección innata contra los patógenos (bacterias intracelulares y virus).

Algunos ejemplos que ilustran la participación de la autofagia en la inmunidad innata son: a) Bacterias libres, por ejemplo A. Streptococci, envueltas en un autofagosoma y luego liberadas para la hidrólisis lisosomal. b) La macroautofagia de bacterias o parásitos que impiden la fusión con el lisosoma, como Listeria monocytogenes, Shigella y Rickettsia conorii, microorganismos capaces de escapar al autofagosoma. Mycobacterium tuberculosis es capaz de sobrevivir y proliferar en el autofagosoma mediante la regulación del mismo [135].

Existe una regulación recíproca entre la autofagia y el inflamasoma (proceso molecular involucrado en la protección inmune innata mediante la inducción de citoquinas proinflamatorias); así, cuando la autofagia se bloquea, la actividad del inflamasoma se incrementa y viceversa.

El mecanismo de señalización que explica el reconocimiento y ejecución de la autofagia durante la respuesta inmunitaria innata sigue siendo objeto de estudio. Uno de los mecanismos mejor descritos identifica a los receptores semejantes a TOLL (TLR) como mediadores de la autofagia asociada a la respuesta contra patógenos.

\subsection{2) Autofagia en la inmunidad adaptativa}

La autofagia también puede participar en varios niveles de la respuesta inmune adaptativa; en la presentación de antígenos extracelulares e intracelulares a las células T CD4+ y en el desarrollo, diferenciación y homeostasis de células T y B [131]. Las proteínas ATG tienen un rol importante en el mantenimiento de un número normal de células $B$, células T CD4+, células T CD8+ y células madre hematopoyéticas fetales. 
Los defectos en la autofagia a nivel de células T se han asociado con una disminución en el aclaramiento mitocondrial durante el proceso de maduración, y con alteración en la eliminación de células T autoreactivas en el timo [136].

La autofagia capacita a las células para digerir su propio citosol, remueve agregados proteicos y elimina organelas no funcionales; además, libera antígenos citosólicos en compartimientos endosomales que contienen moléculas del complejo principal de histocompatibilidad (MHC clase II).

\subsection{3) Autofagia y presentación antigénica}

Hay una creciente evidencia de que la autofagia puede estar involucrada en la presentación de antígenos tipo MHC clase II; sin embargo, su participación en la presentación tipo MHC I sigue siendo especulativa [134].

El sistema inmune detecta antígenos derivados de patógenos (es decir, péptidos) e inicia una respuesta a través de MHC clase I y II. Los fragmentos de péptidos generados por la degradación intracelular de bacterias, incluyendo la degradación autolisosomal, se muestran a las moléculas MHC de clase I y II [137].

Las moléculas del MHC clase I presentan principalmente productos de la degradación proteosomal a las células $\mathrm{T}$ CD8+, mientras que las moléculas de MHC clase II presentan péptidos que son principalmente generados por degradación lisosomal a las células T CD4+. Diversos estudios plantean la participación de la autofagia en la presentación de antígenos intracelulares a las células T CD4+ o su intervención durante el proceso de presentación cruzada de las células T CD8+. 


\subsubsection{1) Autofagia y presentación antigénica en MHC clase I}

Las proteínas $\mathrm{MCH}$ de clase I están presentes en la mayoría de las células y ayudan a la presentación de antígenos a las células T CD8 +. La autofagia interviene en la presentación de antígenos virales y extracelulares para reconocimiento por las células $\mathrm{T} C \mathrm{CD} 8+$, fenómeno denominado presentación-cruzada. Los epítopes de antígenos citoplasmáticos y nucleares comprenden proteínas virales y antígenos tumorales endógenos y/o autoantígenos que son cargados sobre las moléculas de MHC clase I por una ruta dependiente de la degradación proteosomal y un transportador de péptidos antigénicos (TAP). El rol directo de la autofagia en la presentación convencional de antígenos a las células T CD8+ no ha sido claramente demostrado.

La inhibición de la autofagia mediante inhibidores químicos o por defecto en la transcripción genética de proteínas autofágicas normalmente no afecta a la presentación de antígenos MHC de clase I; sin embargo, la inducción de la autofagia en las células diana aumenta su capacidad de actuar como inmunógenos para células dendríticas y por lo tanto la presentación cruzada a las células T CD8 +.

\subsubsection{2) Autofagia y presentación antigénica en MHC clase II}

Las moléculas de MHC clase II presentan péptidos antigénicos derivados de proteínas extracelulares. Estas moléculas se expresan sobre la superficie de células presentadoras de antígenos como células $B$, células dendríticas y macrófagos, así como células epiteliales tímicas medulares y corticales. La autofagia ha sido identificada como una ruta por la cual, entre el $10-25 \%$ de antígenos citoplasmáticos y nucleares (proteína ribosomal S30, c-myc, k-ras y citocromo B5-reductasa) son liberados en los endosomas y cargados sobre moléculas de MHC clase II para la 
presentación a las células T CD4+, de allí su papel crítico en la inducción de respuesta de las células $T$.

Se ha demostrado que una alteración genética de ATG12 inhibe la presentación de antígenos MHC Clase II a las células T CD4 + durante la infección por el virus de Epstein-Barr y que una delección genética de ATG5 también suprime el procesamiento y presentación del antígeno derivado del virus herpes simple 2 (HSV-2-) a las moléculas de MHC de clase II, ocasionando una mayor vulnerabilidad a la infección [137].

\section{7) AUTOFAGIA Y HOMEOSTASIS INTESTINAL}

La función primaria del intestino es la digestión y absorción de nutrientes. Además, sirve como barrera de entrada a microorganismos comensales, microorganismos ambientales y antígenos que pasan por el tubo digestivo. Múltiples células, incluyendo las células epiteliales específicas y células inmunológicas, participan en la producción y mantenimiento de esta barrera fisicoquímica. En el intestino, la autofagia es fundamental en el montaje de la respuesta inmune y la protección antimicrobiana, que se realiza a través de múltiples y complejas vías de señalización, incluyendo macroautofagia y xenofagia. Una disfunción en el mecanismo de la autofagia conduce a la inflamación intestinal crónica, característico de la Ell [138].

De todos los genes identificados asociados al riesgo de desarrollar Ell, muchos juegan un papel clave en el proceso de autofagia. Aunque históricamente se ha considerado como un proceso de degradación no selectivo del contenido citosólico, estudios recientes revelan que la autofagia tiene funciones inmunes selectivas y específicas que son relevantes para el mantenimiento de la homeostasis intestinal, incluyendo xenofagia, mitofagia, presentación de antígenos, secreción y regulación del inflamasoma [139]. 


\section{8) AUTOFAGIA Y MICROBIOTA INTESTINAL}

Muchos de los locus genéticos que confieren riesgo en la Ell interactúan entre sí. Un ejemplo de ello es la interacción directa entre el gen NOD2 y los genes ATG. La activación de NOD2 por bacterias y ligandos bacterianos dan lugar a la formación de vacuolas autofágicas mediadas por ATG16L1 en células epiteliales y células dendríticas [140]. La inducción microbiana de la autofagia se deteriora en variantes NOD2 como ATG16L1 asociadas a la EC. Se han demostrado defectos dependientes del NOD2 en la inducción de la autofagia asociados a la infección por Escherichia coli enteroinvasiva, Salmonella y Shigella, todos ellos vinculados a la EC. Por tanto, la autofagia parece ser una vía convergente clave de los factores de riesgo genético asociados a la Ell, que resultan en respuestas inmunes innatas inapropiadas a la microbiota [50].

\section{9) ROL DE LA AUTOFAGIA EN LA INFLAMACIÓN}

El papel de autofagia en las enfermedades inflamatorias se estableció inicialmente a través de los estudios de asociación del genoma (GWAS). Se ha demostrado la asociación de polimorfismos de los genes que regulan la autofagia, tales como ATG16L1 e IRGM, con la Ell, y al parecer podría haber un solapamiento entre los loci de susceptibilidad para la Ell y las infecciones por micobacterias, como se ha puesto de manifiesto en un reciente análisis GWAS que incluye un total de 75.000 individuos [120]. Las vías de señalización que regulan los procesos inflamatorios tienen un papel en la regulación de la autofagia y viceversa. Además de las señales clásicas tales como la inanición y el agotamiento de energía, varios patrones moleculares asociados a patógenos (PAMPs) han demostrado promover la activación de la autofagia. En este sentido, los receptores tipo Toll (TLR), sensores celulares primarios de PAMP, pueden regular la autofagia a través 
de la activación de los procesos de señalización en los macrófagos y otros tipos de células. Por ejemplo el LPS (lipopolisacárido) bacteriano, un ligando de TLR4, ha sido implicado en varios estudios como un estimulador de la señalización de autofagia en líneas celulares de cultivadas; sin embargo, se discute la capacidad de LPS para inducir la autofagia en macrófagos primarios [137].

Observaciones recientes han puesto de manifiesto una relación entre las proteínas de autofagia y el inflamasoma. Los inflamasomas son complejos multiproteícos citosólicos que constituyen un nuevo mecanismo de señalización inflamatoria y que regulan la maduración y secreción de citoquinas proinflamatorias tales como IL-1 $\beta$, IL-18 e IL-33.

El papel "in vivo" de ATG16L1 en la inflamación intestinal se evaluó mediante la inducción de colitis química con dextrano sulfato de sodio (DSS) en ratones que carecían de ATG16L1, observándose una disminución de la supervivencia y una mayor pérdida de peso tras el tratamiento con DSS en comparación con el grupo control; además, los niveles de citocinas proinflamatorias IL-1 $\beta$ e IL-18 estaban elevados en el suero de ratones deficientes en ATG16L1 tratados con DSS [141]. El estudio concluye que la producción excesiva de citoquinas en ausencia de la autofagia impulsaría el desarrollo de colitis.

Los estudios antes mencionados fueron corroborados recientemente en pacientes con EC. Plantinga et al. demostraron un incremento de mRNA de IL-1 $\beta$ cuando la autofagia se bloqueaba, y una disminución de mRNA IL$1 \beta$ cuando se estimulaba. Sobre la base de estos estudios, IL-1 $\beta$ puede surgir como una atractiva diana terapéutica para los pacientes con EC que albergan el alelo de riesgo ATG16L1 [142]. 


\subsection{0) AUTOFAGIA, ROL ANTIMICROBIANO}

Una deficiencia de nutrientes intracelulares debido a la competencia de microorganismos invasores es probable que haya sido una de las señales que permite a las células eucariotas detectar la invasión microbiana y eliminar los patógenos a través de la autofagia. La carencia de aminoácidos se ha asociado con la autofagia antimicrobiana (también llamado xenofagia) en respuesta a la infección bacteriana y viral [120]

La autofagia tiene un rol en la muerte de patógenos intracelulares. Las proteínas de autofagia median el aclaramiento de patógenos intracelulares a través de vías dependientes e independientes del autofagososma. Algunos patógenos tienen mecanismos para evadir y bloquear la autofagia, como Shigella, que evade su unión a autofagosoma inhibiendo la proteína que se une Atg5-, VirG. M. tuberculosis persiste dentro de los fagosomas porque evade la fusión con los lisosomas. Algunos patógenos son capaces de replicarse en los autofagosomas o lisosomas, como es el caso de Francisella tularensis; cuya unión al autofagosoma resulta en un incremento en su replicación. Coxiella burnetii, Yersinia pseudotuberculosis, Brucella abortus también tienen esta capacidad.

Numerosos estudios han descrito altos niveles de una cepa única de $E$. coli caracterizada por propiedades invasivas y adherentes (AIEC) en la EC. Los AIEC son capaces de sobrevivir y replicarse dentro de las células; además de inhibir la apoptosis, incrementan la secreción de TNF alfa, aumentando la permeabilidad intestinal. Se han asociado altos niveles de AIEC con defectos en la autofagia.

La autofagia cumple roles diferentes dependiendo del tipo de infección bacteriana. Puede restringir la replicación bacteriana (autofagia antibacteriana), actuar en la señalización celular (autofagia no bacteriana) 
o apoyar la replicación bacteriana (autofagia pro-bacteriana), cumpliendo un rol más amplio en la respuesta del huésped a la infección que sólo la entrega de las bacterias a los lisosomas [143].

Los mecanismos por los que los patógenos intracelulares son diana de la autofagia son desconocidos. Una hipótesis es que la infección, ya sea con Shigella o con Salmonella, desencadenaría una disminución aguda de aminoácidos en respuesta a daños de la membrana, lo que resulta en la inducción de la autofagia.

Además de sus acciones intracelulares, la autofagia actúa en la liberación de mediadores inmunológicos extracelulares, algunos de los cuales se almacenan en gránulos. La secreción defectuosa de lisozima a partir de células de Paneth en ratones hipomorficos-ATG16L1 resulta en un fenotipo intestinal que corresponde a la de los pacientes con EC [120] (Figura 14). 


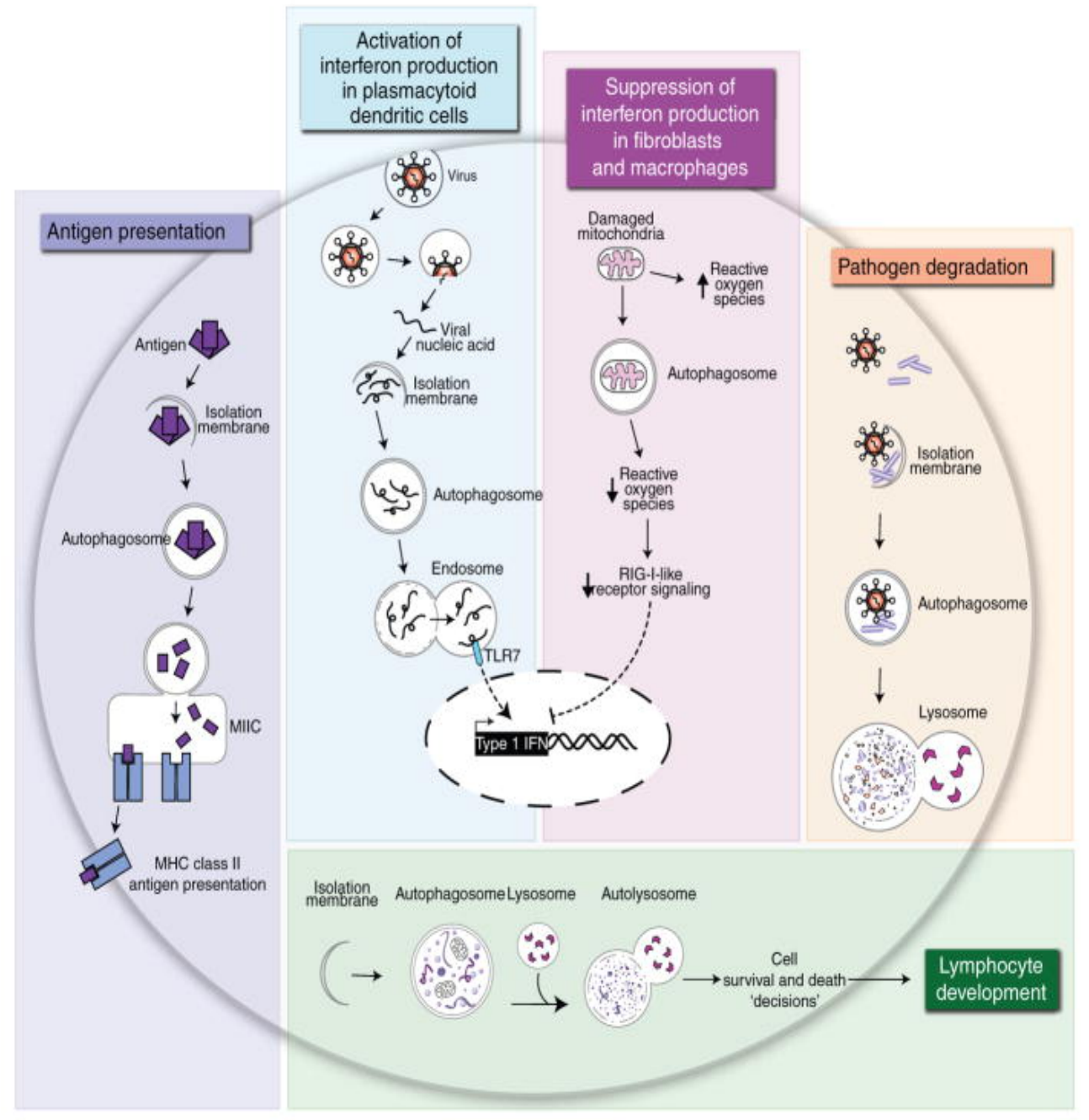

Figura 14. Procesos inmunológicos asociados a la autofagia ${ }^{[134]}$ 
4) AUTOFAGIA EN LA EII 
Los progresos en el conocimiento de la base genética de la Ell han logrado identificar vías biológicas antes insospechadas, que juegan un papel en la patogénesis de la enfermedad; la autofagia es una de ellas. Los procesos dependientes de la autofagia involucrados en la Ell incluyen la muerte intracelular bacteriana por xenofagia, la secreción de péptido antimicrobiano por las células Paneth, la producción de citocinas proinflamatorias por los macrófagos, la presentación de antígenos y las respuestas al estrés del retículo endoplasmático (ER) en los enterocitos [24].

El vínculo entre la Ell y la autofagia fue descrita por primera vez por Hampe quien estableció la asociación entre la EC y el polimorfismo rs2241880 del gen relacionado con la autofagia ATG16L1, que da lugar a una sustitución de treonina por alanina en la posición 300 de la proteína p.T300A [65]. Una mutación del gen ATG16L1 podría resultar en la perdida de tolerancia y aumento de la liberación de citoquinas inflamatorias por las células mutadas, lo que desencadenaría una inflamación incontrolada debido a la invasión bacteriana [127]. Análisis genéticos han demostrado el rol de la autofagia en la respuesta immune en la Ell; en este sentido, se han identificado dos genes asociados a la autofagia, ATG16L1 y IRGM. La disfunción de alguno de ellos se traduce en un deficiente control de bacterias invasoras intracelulares, una aberrante función de las células de Paneth y una secreción incontrolada de citoquinas proinflamatorias incrementando la susceptibilidad a las infecciones bacterianas y el inicio de colitis [144].

Según recientes estudios, la autofagia tendría un efecto antimicrobiano adicional desencadenado por NOD2. Esta interacción genética tendría efectos a distintos niveles: NOD2 actuaría como guía a ATG16L1 al sitio de entrada de bacterias para iniciar la autofagia, en la presentación de antígenos del MHC de clase II a las células T, iniciando así 
la respuesta inmune adaptativa, y en la activación de la señalización proinflamatoria mediada por NOD2. Estos estudios refuerzan el concepto de que la susceptibilidad a la Ell se debe a una desregulación en la vía central más que a la disfunción de un gen especifico [8].

NOD2 actúa como un sensor para las bacterias intracelulares mediante la activación de la autofagia a través de la interacción con ATG16L1. Cooney et al. [145] demostraron que las células con una variante en NOD2 o en ATG16L1 muestran una reducción de la inducción de la autofagia tras la estimulación con muramil dipéptido (un ligando NOD2)[131].

Por otro lado, células epiteliales intestinales con una alteración de la autofagia pierden su capacidad adhesiva en presencia de TNF-alfa. El deterioro de la autofagia conduce a la disrupción de las capas de células epiteliales intestinales en entornos ricos en TNF-alfa [146]

Por lo tanto, la autofagia juega un rol en los desórdenes inflamatorios por eliminación directa de bacterias intracelulares y la activación de señales involucrados en la homeostasis y la patogénesis de la EC[60].

Lo más probable es que la aparición de EC se desencadene por una pérdida de tolerancia, así como por una disfunción de la autofagia, que finalmente resulta en la aparición de la inflamación intestinal crónica [144] (Figura 15). Sin embargo, los mecanismos precisos por lo que los polimorfismos en genes de la autofagia contribuyen a la patogénesis de Ell necesitan aclaración adicional.

Con los datos disponibles en la actualidad, la autofagia tendría un papel importante en el mantenimiento de la homeostasis intestinal y una disfunción en ella sería un factor de riesgo para la aparición de la inflamación intestinal crónica.

Como hemos visto anteriormente, existen muchos estudios que describen una fuerte asociación entre el proceso de autofagia y la EC; sin embargo, su 
asociación con la CU aún no es concluyente. Uno de los estudios donde se describe una asociación con la CU es el metaanálisis conducido por Umeno et al. [147], donde se demuestra la asociación de la CU con los siguientes polimorfismos: ATG16L1 (rs2241880, rs10210302 and rs3828309), LRRK2MUC19 (rs11175593) e IRGM (rs4958847), concluyendo que la autofagia tendría un rol en ambas enfermedades, aunque con menor efecto en la CU [147].

\section{1) AUTOFAGIA COMO DIANA TERAPÉUTICA}

Uno de los principales avances conceptuales de los estudios de asociación genética y el riesgo de desarrollar Ell vino con el reconocimiento de la importancia de la autofagia. De hecho, las mutaciones en el gen ATG16L1 son uno de los mayores determinantes individuales de riesgo genético en la Ell.

Defectos en la autofagia resulta en defectos en la función de la barrera epitelial, que se traducen en defectos en el aclaramiento de bacterias intracelulares y falta de resolución del "stress celular" lo que induce una inflamación transmural en modelos murinos y un incremento en la secreción de citoquinas proinflamatorias en respuesta al stress celular. En este contexto, se ha descrito el uso de sirolimus, un inhibidor de la diana de la rapamicina (mTOR) con potentes propiedades inductoras de la autofagia, para el tratamiento de un individuo con EC refractaria [41]. Sin embargo, en otro estudio en fase II de EC con everolimus (un inhibidor mTOR relacionado) no se encontró beneficio. Si el objetivo es el aumento de la autofagia en individuos con defectos genéticos, pueden surgir como un complemento terapéutico en la ElI [148]. De esta forma, la autofagia es un objetivo potencial para el desarrollo de terapias en la Ell por el papel que juega en la inmunidad. Sin embargo, es difícil determinar los efectos beneficiosos de la inducción o supresión de la autofagia pues, como hemos 
visto, la autofagia está involucrado en múltiples vías de la regulación inmune [127].

Por todo lo mencionado, la autofagia y su papel clave en la regulación de la homeostasis en la mucosa intestinal, la convierten en una atractiva diana para explorar futuras vías terapéuticas en la Ell. 
AUTOFAGIA EN LA EII

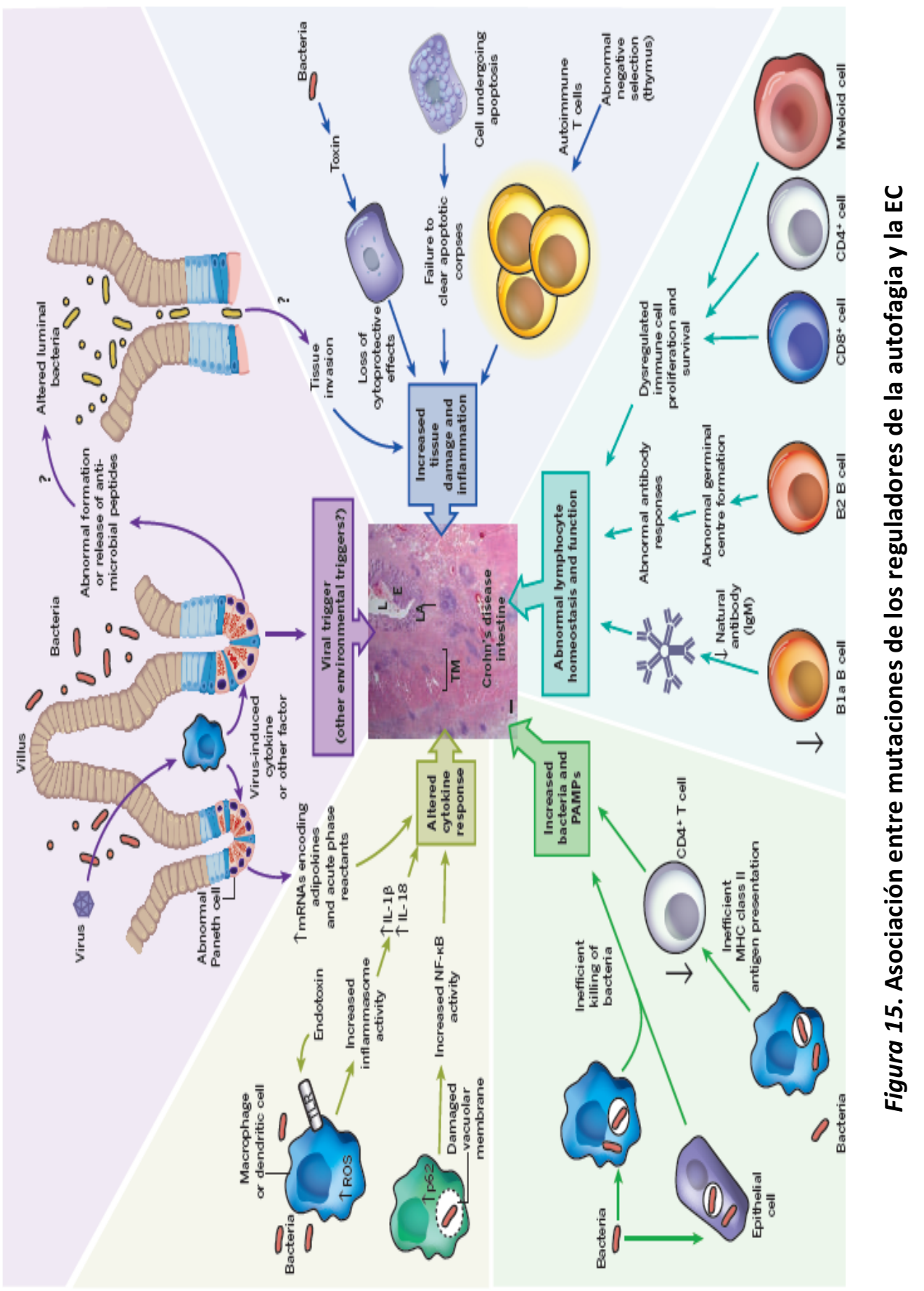


5) GENES A ESTUDIO 


\section{1) ATG5}

El gen ATG 5 es esencial para la formación del autofagosoma. Como ya se ha descrito, la generación de autofagosomas necesita de dos vías de conjugación similares a la ubiquitina, siendo ATG5 esencial en ambos procesos; cumple un papel enzimático primario y acelera la unión de fosfatidiletanolamina al C-terminal de LC3, paso crítico para la formación del autofagosoma. ATG5 forma parte del complejo ATG12 ATG5-ATG16L1 que se localiza en la membrana autofagosomal antes de la fusión del fagosoma con el lisosoma[149].

ATG5 no solo está implicado en la formación del autofagosoma, además, aumenta la susceptibilidad a estímulos apoptóticos, de tal manera que cuando ATG5 es escindido por proteólisis mediada por las Calpaínas 1 y 2 , se libera un ATG5 truncado de $24 \mathrm{KDa}$ (que comprende los aminoácidos 1-193) que se trasloca del citosol a la mitocondria, donde se asocia con $\mathrm{Bcl}-\mathrm{XL}$, bloqueando su función proapoptótica y permitiendo la liberación de citocromo-c, regulando de esta forma la señalización entre autofagia y apoptosis [150].

ATG5 está implicado en múltiples etapas de la respuesta inmune, entre las que se encuentran: la biogénesis y la secreción de IL-1 $\beta$ por macrófagos, la función de las células de Paneth, de los linfocitos T y el desarrollo de las células B.

El rol de la autofagia en la función de células $B$ se ha mostrado en un estudio realizado en ratones cuyos linfocitos B carecían de ATG5. La ausencia de la expresión de ATG5 se manifiesta por una disminución en la respuesta de anticuerpos durante la inmunización específica de antígeno, la infección parasitaria y la inflamación mucosa. A nivel intestinal, se observó una disminución de IgA en heces y que tras la inducción de colitis con DSS, los niveles de IgA en el intestino de ratones que carecían de ATG5 
era reducida comparada con ratones que expresaban ATG5. Además, las células B deficientes en ATG5- son incapaces de responder a la estimulación TLR, probablemente debido a una incapacidad para regular positivamente los factores de transcripción de células plasmáticas. Estos resultados demuestran un papel de ATG5 en el desarrollo temprano de células $B$ y en las últimas etapas de activación de células $B$ y posterior diferenciación a PC [151].

La autofagia también actúa en la selección de células T CD4 en el timo: la deficiencia o falta de ATG5 generaría células T autoreactivas que predisponen al desarrollo de colitis [134, 152]. Las células de Paneth deficientes en ATG5, ATG7 o ATG16L1 presentan anomalías en la secreción de péptidos antimicrobianos a partir de gránulos [153].

Las acciones del ATG5 no se limitan a la vía de la autofagia, también se ha descrito un papel clave en la actividad antiviral desencadenada por IFN$\gamma$ independiente de la autofagia[125], lo que se observó en un estudio realizado en ratones, donde se demostró que ATG5 cumple un papel crítico en el control mediado por IFNgamma de la replicación de norvovirus en macrófagos [154].

\section{2) ATG16L1}

El vínculo entre la Ell y la autofagia se estableció por primera vez cuando se describió una asociación entre el gen ATG16L1 y la EC. Uno de estos alelos del gen ATG16L1 ha demostrado tener un rol en la Ell. El polimorfismo ATG16L1 (rs2241880) es resultado de un cambio-treonina-a alanina en la posición del aminoácido 300 de la proteína (T300A). La variante rs2241880 se encuentra comúnmente en la población, el 45-50\% de los sujetos sanos son portadores del alelo [8]. Los individuos homocigóticos para la variante que codifica T300A-de ATG16L1 tienen mayor riesgo de desarrollar EC; además de encontrarse una mayor 
frecuencia del polimorfismo rs2241880 en los pacientes con afectación ileal, siendo la asociación significativa con la enfermedad del intestino delgado [155].

La proteína codificada por el gen ATG16L1 es expresada en el colon, intestino delgado células epiteliales intestinales y leucocitos.

El gen ATG16L1 está localizado en el cromosoma 2q37.1 y codifica una proteína involucrada en la formación del autofagosoma y en otros procesos celulares inmunológicos. Interactúa con otras dos proteínas de la autofagia, ATG5 y ATG12, para formar el complejo esencial en el proceso de autofagia. La deficiencia de ATG16L1 interrumpe el reclutamiento del complejo Atg12-ATG5 a la membrana del fagosoma. En consecuencia, tanto la formación autofagosoma como la degradación de las proteínas de vida larga se ven seriamente perjudicados en estas células.

La asociación entre las variantes del gen ATG16L1 y el riesgo de desarrollar Ell está determinada por diferentes mecanismos. La deficiencia del gen ATG16L1 conlleva una alteración en el aclaramiento de patógenos intracelulares y una pérdida de la tolerancia inmune desencadenando así inflamación $y$, la liberación de citoquinas inflamatorias por parte de macrófagos; se ha descrito que macrófagos deficientes en ATG16L1 producen más citoquinas inflamatorias IL-1 $\beta$ e IL-18 tras la estimulación con LPS. Otro posible mecanismo asociaría la autofagia y la apoptosis, que comparten muchos estímulos e interacciones inhibitorias. Se plantea la hipótesis de que una autofagia defectuosa podría alterar el proceso intestinal de apoptosis de las células inflamatorias en EC y CU, lo que contribuiría en última instancia a la patogénesis de la Ell [156]. También cumple una función a nivel de las células de Paneth, demostrándose en un estudio realizado en una línea de ratones hipomórficos en ATG16L1 que expresan aproximadamente $1 \%$ del nivel normal de ATG16L1, anormalidades en los gránulos de las células de Paneth que son similares a 
los encontrados en las resecciones ileales en pacientes con EC portadores de la variante del gen ATG16L1 [157].

La asociación entre la EC y el gen ATG16L1 ha sido confirmada en múltiples estudios; sin embargo, su asociación con la CU no es tan clara. Algunos estudios confirman una asociación positiva pero modesta entre el polimorfismo rs2241880 de ATG16L1 con la predisposición a la CU [156].

\section{3) ATG 2B}

El gen ATG2 codifica dos proteínas (ATG2A y ATG2B), ambas cumplirían funciones en la biogénesis del autofagosoma [158]. El ATG2 interactúa con el ATG18, un PI3P de unión que presumiblemente tiene funciones en una etapa tardía en la formación de fagosoma y / o etapas posteriores de la autofagia[127].

Un análisis ultraestructural de la formación del autofagosoma demostró que el ATG2B es fundamental en el aislamiento de la membrana y en la regulación del tamaño y distribución de los agregados lipídicos. El silenciamiento de ATG2A y ATG2B produce unas estructuras autofágicas intermedias aberrantes que se acumulan en la célula [159]. Según estos hallazgos, el ATG2A y ATG2B en mamíferos tendrían una función tanto en la formación del autofagosoma como en la regulación de volumen de gotas de lípidos y su distribución [158].

La función del gen ATG2B no está bien caracterizada en seres humanos y no existen estudios de su asociación con la Ell; sin embargo es objeto de investigación en el cáncer, donde se ha estudiado ampliamente su capacidad para modular la autofagia, pues este mecanismo de supervivencia también estaría presente en células cancerosas para afrontar la inanición y la hipoxia, por lo que un mecanismo de inhibir la 
replicación tumoral podría asociarse a la inhibición del proceso de autofagia.

Se ha demostrado una sobreexpresión del gen ATG2B en pacientes con cáncer de pulmón[160], neoplasia mieloides [161] y junto al ATG5 al desarrollo del cáncer gástrico y colorectal [162].

\section{4) ATG 10}

ATG10 es una enzima E2 like que es esencial para la formación del autofagosoma. ATG12 se activa por ATG7, lo que permite que se transfiera a ATG10 para finalmente unirse covalentemente a ATG5. La unión se realiza entre el extremo carboxiterminal de ATG12 y un residuo de Lisina de ATG5. El conjugado se asocia con ATG16L1 y el complejo se homooligomeriza. Como resultado, forman un complejo ATG12, ATG5 y ATG16L1. Una fracción del complejo multimérico se localiza en membranas aisladas, mientras que la mayoría está difusa en el citoplasma. El conjugado ATG12-ATG5-ATG16L1 se disocia justo tras la completa formación de la vacuola autofágica; mutaciones en los sitios de unión del ATG7 y ATG10 interfieren en la formación de ATG12-ATG5 conjugado[163].

No existen estudios de asociación entre la Ell y el gen ATG10, pero se ha descrito su asociación con el cáncer colorectal. Los resultados indican que la expresión ATG10 está fuertemente asociada a la invasión tumoral y la metástasis. Es considerada una proteína oncogénica y podría ser tener utilidad como marcador pronóstico y como diana terapéutica en el cáncer colorrectal[163].

A pesar que en la actualidad no existen estudios que analicen la asociación entre los polimorfismos de los genes ATG5, ATG2 ni ATG10 con la Ell; su asociación a otras enfermedades está descrita. En un reciente estudio realizado en una cohorte española de pacientes con Enfermedad 
de Paget (EP), que investigó la asociación de los genes de autofagia con el desarrollo de esta enfermedad, demostraron que los portadores del alelo $\mathrm{G}$ del polimorfismo del gen ATG16L1 y del polimorfismo rs2245214 del gen ATG5 se asocian con un mayor riesgo de desarrollar EP, mientras que ser portador del alelo T del polimorfismo rs1864183 del ATG10 disminuye el riesgo de desarrollar la enfermedad; no se encontró asociación con el gen ATG2B[164]. 
6) HIPÓTESIS 
La autofagia es un proceso vinculado a múltiples eventos de la respuesta inmune en el sistema gastrointestinal.

Los procesos dependientes de la autofagia involucrados en la Ell incluyen la muerte intracelular bacteriana, la actividad de las células de Paneth, la producción de citocinas proinflamatorias y la presentación de antígenos.

Se han implicado a los genes ATG en la etiopatogenia de la Ell, en particular en la EC. El gen ATG16L1 y su asociación con la EC no solo afectarían a la predisposición a padecer la enfermedad sino también al fenotipo de la misma; sin embargo, su asociación con la CU aún no se ha demostrado de manera concluyente. Por otra parte, hasta el momento no se han realizado estudios que investiguen la función de otros genes involucrados en el proceso de autofagia, tales como ATG2B, ATG5 y ATG10, y su asociación con la Ell.

Nuestra hipótesis es que polimorfismos genéticos de los genes ATG2B, ATG16L1, ATG5 y ATG10 podrían predisponer al desarrollo de CU. 
7) OBJETIVOS 
Describir las características clínicas de una cohorte de pacientes con Colitis Ulcerosa controlados en el Hospital Universitario de Salamanca.

Estudiar los polimorfismos de los genes ATG2B rs3759601, ATG16L1 rs2241880, ATG10 rs1864183 y ATG5 rs2245214 en una cohorte de pacientes con Colitis Ulcerosa.

Analizar si existe alguna asociación entre los diferentes alelos con la susceptibilidad a padecer Colitis Ulcerosa y con distintas variables: la edad de inicio; el comportamiento en el curso de la enfermedad; la necesidad de colectomía y la respuesta a fármacos, y comparar los datos con lo descrito en este aspecto en otras poblaciones. 
8) MATERIAL Y MÉTODOS 


\section{1) TIPO DE ESTUDIO}

Estudio observacional casos-controles.

\section{2) POBLACIÓN}

\section{Pacientes}

Se incluyeron 114 pacientes diagnosticados de Colitis Ulcerosa seleccionados de forma aleatoria. Los pacientes fueron reclutados en la consulta de Enfermedad Inflamatoria Intestinal del Hospital Universitario de Salamanca entre enero de 1998 y diciembre de 2014.

En todos ellos, el diagnóstico de CU se estableció mediante criterios clínicos, radiológicos, histológicos y endoscópicos (criterios de LennardJones). La extensión y comportamiento de la enfermedad se definieron mediante estudio endoscópico y técnicas radiológicas, y se clasificaron según los criterios de Montreal 2005. Se recogieron variables demográficas y clínicas.

\section{Controles}

Como grupo control se incluyeron 264 sujetos sin Ell de la población de Salamanca en los que se habían estudiado los polimorfismos de los genes implicados en este estudio, cuyos datos constaban en los archivos de la Unidad de Medicina Molecular de la Universidad de Salamanca.

El estudio fue aprobado por los Comités de Ética locales de la Universidad y del Hospital de Salamanca (Salamanca, España).

Todos los pacientes y controles firmaron un consentimiento informado previo a la recogida de la muestra (ver ANEXO). 


\section{3) RECOGIDA Y PROCESADO DE LAS MUESTRAS}

A todos los sujetos del estudio se les recogió una muestra de sangre periférica.

Las muestras de DNA se obtuvieron a partir de células mononucleadas de sangre periférica.

\section{4) RECOGIDA DE DATOS CLÍNICOS}

Se revisaron las historias de todos los pacientes y se completaron mediante entrevista presencial o telefónica en aquellos casos en los que la información era incompleta. Los datos se incluyeron en una tabla de SPSS para posterior tratamiento estadístico.

\section{5) VARIABLES CLÍNICAS}

Edad al diagnóstico: se recogió la edad de cada paciente al diagnóstico de la enfermedad. Se estratificaron en 3 grupos de acuerdo con la edad al diagnóstico, según la clasificación de Montreal: A1 $\leq 16$ años, A2 > 16 y $\leq$ $40, \mathrm{~A} 3>40$.

Género: hombre o mujer.

Antecedentes familiares de Ell: se tuvo en cuenta si los pacientes tenían familiares de primer o de segundo grado con antecedentes de Ell.

Hábito tabáquico: se definieron tres categorías: fumador, no fumador y ex fumador.

Fenotipo de la enfermedad: se agruparon los pacientes siguiendo la clasificación de Montreal, descrita previamente.

Manifestaciones extraintestinales: se diferenciaron entre los que las tenían y los que no. Se tuvieron en cuenta la artropatía, el eritema nodoso, el pioderma gangrenoso o la uveítis. 
Enfermedad perianal al diagnóstico y/o en la evolución: la enfermedad perianal (EPA) se consideró valorando la presencia de fisuras, fístulas o abscesos.

Ingresos por brote de la enfermedad o por problemas asociados a la misma: se analizó si el paciente había requerido ingreso hospitalario en el transcurso de su enfermedad.

Uso de corticoides en el primer brote y durante la evolución de la enfermedad: utilización de tratamiento esteroideo en el primer brote de la enfermedad y/o durante el curso de la misma.

Desarrollo de corticodependencia o corticorresistencia: corticodependencia, definida como la reaparición de la sintomatología al reducir la dosis o la necesidad de dos ciclos de corticoides en un periodo de seis meses o de tres ciclos en un año. Corticorresistencia, definida como la ausencia de respuesta a tratamiento con corticoides a dosis adecuadas durante un periodo de tiempo preestablecido antes de iniciar el tratamiento, entre una y dos semanas en función de la gravedad del cuadro.

Desarrollo de complicaciones asociada a la enfermedad: se analizó la presencia de complicaciones como megacolon, hemorragia digestiva, perforación y desarrollo de displasia de alto grado o CCR.

Utilización de inmunosupresores o de biológicos: se analizó si el paciente durante el curso de la enfermedad, había recibido tratamiento con fármacos inmunomoduladores (azatioprina, 6-mercaptopurina o metotrexato) o con fármacos biológicos (infliximab o adalimumab). En cada caso se registró: a) Indicación: inducción de la remisión; mantenimiento; manifestaciones extra-intestinales. b) Respuesta clínica: mejoría de la sintomatología sin/con otro tratamiento concomitante. c) Remisión clínica: desaparición de la sintomatología en ausencia de otro tratamiento 
concomitante. d) Aparición de efectos adversos o si su aparición obligó a la retirada del fármaco.

Reservoritis: se analizó la presencia de reservoritis y la necesidad o no de cirugía en esta situación.

Cirugía: se evaluó si el paciente había requerido cirugía o no en relación con la Ell y si el paciente había recibido más de una intervención quirúrgica. En el caso de la EPA, resección de fístulas y/o drenaje de abscesos.

\section{6) ESTUDIO DE VARIANTES GENÉTICAS}

\subsection{1) Metodología del análisis de polimorfismos}

Los polimorfismos se analizaron mediante sondas TaqMan en un termociclador StepOne Plus de Applied Biosystems, previa amplificación de las secuencias específicas de los genes por PCR (Reacción en Cadena de la Polimerasa). Las reacciones de PCR se llevaron a cabo usando TaqMan Universal PCR Maxter Mix (Applied Biosystems) siguiendo las instrucciones en un sistema en tiempo real PCR Paso-One Plus.

Las reacciones de amplificación se realizaron con el producto comercial PCR Master Mix (Promega) (DNA Taq polimerasa; dATP,dGTP, dCTP, dTTP; MgCl2). Se llevaron a cabo en un volumen de $25 \mu \mathrm{L}$ :

- $12.5 \mu \mathrm{L}$ de Master Mix

- $10.5 \mu \mathrm{L}$ de agua libre de nucleasas

- $0.5 \mu \mathrm{L}$ de cada oligo cebador (sentido=forward y antisentido=reverse)

- $1 \mu \mathrm{L}$ de DNA

Como control negativo, para asegurar que no existía contaminación y que las reacciones eran específicas para cada muestra de partida, se 
preparó un tubo de reacción con todos los componentes antes citados excepto el DNA molde.

\subsection{2) Aislamiento de ADN y genotipado del polimorfismo}

Se extrajo ADN genómico a partir de sangre periférica mediante el procedimiento de fenol / cloroformo estándar. El Genotipado de polimorfismos ATG2B rs3759601, ATG16L1rs2241880, ATG10 rs1864183 y ATG5 rs2245214 se realizó utilizando ensayos TaqMan de discriminación alélica 5 'exonucleasa (Tabla 8) para amplificar la secuencias polimórficas y para detectar los dos alelos de cada polimorfismo, dos sondas marcadas con tintes VIC y FAM [165]. Inicialmente, se seleccionaron polimorfismos no sinónimos con una frecuencia poblacional del alelo menor superior al $10 \%$ en la población caucásica y cuyas secuencias se encontraban altamente conservadas durante la evolución. Los polimorfismos ATG2B rs3759601, ATG16L1 rs2241880 y ATG10 rs1864183 son mutaciones sin sentido mientras que el polimorfismo ATG5 rs2245214 es intrónico, pero elegimos este polimorfismo porque ya estaba descrito previamente en la literatura que la frecuencia del alelo menor es mayor de $10 \%$ en caucásicos y se asocia con la pérdida de sitios de reconocimiento para una proteína SRp40 que está involucrada en el empalme de mRNA.

\subsection{3) Discriminación alélica mediante PCR con sondas TaqMan}

En la discriminación alélica mediante PCR con sondas TaqMan, la amplificación y la detección del genotipo ocurren simultáneamente. Las sondas TaqMan son oligonucleótidos que hibridan específicamente con cada alelo en la región donde se localiza el polimorfismo de estudio. Las sondas están marcadas con un fluorocromo donador en el extremo 5', que emite fluorescencia al ser excitado, y un aceptor ("quencher") en el extremo 3', que absorbe la fluorescencia liberada por el donador cuando la sonda está intacta y ambos se encuentran próximos. Las sondas utilizadas 
en nuestro trabajo estaban marcadas con los fluorocromos VIC y FAM para cada alelo. La reacción de PCR requiere además: Taq DNA polimerasa, dNTPs, $\mathrm{MgCl} 2$ y cebadores sentido y anti-sentido. La reacción se lleva a cabo en termocicladores que incorporan un lector de fluorescencia. Durante la amplificación del DNA diana, la sonda hibrida con su cadena complementaria y la DNA polimerasa, que tiene actividad 5'-3' exonucleasa, al desplazarse a lo largo de la cadena hidroliza el extremo libre $5^{\prime}$ de la sonda produciéndose la liberación del fluorocromo donador; al quedar separados, la fluorescencia emitida por el fluorocromo es captada por el lector (Fig. 16).

Además, la emisión de fluorescencia producida en la reacción es proporcional a la cantidad de DNA formado, permitiendo en todo momento conocer y registrar la cinética de la reacción de amplificación.

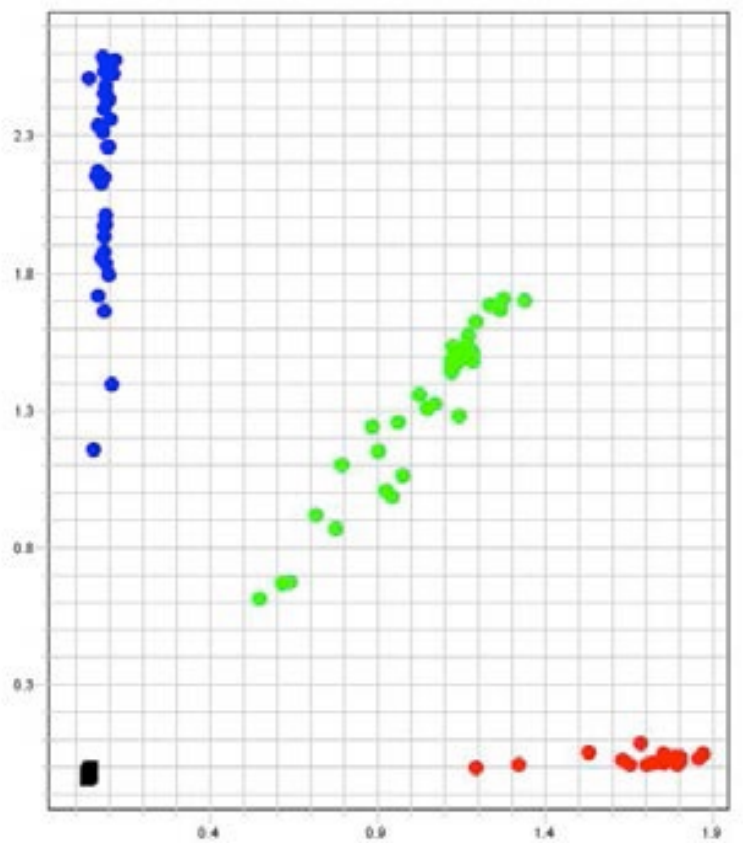

Figura 16. Representación de los resultados de la discriminación alélica con sondas TaqMan del polimorfismo rs3759601 del gen ATG2B.

Cada nube de puntos representa uno de los genotipos posibles: los azules son homocigotos GG, los verdes son heterocigotos CG y los rojos son homocigotos CC. 


\begin{tabular}{|c|c|c|c|c|}
\hline Gen & Polimorfismo & $\begin{array}{c}\text { Cambio de } \\
\text { base }\end{array}$ & $\begin{array}{c}\text { Localización } \\
\text { cromosómica }\end{array}$ & Sonda taqman \\
\hline ATG2B & rs3759601 & C>G & 14 & c_9690166_10 \\
\hline ATG16L1 & rs2241880 & G>A & 2 & c_9095577_20 \\
\hline ATG10 & rs1864183 & C>T & 5 & c_11953871_20 \\
\hline ATG5 & rs2245214 & C>G & 6 & c_3001905_20 \\
\hline
\end{tabular}

Tabla 8. Polimorfismos de los genes relacionados con la autofagia analizados en este estudio.

${ }^{\mathrm{a}}$ Todos los ensayos estaban disponibles comercialmente en Applied Biosystems

\section{7) ANÁLISIS ESTADÍSTICOS}

Métodos estadísticos: La descripción de las variables cualitativas se realizó mediante porcentajes; las continuas con los descriptivos básicos de media y desviación típica para distribuciones Normales y medianas y rangos intercuartílicos en distribuciones no Normales. Se ha utilizado el test de Kolmogorov-Smirnov para comprobar la normalidad de las variables cuantitativas. Para analizar la asociación entre genes y los casos-controles, así como la asociación entre las variables clínicas, se utilizó el test Chicuadrado para tablas de contingencia. También se utilizó el test Chicuadrado para comprobar el equilibrio de Hardy-Weinberg. Se aplicó la regresión logística para el análisis del riesgo del polimorfismo; se calcularon la odds ratio (OR) y los intervalos de confianza del 95\% (95\% IC) para cada variante polimórfica, así como, para analizar el efecto de las covariables edad y género. Se ha utilizado el test $t$ (dos grupos) o el análisis de la varianza (más de dos grupos) para comparación de medias cuando las variables seguían distribuciones normales y la $U$ de Mann-Whitney (dos grupos) o el test de Kruskal-Wallis (más de dos grupos) cuando las distribuciones no son Normales. Se ha utilizado la penalización de Bonferroni en las comparaciones múltiples. El nivel de significación utilizado es de 0,05, de manera que si el p-valor <0,05 los resultados se 
consideran estadísticamente significativos. Para realizar los análisis estadísticos se ha utilizado el Software IBM-SPSS versión 21. 


\section{9) RESULTADOS}


Se analizaron un total de 114 pacientes con diagnóstico de CU y 264 controles. La edad media entre los enfermos era de 52,9 años; de ellos el $53,5 \%$ eran hombres.

\section{1) CARACTERÍSTICAS CLÍNICAS}

En nuestra muestra la edad media al diagnóstico fue de 37,7 años y la edad media al registro fue de 52,9 años; esta variable tiene una distribución de frecuencia bastante simétrica, si bien hay mayor concentración de pacientes con edades comprendidas entre 40 y 45 años. Los años de seguimiento tuvieron una media de 15 años.

Si realizamos un análisis por grupos, existe un predominio de los diagnosticados entre 16 y 40 años (A2 de la clasificación de Montreal, $60 \%$ ). Los porcentajes de los distintos grupos de edad ( $A 1, A 2, A 3)$ se muestran en la figura 17.

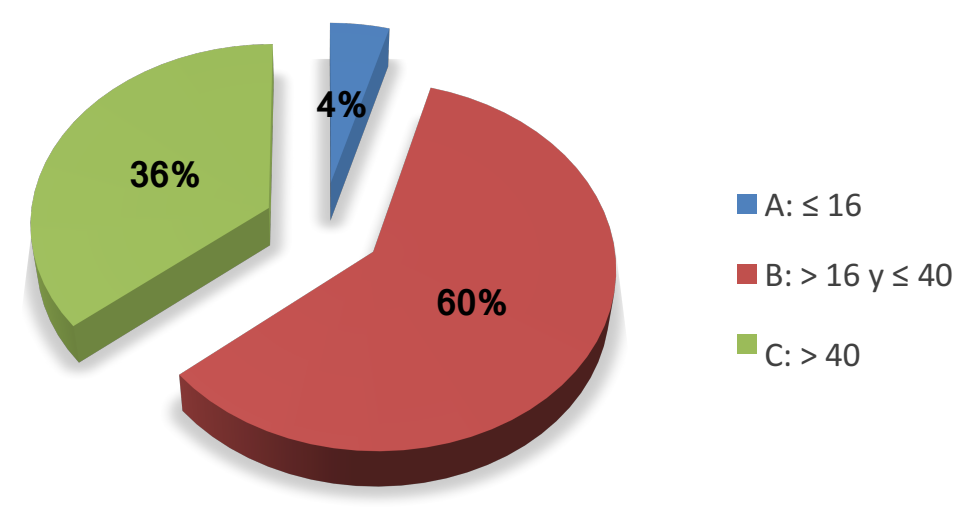

\section{Figura 17. Distribución de la edad al diagnóstico según la clasificación de Montreal}

La distribución de las edades de diagnóstico es muy similar a la edad de registro, si bien hay varios individuos con valores de edad avanzada (Figura 18). 


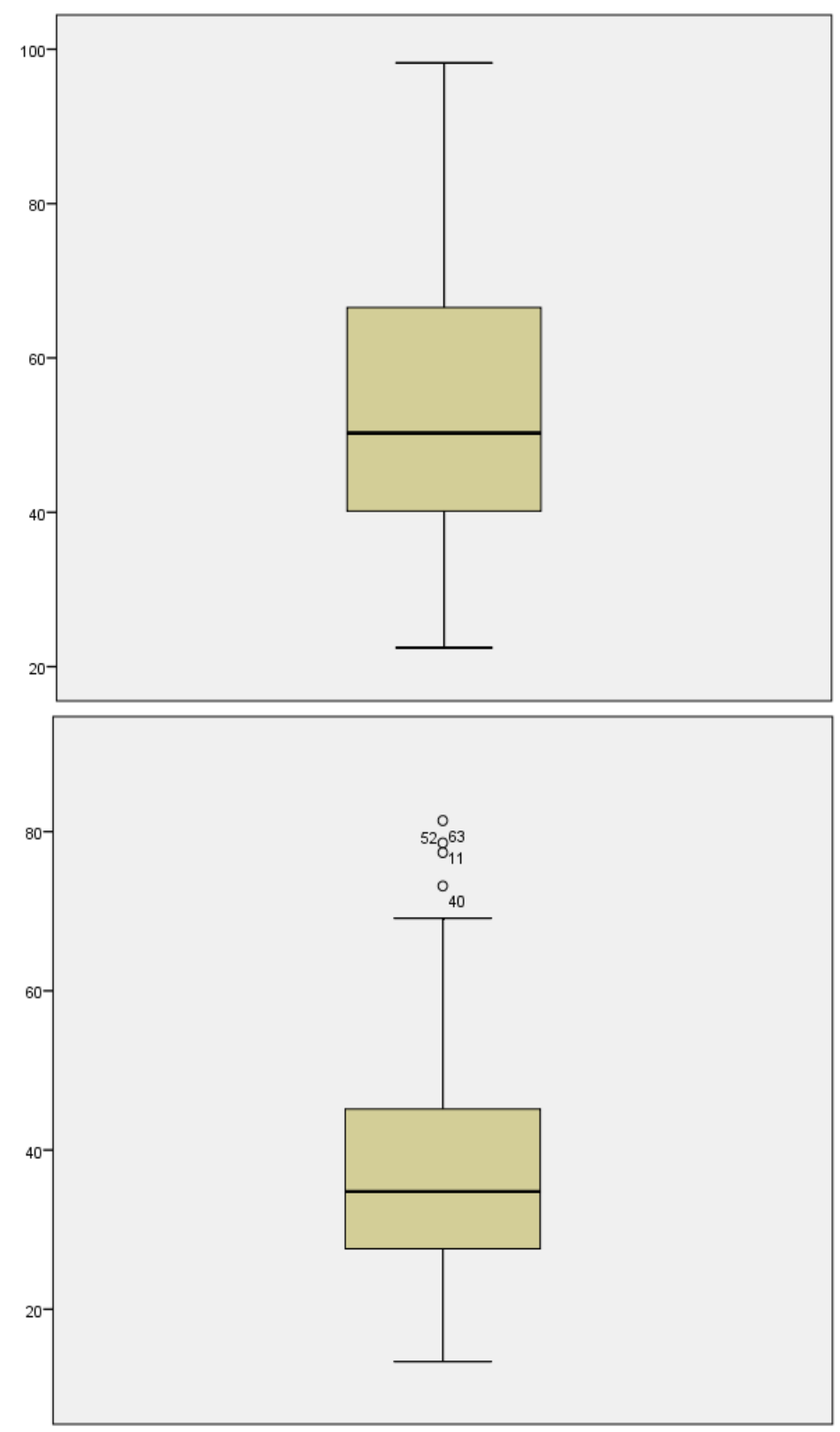

Figura 18. Distribución de las edades al registro y al diagnóstico. 
En cuanto al género, la relación hombre/mujer muestra un ligero predominio del sexo masculino $(53,6 \%)$, sin embargo las diferencias no son significativas.

El 13,2\% de nuestra población tenían algún antecedente familiar de primer o segundo grado de Ell y el $51,8 \%$ de los pacientes eran fumadores o exfumadores (Figura 19 y 20). Las características generales se resumen en la tabla 9.

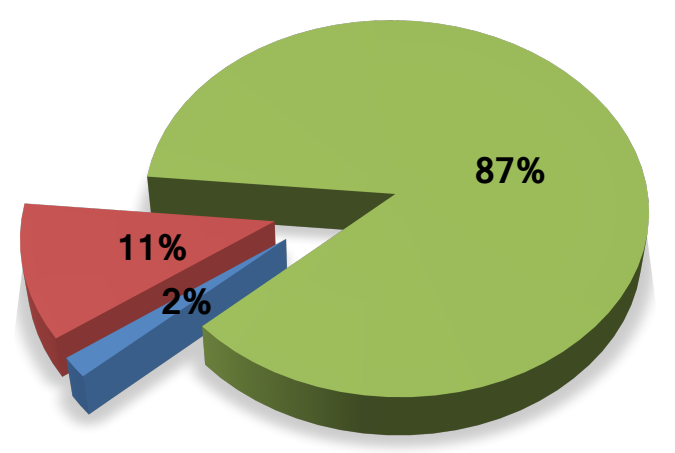

- Antecedente Familiar de 1ㅇ grado

- Antecedente familiar de 20 grado

Ninguno

Figura 19. Distribución según la presencia de antecedentes familiares de Ell
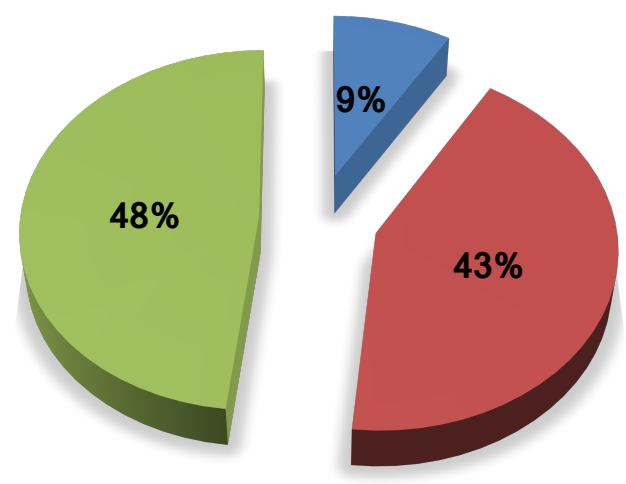

- Fumador

Ex fumador

No fumador

Figura 20. Distribución según hábito tabáquico 


\begin{tabular}{|c|c|c|}
\hline \multicolumn{2}{|l|}{ Variables } & N (\%) \\
\hline \multirow{2}{*}{ Género } & Hombres & $61(53,5 \%)$ \\
\hline & Mujeres & $53(46,5 \%)$ \\
\hline $\begin{array}{l}\text { Media Edad de registro en } \\
\text { años (rango) }\end{array}$ & \multicolumn{2}{|c|}{$52,93( \pm 16,9)$} \\
\hline $\begin{array}{l}\text { Media Edad al diagnóstico en } \\
\text { años (rango) }\end{array}$ & \multicolumn{2}{|c|}{$37,70( \pm 14,9)$} \\
\hline \multirow{3}{*}{ Antecedentes familiares Ell } & 10 grado & $2(1,8 \%)$ \\
\hline & 2o grado & $13(11,4 \%)$ \\
\hline & Sin antecedente & $99(86,8 \%)$ \\
\hline \multirow{3}{*}{ Hábito tabáquico } & Fumador & $10(8,8 \%)$ \\
\hline & No fumador & $55(48,2 \%)$ \\
\hline & Ex fumador & $49(43 \%)$ \\
\hline
\end{tabular}

Tabla 9. Características generales de los pacientes

En relación a la extensión de la enfermedad, en cerca de la mitad de los pacientes la afectación izquierda (E2) mostraba un ligero predominio $(44,7 \%)$ respecto a la pancolitis (E3) $(43,9 \%)$ y la proctitis (E1) $(11,4 \%)$. Hubo un predominio de enfermedad leve (S1) (48,2\%) y hasta un $13,2 \%$ de enfermedad grave (S3).

En el $17,5 \%$ de los casos (20) se asociaban a MEI, de los cuales el $75 \%$ presentaban afectación musculoesquelética; sólo el 4,4\% de los pacientes presentaba enfermedad perianal.

Durante el seguimiento, el 52,6\% de los pacientes habían tenido al menos un ingreso hospitalario y el 4,4\% presentó alguna complicación asociada a la enfermedad (CCR y/o perforación).

El $10,5 \%$ de pacientes fueron intervenidos quirúrgicamente y la principal indicación fue la falta de respuesta al tratamiento médico, en el 58,3\%. Se resumen las características clínicas en la tabla 10. 


\begin{tabular}{|c|c|c|}
\hline \multicolumn{2}{|c|}{ Variables } & $\mathbf{N}(\%)$ \\
\hline \multirow{3}{*}{ Extensión } & E1 & $13(11,4 \%)$ \\
\hline & E2 & $51(44,7 \%)$ \\
\hline & E3 & $50(43,9 \%)$ \\
\hline \multirow{3}{*}{ Gravedad } & S1 & $55(48,2 \%)$ \\
\hline & S2 & $44(38,6 \%)$ \\
\hline & S3 & $15(13,2 \%)$ \\
\hline \multirow{4}{*}{ MEI } & No & $94(82,5 \%)$ \\
\hline & $\mathrm{Si}$ & $20(17,5 \%)$ \\
\hline & Espondilitis & $5(20 \%)^{1}$ \\
\hline & Artritis & $11(55 \%)^{1}$ \\
\hline \multirow{2}{*}{$\begin{array}{l}\text { Enfermedad } \\
\text { perianal }\end{array}$} & No & $109(95,6 \%)$ \\
\hline & $\mathrm{Si}$ & $5(4,4 \%)$ \\
\hline \multirow{2}{*}{$\begin{array}{c}\text { Ingresos } \\
\text { hospitalarios }\end{array}$} & No & $54(47,4 \%)$ \\
\hline & $\mathrm{Si}$ & $60(52,6 \%)$ \\
\hline \multirow{4}{*}{ Complicaciones } & No & $109(95,6 \%)$ \\
\hline & $\mathrm{Si}$ & $5(4,4 \%)$ \\
\hline & Perforación & $2(1,8 \%)$ \\
\hline & CCR/Displasia & $3(2,6 \%)$ \\
\hline \multirow{2}{*}{ Cirugía } & No & $102(89,5 \%)$ \\
\hline & $\mathrm{Si}$ & $12(10,5 \%)$ \\
\hline \multirow{3}{*}{ Indicación cirugía } & Perforación & $2(16,7 \%)^{1}$ \\
\hline & CCR/Displasia & $3(25 \%)^{1}$ \\
\hline & $\begin{array}{l}\text { Falta de respuesta al } \\
\text { tratamiento médico }\end{array}$ & $7(58,3 \%)^{1}$ \\
\hline \multirow{2}{*}{ Reservoritis } & No & $1(20 \%)$ \\
\hline & $\mathrm{Si}$ & $4(80 \%)$ \\
\hline
\end{tabular}

${ }^{1}$ Estos porcentajes se realizaron sobre el total de pacientes con MEI o con cirugía. Tabla 10. Características clínicas

\section{2) TIPO DE TRATAMIENTO}

En relación al tratamiento recibido, el $71,1 \%$ de los pacientes emplearon corticoides en el curso de la enfermedad y el 39,5\% los recibió en el primer brote. De los pacientes que recibieron corticoides, el 45,67\% desarrolló corticodependencia y el 11.11\% corticorresistencia (Figura 21). 


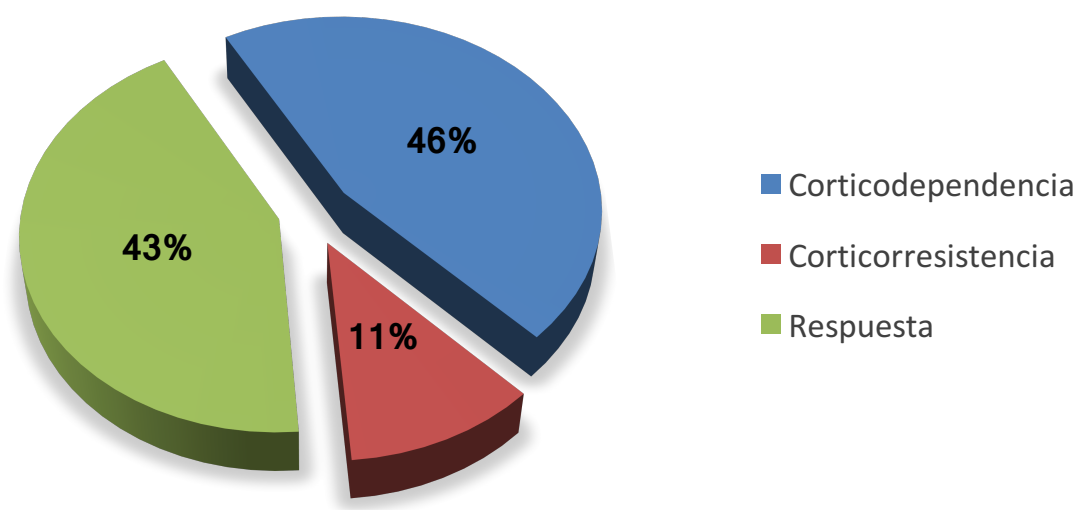

Figura 21. Respuesta a corticoides

Se utilizó azatioprina en el 34,2\% de los casos; en monoterapia en 32 casos (28.1\%) y en combinación con biológico en 7 casos $(6,1 \%)$, obteniéndose respuesta en 37 casos $(94,87 \%)$ de los que la recibieron. La indicación principal fue el mantenimiento de la remisión en el 84, 61\% (Figura 22 y 23 ).

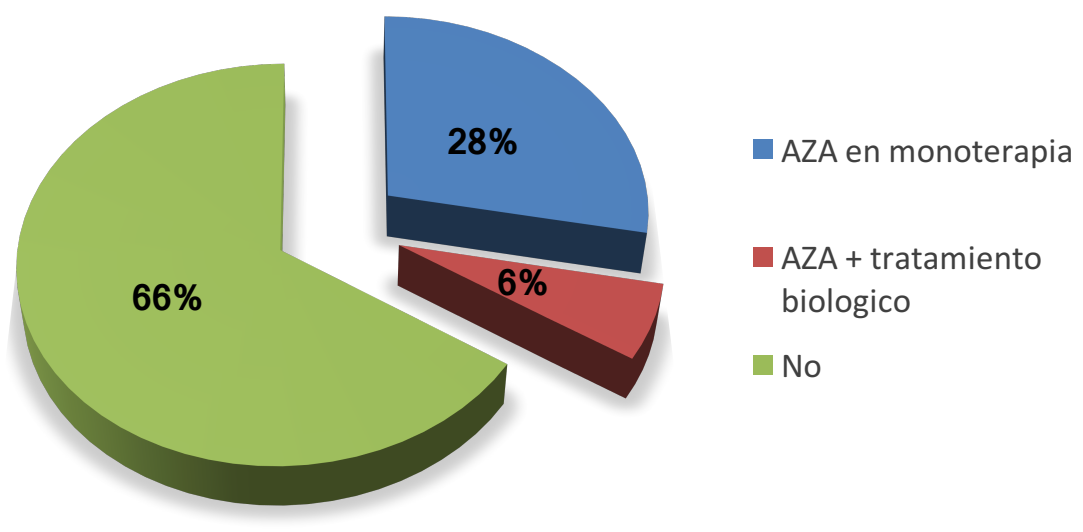

Figura 22. Porcentaje de pacientes que recibieron tratamiento con AZA 


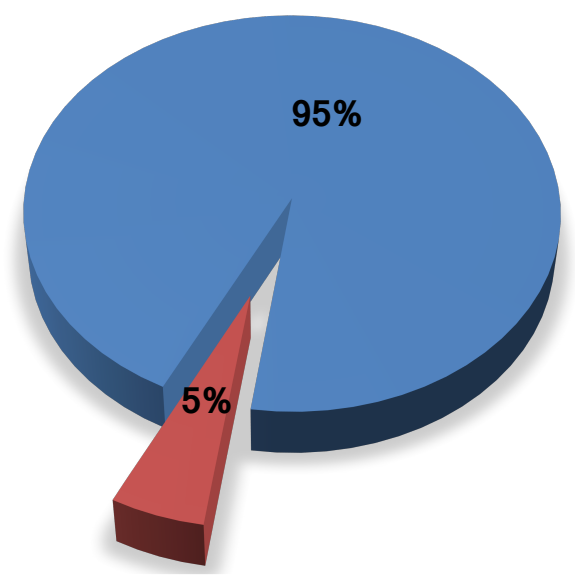

Respuesta

No respuesta

Figura 23. Porcentaje de pacientes con respuesta a AZA

Recibieron tratamiento con infliximab 9 pacientes $(7,9 \%)$ y la indicación principal fue la inducción de la remisión (6 casos). De los 9 pacientes tratados con infliximab alcanzaron remisión 8. Sólo 1 paciente recibió adalimumab, alcanzando respuesta clínica (Figura 25 y 26).

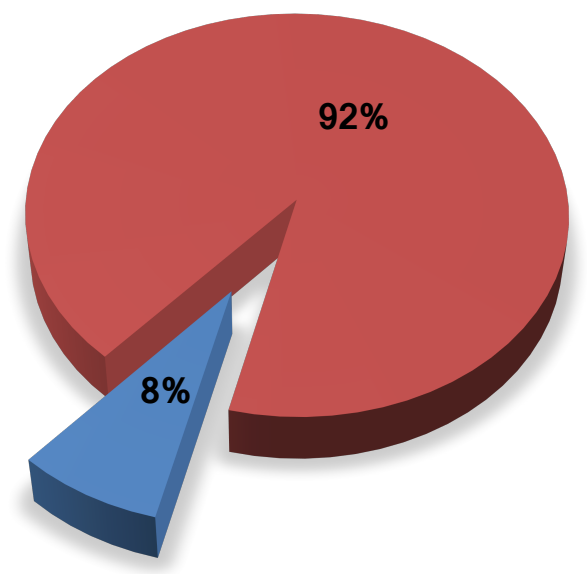

Uso de Infliximab

- No uso de Infliximab

Figura 24. Porcentaje de pacientes que recibieron Infliximab 


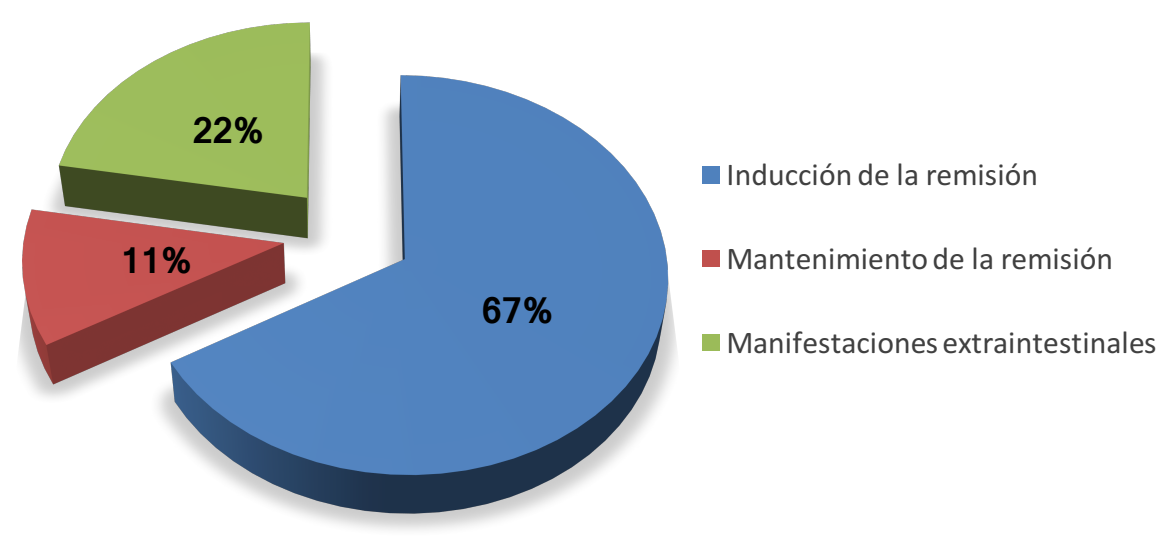

Figura 25. Indicación del tratamiento con infliximab

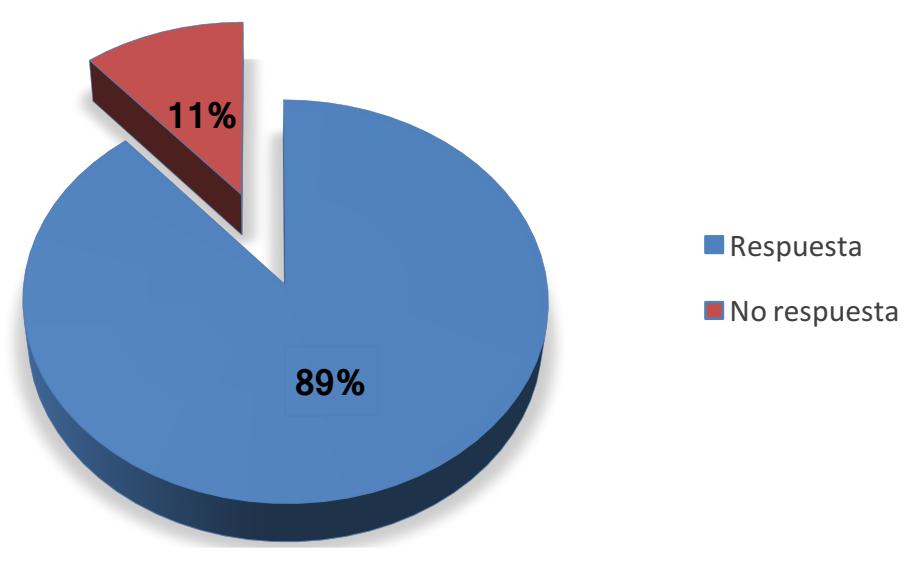

Figura 26. Porcentaje de pacientes que respondieron a infliximab

En 8 casos (7\%) fue necesario el uso de ciclosporina, obteniéndose respuesta en 2 de ellos; de los que no respondieron, uno alcanzó la remisión con infliximab y a los otros 5 se les sometió a colectomía. El 5,3\% de los pacientes presentaron alguna reacción adversa estos fármacos, 3 de ellos asociados a azatioprina, 1 a 6 - mercaptopurina y 2 a infliximab.

En 12 casos $(10,5 \%)$ se requirió intervención quirúrgica, dos por perforación (diagnóstico de CU tras la operación), tres por displasia/CCR y 7 
por resistencia al tratamiento ( 5 no respondieron a ciclosporina y dos a tratamiento combinado con AZA-IFX en el mantenimiento) (Figura 28).

El tipo de cirugía más frecuente fue pancolectomía restauradora con ileostomía temporal en el $50 \%$ de las intervenciones, seguida de una reconstrucción con reservorio ileoanal en el $41,66 \%$ (en el resto de los casos se dejó una ileostomía definitiva). De los 5 casos que tenían reservorio, uno fue operado por segunda vez con exéresis del reservorio por falta de respuesta a tratamiento médico. El 3,5\% de todos los pacientes fueron operados por absceso y/o fistulas, (tabla 11).

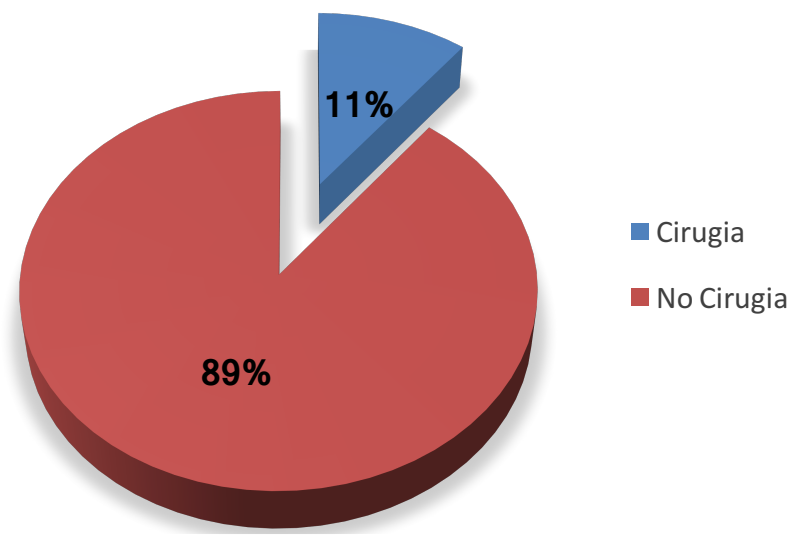

Figura 27. Porcentaje de pacientes intervenidos quirugicamente

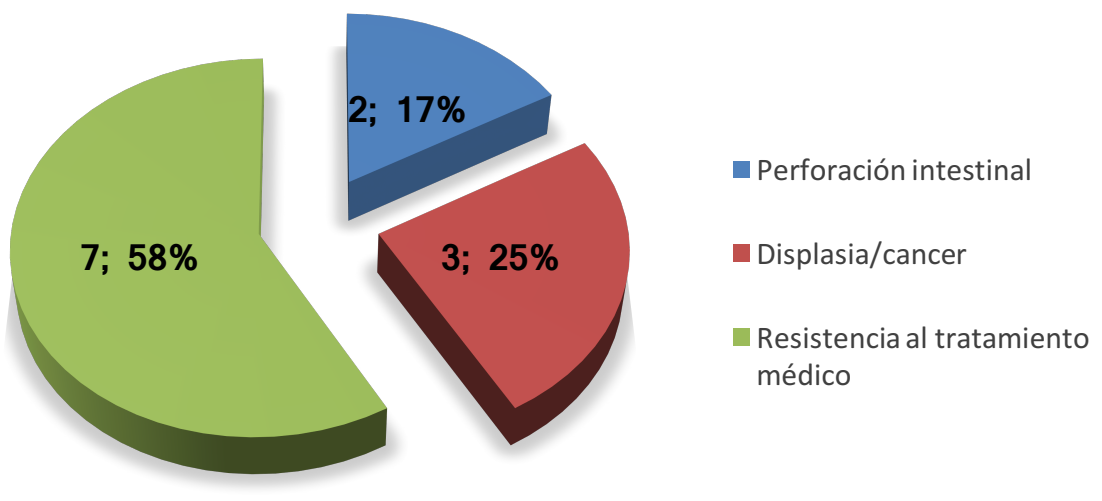

Figura 28. Indicación del tratamiento quirúrgico 


\begin{tabular}{|c|c|c|}
\hline \multicolumn{2}{|r|}{ Variable } & $\mathbf{N}(\%)$ \\
\hline \multirow{3}{*}{ Uso corticoides } & No & $33(28,9 \%)$ \\
\hline & Si & $81(71,1 \%)$ \\
\hline & Primer brote & $45(39,5 \%)$ \\
\hline \multirow{3}{*}{ Respuesta a GC } & Corticodependencia & $37(45,67 \%)^{a}$ \\
\hline & Corticorresistencia & $9(11,11 \%)^{a}$ \\
\hline & Respuesta & $35(43,22)^{a}$ \\
\hline \multirow{3}{*}{ Uso Azatioprina } & No & $75(65,8 \%)$ \\
\hline & $\mathrm{Si}$ & $39(34,2 \%)$ \\
\hline & Respuesta & $37(94,87 \%)^{a}$ \\
\hline \multirow{3}{*}{ Uso Infliximab } & No & $105(92,5 \%)$ \\
\hline & $\mathrm{Si}$ & $9(7,9 \%)$ \\
\hline & Respuesta & $8(88,8 \%)^{a}$ \\
\hline \multirow{3}{*}{ Uso Adalimumab } & No & $113(99,12 \%)$ \\
\hline & $\mathrm{Si}$ & $1(0,87 \%)$ \\
\hline & Respuesta & $1(100 \%)^{a}$ \\
\hline \multirow{3}{*}{ Uso Ciclosporina } & No & $106(93 \%)$ \\
\hline & Si & $8(7 \%)$ \\
\hline & Respuesta & $2(25 \%)^{a}$ \\
\hline Reacción adversa & & $6(5,3 \%)$ \\
\hline \multirow{2}{*}{ Cirugía } & No & $102(89,5 \%)$ \\
\hline & $\mathrm{Si}$ & $12(10,5 \%)$ \\
\hline \multirow{3}{*}{ Indicación cirugía } & Perforación & $2(16,6 \%)^{a}$ \\
\hline & CCR/Displasia & $3(25 \%)$ \\
\hline & Resistencia a tratamiento & $7(58,3 \%)$ \\
\hline
\end{tabular}

Tabla 11. Tratamiento recibido y respuesta

${ }^{a}$ Representan los porcentajes respecto a los que recibieron tratamiento médico o quirúrgico.

\section{3) ASOCIACIÓN ENTRE VARIABLES CLÍNICAS}

Se procedió a realizar estudios de asociación entre las distintas variables clínicas. Se realizaron los cruces en base a la edad al diagnóstico, gravedad y extensión de la enfermedad y respuesta a fármacos, y cada uno de ellas se asoció con la presencia de $\mathrm{MEI}$, tabaquismo, tratamiento médico y cirugía. 
No hemos encontrado asociación entre la extensión de la enfermedad con el uso del tabaco ni con los tratamientos biológicos. Tampoco hemos encontrado asociación entre la edad en el momento de inclusión al estudio y el tratamiento farmacológico o la presencia de manifestaciones extraintestinales. En nuestra población no hallamos asociación entre la respuesta al tratamiento médico con el hábito tabáquico.

Esta ausencia de significación estadística entre las variables clínicas analizadas puede ser debida al tamaño de la muestra de nuestro estudio.

Se ha encontrado relación estadísticamente significativa entre la extensión de la enfermedad con las siguientes variables: la presencia de $\mathrm{MEl}$; el uso de corticoides, azatioprina y ciclosporina; el desarrollo de corticodependencia o corticorefractariedad y la necesidad de cirugía. También se ha encontrado relación entre la gravedad y las variables mencionadas excepto con la presencia de $\mathrm{MEl}$; además, se ha encontrado relación significativa entre la gravedad y el uso de infliximab (no así con adalimumab, pues no es posible sacar conclusiones por el pequeño tamaño muestral).

\section{Edad al diagnóstico}

No hemos encontrado asociación entre la edad al diagnóstico (clasificados según la clasificación de Montreal) y las variables analizadas; sin embargo, al analizar la media de la edad al diagnóstico se han encontrado diferencias significativas con el uso de azatioprina (tabla 12). En el caso de la variable uso de corticoides, la distribución de la edad de diagnóstico de los que no han usado corticoides es simétrica ( $p$ valor $=0,200$ ) y asimétrica a la derecha para la edad de diagnóstico de los que han usado corticoides. Debido a la asimetría de uno de los grupos se ha realizado el contraste no paramétrico; en este caso se obtuvieron resultados significativos ( $p$-valor=0,034), como se muestra en la tabla 13 . 


\begin{tabular}{|c|c|c|c|c|c|c|}
\hline \multicolumn{2}{|c|}{ Variables clínicas } & N & $\begin{array}{c}\bar{X} \\
\text { de edad al } \\
\text { diagnóstico }\end{array}$ & S & ES & p-valor \\
\hline \multirow{2}{*}{ MEI } & NO & 94 & 38,24 & 15,503 & 1,599 & \multirow{2}{*}{0,452} \\
\hline \multirow{2}{*}{ Corticoides } & SÍ & 20 & 35,14 & 12,252 & 2,740 & \\
\cline { 2 - 8 } & Corticodependencia & 37 & 32.31 & 15.753 & 2.590 & 0,116 \\
\hline Uso & Respuesta a GCS & 35 & 39.37 & 15.466 & 2.614 & \\
azatioprina & NO & 75 & 41,23 & 14,772 & 1,706 & \multirow{2}{*}{0,0001} \\
\hline $\begin{array}{c}\text { Uso de } \\
\text { infliximab }\end{array}$ & SI & 39 & 30,89 & 13,051 & 2,090 & \\
\hline \multirow{2}{*}{$\begin{array}{c}\text { Uso } \\
\text { ciclosporina }\end{array}$} & NO & 105 & 37,64 & 14,774 & 1,442 & \multirow{2}{*}{0,882} \\
\hline \multirow{2}{*}{ Cirugía } & NO & 106 & 37,71 & 15,158 & 1,472 & \multirow{2}{*}{0,960} \\
\hline
\end{tabular}

Tabla 12. Asociación entre la edad en años al diagnóstico y variables clínicas

\begin{tabular}{|c|c|c|c|c|c|c|c|c|}
\hline $\begin{array}{c}\text { Uso de } \\
\text { GCs }\end{array}$ & $\mathbf{N}$ & $\overline{\mathbf{X}}$ & $\mathbf{S}$ & $\mathbf{E S}$ & $\mathbf{p}$-valor & Mdn & $\mathbf{R I}$ & $\mathbf{p}$-valor \\
\hline No & 33 & 41,42 & 13,379 & 2,329 & 0,09 & 40 & 16 & $\mathbf{0 , 0 3 4}$ \\
$\mathrm{Si}$ & 81 & 36,18 & 15,408 & 1,712 & 0,09 & 33,19 & 18 & \\
\hline
\end{tabular}

$\bar{X}$ media, S desviación estándar, ES media del error estándar, Mdn mediana, RI rango intercuartílico

Tabla 13. Asociación entre edad al diagnóstico y el uso de corticoides

\subsection{1) Según extensión de la enfermedad}

Se ha detectado asociación estadística significativa entre la extensión y la presencia de MEI (p-valor=0,002). El 32\% de los pacientes con pancolitis presentaba MEI (Figura 29). También se han obtenido diferencias significativas entre la extensión y el uso de corticoides, el desarrollo de corticodependencia, corticorefractariedad, el uso de azatioprina y de ciclosporina y la necesidad de cirugía. Tabla 14. 


\begin{tabular}{|c|c|c|c|c|c|}
\hline \multirow{2}{*}{\multicolumn{2}{|c|}{ Variables Clínicas }} & \multicolumn{3}{|c|}{ Extensión } & \multirow{2}{*}{ p-valor } \\
\hline & & \multirow{2}{*}{$\begin{array}{c}\text { E1 } \\
1(7,7 \%)\end{array}$} & \multirow{2}{*}{$\frac{\text { E2 }}{9 \%)}$} & \multirow{2}{*}{$\frac{\text { E3 }}{16(32 \%)}$} & \\
\hline \multirow{2}{*}{ MEI } & $\mathrm{Si}$ & & & & \multirow{2}{*}{0,002} \\
\hline & No & $12(92,3 \%)$ & $48(94,1 \%)$ & $34(68 \%)$ & \\
\hline \multirow{3}{*}{$\begin{array}{l}\text { Hábito } \\
\text { tabaquico }\end{array}$} & $\mathrm{Si}$ & $2(15,4 \%)$ & $2(3,9 \%)$ & $6(12 \%)$ & \multirow{3}{*}{0,581} \\
\hline & No & $5(38,5 \%)$ & $26(51 \%)$ & $24(48 \%)$ & \\
\hline & Exfumador & $6(46,2 \%)$ & $2(45,1 \%)$ & $20(40 \%)$ & \\
\hline \multirow{2}{*}{$\begin{array}{l}\text { Uso de } \\
\text { corticoides }\end{array}$} & $\mathrm{Si}$ & $3(23,1 \%)$ & $28(54,6 \%)$ & $50(100 \%)$ & \multirow{2}{*}{$<0,0001$} \\
\hline & No & $10(76,9 \%)$ & $23(45,1 \%)$ & $0 \%$ & \\
\hline \multirow{3}{*}{$\begin{array}{c}\text { Respuesta a } \\
\text { corticoides }\end{array}$} & $C D$ & 0 & $13(25, \%)$ & $24(48 \%)$ & \multirow{3}{*}{$<0,0001$} \\
\hline & $\mathrm{CR}$ & $1(7,7 \%)$ & 0 & $8(16 \%)$ & \\
\hline & Respuesta & $12(92,3 \%)$ & $38(74,5 \%)$ & $18(36 \%)$ & \\
\hline \multirow{2}{*}{ Azatioprina } & $\mathrm{Si}$ & $1(7,7 \%)$ & $12(23,5 \%)$ & $26(52 \%)$ & \multirow{2}{*}{0,001} \\
\hline & No & $12(92,3 \%)$ & $39(76,5)$ & $24(48 \%)$ & \\
\hline \multirow{2}{*}{ Infliximab } & $\mathrm{Si}$ & $2(15,4 \%)$ & $2(3,9 \%)$ & $5(10 \%)$ & \multirow{2}{*}{0,197} \\
\hline & No & $11(84,6 \%)$ & $49(96,1)$ & 45 (90\%) & \\
\hline \multirow{2}{*}{ Ciclosporina } & $\mathrm{Si}$ & 0 & 0 & $8(16 \%)$ & \multirow{2}{*}{0,002} \\
\hline & No & $13(100 \%)$ & $51(100 \%)$ & $42(84 \%)$ & \\
\hline \multirow{2}{*}{ Cirugía } & $\mathrm{Si}$ & $1(7,7 \%)$ & $1(2 \%)$ & $10(20 \%)$ & \multirow{2}{*}{0,009} \\
\hline & No & $12(92,3 \%)$ & $50(98 \%)$ & $40(80 \%)$ & \\
\hline
\end{tabular}

Tabla 14. Asociación entre la extensión y las variables clínicas

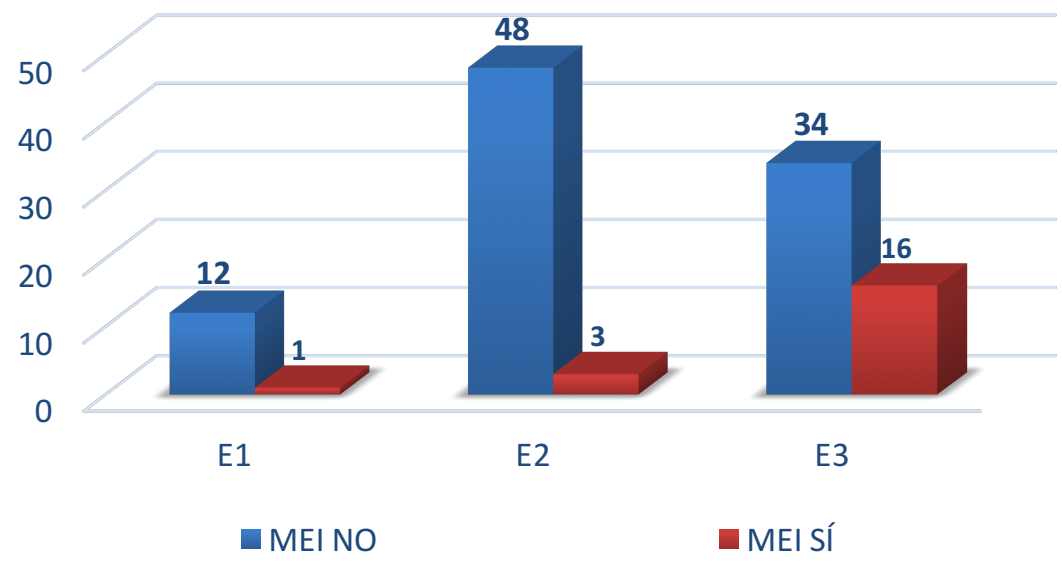

Figura 29. Presencia de MEI según extensión 


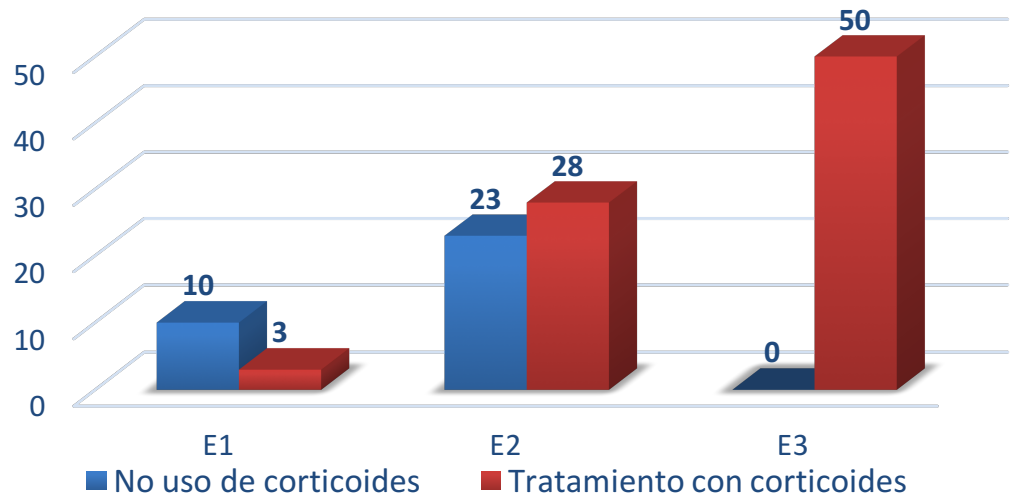

Figura 30. Pacientes con corticoides según extension

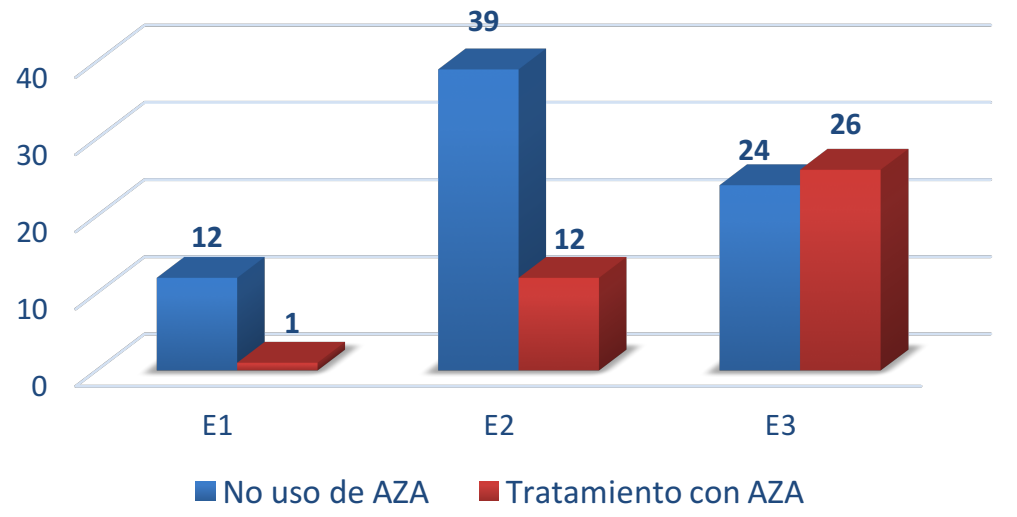

Figura 31. Pacientes con azatriopina según extension

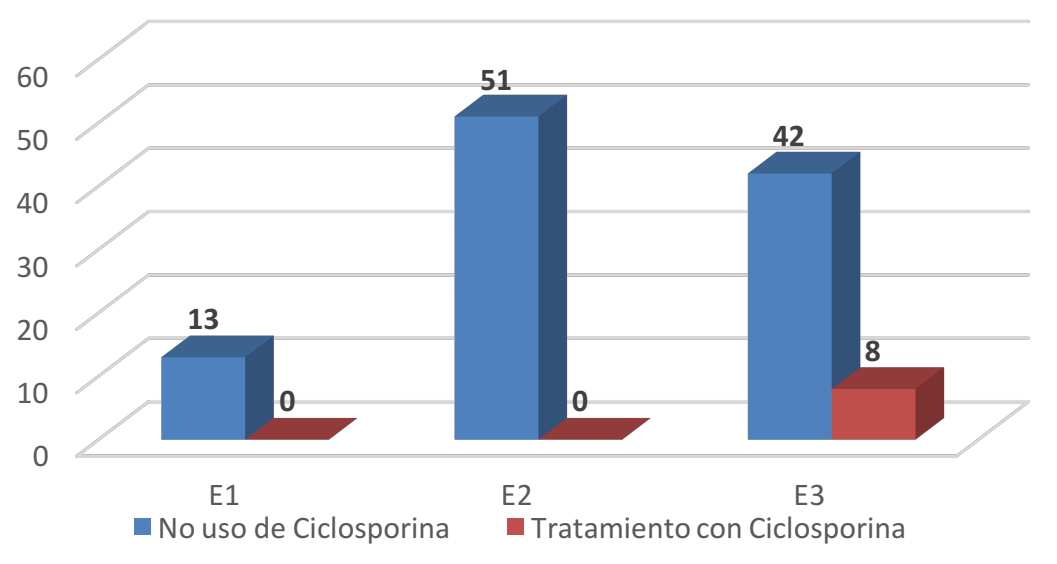

Figura 32. Uso de Ciclosporina según extension 


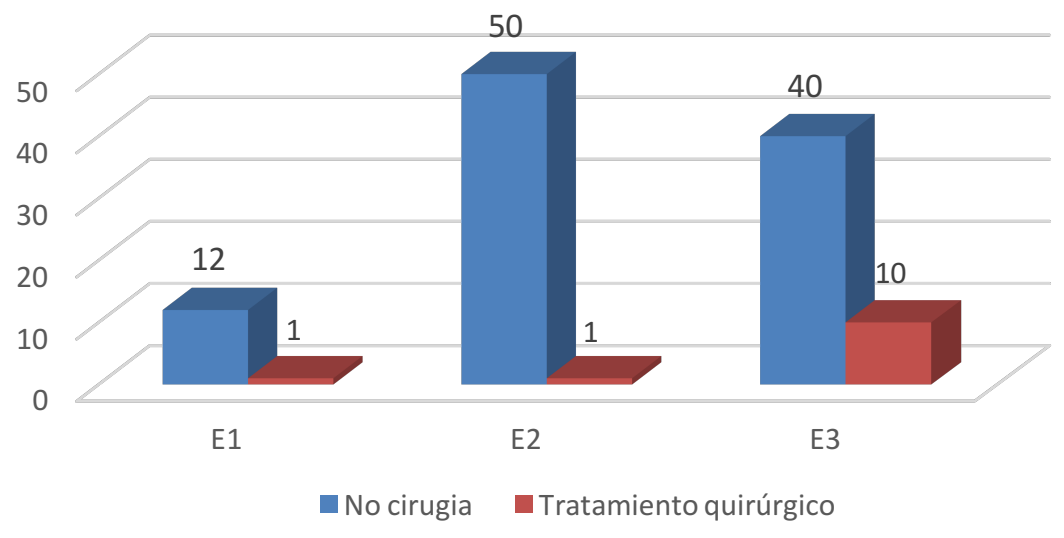

Figura 33. Cirugía según extensión

\subsection{2) Según gravedad (S1, S2, S3)}

De los pacientes con enfermedad grave (S3) el 33\% presentaban MEl; este porcentaje es del $25 \%$ en pacientes con enfermedad moderada (S2) y del 7,3\% en pacientes con enfermedad leve (S1), siendo estas diferencias no significativas ( $p$-valor $=0,15$ ).

Respecto al uso de corticoides, se trataron con corticoides al $100 \%$ de pacientes con enfermedad grave y moderada y al $40 \%$ de pacientes con enfermedad leve, diferencias con una fuerte significación estadística. De los pacientes con enfermedad grave, el $60 \%$ eran corticorefractarios y el $26,7 \%$ corticodependientes. El $18,2 \%$ y el $65,9 \%$ de los pacientes con enfermedad leve y moderada respectivamente eran corticodependientes (p-valor<0,0001).

En relación al tratamiento con azatioprina, el grupo de CU moderada fue el más numeroso en corticodependientes; de ellos el 63,6\% recibieron tratamiento con azatioprina. El $46,7 \%$ de pacientes con enfermedad grave y el $7,3 \%$ de aquellos con enfermedad leve requirieron tratamiento con azatioprina, siendo estas diferencias significativas ( $p$-valor $<0,0001$ ). 
El 53,3\% (8) de pacientes con CU grave recibieron tratamiento con ciclosporina: 2 de ellos obtuvieron respuesta, 6 no respondieron y 1 de ellos respondió a infliximab; los 5 restantes requirieron colectomía. 7 pacientes con $\mathrm{CU}$ grave no recibieron ciclosporina puesto que dos de ellos fueron sometidos a colectomía urgente por perforación antes de iniciar el tratamiento, otros dos recibieron infliximab puesto que habían recibido previamente tratamiento con AZA y tres de ellos respondieron a corticoides. El $20 \%$ de pacientes con enfermedad grave recibió Infliximab (3 pacientes: uno tras no haber respondido a ciclosporina y los otros dos porque habían recibido $A Z A)$. Ningún paciente con enfermedad leve o moderada recibió infliximab ( $p$-valor $=0,002)$. Solo un paciente recibió tratamiento con adalimumab.

Se sometieron a colectomía el $10,5 \%$ de toda nuestra población: el $53,3 \%$ por un brote grave ( 2 por perforación y 6 por falta de respuesta a tratamiento médico); el 6,8\% con enfermedad moderada (los 3 por displasia de alto grado y/o CCR) y el $1,8 \%$ con enfermedad leve (falta de respuesta a tratamiento médico), siendo estas diferencias estadísticamente significativas ( $p$-valor $<0,0001$ ). Los resultados se resumen en la tabla 15. 


\begin{tabular}{|c|c|c|c|c|c|}
\hline \multirow{2}{*}{\multicolumn{2}{|c|}{ Variables clínicas }} & \multicolumn{3}{|c|}{ Gravedad } & \multirow{2}{*}{ p-valor } \\
\hline & & \multirow{2}{*}{$\frac{\text { S1 }}{4(7,3 \%)}$} & \multirow{2}{*}{$\frac{\text { S2 }}{11(25 \%)}$} & \multirow{2}{*}{$\frac{\text { S3 }}{5(33,3 \%)}$} & \\
\hline \multirow{2}{*}{ MEI } & $\mathrm{Si}$ & & & & \multirow{2}{*}{0,15} \\
\hline & No & $51(92,7 \%)$ & $33(75 \%)$ & $10(66,7 \%)$ & \\
\hline \multirow{3}{*}{$\begin{array}{l}\text { Hábito } \\
\text { tabáquico }\end{array}$} & Si & $5(9,1 \%)$ & $5(11,4 \%)$ & 0 & \multirow{3}{*}{0,545} \\
\hline & No & $26(47,3 \%)$ & $23(52,3 \%)$ & $6(40 \%)$ & \\
\hline & Exfumador & $24(46,3 \%)$ & $16(36,4 \%)$ & $9(60 \%)$ & \\
\hline \multirow{2}{*}{$\begin{array}{l}\text { Uso de } \\
\text { Corticoides }\end{array}$} & $\mathrm{Si}$ & 22 (40\%) & 44 (100\%) & 15 (100\%) & \multirow{2}{*}{$<0,0001$} \\
\hline & No & $33(60 \%)$ & 0 & $0 \%$ & \\
\hline \multirow{3}{*}{$\begin{array}{l}\text { Respuesta a } \\
\text { Corticoides }\end{array}$} & $C D$ & $4(18,2 \%)$ & $29(65,9 \%)$ & $4(26,7 \%)$ & \multirow{3}{*}{$<0,0001$} \\
\hline & CR & 0 & 0 & $9(60 \%)$ & \\
\hline & Respuesta & $18(81,8 \%)$ & $15(34,1 \%)$ & $2(13,3 \%)$ & \\
\hline \multirow{2}{*}{ Azatioprina } & Si & $4(7,3 \%)$ & $28(63,6 \%)$ & $7(46,7 \%)$ & \multirow{2}{*}{$<0,0001$} \\
\hline & No & $51(92,7 \%)$ & $16(36,4)$ & $8(53,3 \%)$ & \\
\hline \multirow{2}{*}{ Infliximab } & $\mathrm{Si}$ & 0 & 0 & $3(20 \%)$ & \multirow{2}{*}{0,002} \\
\hline & No & 55 (100\%) & 4 (100\%) & $12(80 \%)$ & \\
\hline \multirow{2}{*}{ Ciclosporina } & $\mathrm{Si}$ & 0 & 0 & $8(53,3 \%)$ & \multirow{2}{*}{$<0,0001$} \\
\hline & No & $55(100 \%)$ & $51(100 \%)$ & $7(46,7 \%)$ & \\
\hline \multirow{2}{*}{ Cirugía } & $\mathrm{Si}$ & $1(1,8 \%)$ & $3(6,8 \%)$ & $8(53,3 \%)$ & \multirow{2}{*}{$<0,0001$} \\
\hline & No & $54(98,2 \%)$ & $41(93,2 \%)$ & $7(46,7 \%)$ & \\
\hline
\end{tabular}

Tabla 15. Asociación entre la gravedad y variables clínicas

Respuesta a fármacos y hábito tabáquico: No hemos hallado diferencias significativas respecto a la respuesta al tratamiento médico, el desarrollo de corticodependencia o corticoresistencia ni la necesidad de cirugía respecto al hábito tabáquico; aunque estos resultados es necesario tomarlos con cautela por el pequeño número de pacientes. Tabla 16. 


\begin{tabular}{|c|c|c|c|c|c|}
\hline \multicolumn{2}{|c|}{ Tratamiento } & $\begin{array}{c}\text { No } \\
\text { fumador }\end{array}$ & Fumador & $\begin{array}{c}\text { Ex } \\
\text { fumador }\end{array}$ & p-valor \\
\hline Respuesta a Aza & $\mathrm{Si}$ & $22(59,5 \%)$ & $1(2,7 \%)$ & $14(37,8 \%)$ & 0,925 \\
& $\mathrm{No}$ & $1(50 \%)$ & 0 & $1(50 \%)$ & \\
\hline Respuesta a IFX & $\mathrm{Si}$ & $5(62,5 \%)$ & 0 & $3(37,5 \%)$ & $>$ \\
\hline $\begin{array}{c}\text { Respuesta a } \\
\text { ciclosporina }\end{array}$ & $\mathrm{No}$ & $1(100 \%)$ & 0 & 0 & \\
\hline \multirow{2}{*}{ Cirugía } & $\mathrm{Si}$ & $1(50 \%)$ & 0 & $1(50 \%)$ & $>0,99$ \\
\hline
\end{tabular}

Tabla 16. Asociación entre hábito tabáquico y el tratamiento

\section{4) ESTUDIO DE POLIMORFISMOS}

\subsection{1) Comparación de polimorfimos con grupo control} (susceptibilidad)

En la tabla 17 se resumen la distribución de los polimorfismos de los genes a estudio en la cohorte de pacientes con CU y en el grupo control.

En el estudio del polimorfismo del gen ATG10 se observa una mayor frecuencia del homocigoto $\mathrm{CC}$ en el grupo de pacientes con $\mathrm{CU}$ respecto al control (35,2\% vs 25,8\%), mientras que los otros dos genotipos (CT y TT) son más frecuentes en el grupo control, aunque sin diferencias significativas ( $p$-valor $=0,409)$.

En el estudio del polimorfismo del gen ATG16L1, todos los genotipos son más frecuentes en el grupo control, no se ha encontrado asociación entre ambos grupos ( $p$-valor=0,131).

En el estudio del gen ATG5, la frecuencia del homocigoto GG es discretamente mayor en pacientes con CU frente a los controles (14\% vs $11,7 \%)$; la frecuencia del heterocigoto CG es similar en ambos grupos. En este gen tampoco hemos detectado asociación ( $p$-valor=0,814). 
No se encontraron diferencias estadísticamente significativas en la distribución genotípica de los polimorfismos ATG10, ATG16L1 y ATG5 entre pacientes con $\mathrm{CU}$ y controles.

Sí se encontraron diferencias estadísticamente significativas en la distribución genotípica del polimorfismo ATG2B rs3759601 entre pacientes con CU y controles. En el gen ATG2B, el homocigoto GG es más frecuente en los pacientes con CU frente al grupo control (56,7\% vs el $43,3 \%)$. El homocigoto CC es más frecuente en el grupo control que en el grupo de CU $(88,7 \%$ vs $11,3 \%)$, siendo esta diferencia estadísticamente significativa $(p=0,0000)$ (Tabla 17).

Ambos grupos siguen la ley de Hardy-Weinberg. (Controles, pvalor=0,332; casos, $\mathrm{p}$-valor $=0,68)$.

\begin{tabular}{|c|c|c|c|c|}
\hline SNP & Genotipo & Pacientes CU & Controles & p-valor \\
\hline $\begin{array}{c}\text { ATG2B } \\
\text { rs3759601 }\end{array}$ & CC & $14(11,3 \%)$ & $110(88,7 \%)$ & \\
& GG & $49(29,9 \%)$ & $115(70,1 \%)$ & $<0,0000$ \\
\hline $\begin{array}{c}\text { ATG10 } \\
\text { rs1864183 }\end{array}$ & CC & $31(56,7 \%)$ & $39(43,3 \%)$ & \\
\hline CT & $59(55,2 \%)$ & $68(25,8 \%)$ & \multirow{2}{*}{0,409} \\
ATG16L1 & TT & $18(15,8 \%)$ & $45(17,0 \%)$ & \\
rs2241880 & TC & $27(23,7 \%)$ & $63(23,9 \%)$ & \multirow{2}{*}{0,131} \\
\hline ATG5 & CC & $38(33,3 \%)$ & $63(23,9 \%)$ & \\
rs2245214 & CC & $43(37,7 \%)$ & $106(40,2 \%)$ & \multirow{2}{*}{0,814} \\
\hline
\end{tabular}

Tabla 17. Distribución genotípica entre pacientes y controles en el estudio de polimorfismos

Si realizamos la regresión logística para estimar los odds-ratios considerando como grupo de referencia GG obtenemos los resultados reflejados en la tabla 18. 


\begin{tabular}{|c|c|c|c|c|c|}
\hline SNP & Genotipo & Pacientes CU & Controles & p-valor & OR (95\% IC) \\
\hline \multirow{3}{*}{ ATG2B } & GG & $51(44,7 \%)$ & $39(14,8 \%)$ & $<0,0000$ & $10,275(5,127-20,589)$ \\
\cline { 2 - 6 } & CC & $14(12,3 \%)$ & $110(41,7 \%)$ & & \\
\cline { 2 - 6 } & GG & $51(44,7 \%)$ & $39(14,8 \%)$ & $<0,0000$ & $3,069(1,79-5,23)$ \\
\cline { 2 - 6 } & CG & $49(43 \%)$ & $115(43,6 \%)$ & & \\
\hline
\end{tabular}

Tabla 18. Análisis y estimación del OR del gen ATG2B

Según estos datos, los homocigotos GG tienen 10 veces más riesgo de desarrollar CU que cuando el genotipo es CC y 3 veces más riesgo que cuando el genotipo es CG. Si hacemos el estudio alélico obtenemos los resultados descritos en la tabla 19.

\begin{tabular}{|c|c|c|c|c|}
\hline Alelos ATG2B & casos & Controles & p-valor & OR (95\% IC) \\
\hline G & $151(43,9 \%)$ & $193(56,10)$ & \multirow{2}{*}{$<0,00001$} & \multirow{2}{*}{$3,4(2,46-4)$} \\
\hline C & $77(18,69 \%)$ & $335(81,31 \%)$ & & \\
\hline
\end{tabular}

Tabla 19. Estudio alélico del gen ATG2B

Observamos que existe una fuerte asociación entre los alelos y los casos y controles (p-valor<0,00001). El odds-radio es 3,40 (IC95\%: 2,464,72). La presencia del alelo $G$ multiplica por 3,4 el riesgo de desarrollar Colitis Ulcerosa que el alelo $\mathrm{C}$.

Según el modelo dominante, que considera el homocigoto del alelo más frecuente frente a los otros dos genotipos, la asociación es altamente significativa (p-valor<0,0001); el odds-ratio es 4,67 (IC95\%:2,89-7,71). Es decir el genotipo GG multiplica por 4,6 el riesgo de desarrollar CU que cualquiera de los otros genotipos.

Según el modelo recesivo, se ha detectado asociación (pvalor<0,0001). El odds-ratio es de 5,10 (IC95\% 2,77-9,39); estos datos se resumen en la tabla 20. 


\begin{tabular}{|c|c|c|c|c|c|}
\hline SNP & Genotipo & Pacientes CU & Controles & p-valor & OR (95\% IC) \\
\hline \multirow{8}{*}{ ATG2B } & GG & $51(44,7 \%)$ & $39(14,8 \%)$ & \multirow{2}{*}{$<0,0000$} & \multirow{2}{*}{$10,275(5,127-20,589)$} \\
\hline & CC & $14(12,3 \%)$ & $110(41,7 \%)$ & & \\
\hline & GG & $51(44,7 \%)$ & $39(14,8 \%)$ & \multirow{2}{*}{$<0,0000$} & \multirow{2}{*}{$3,069(1,79-5,23)$} \\
\hline & CG & $49(43 \%)$ & $115(43,6 \%)$ & & \\
\hline & GG & $51(47,4 \%)$ & $39(14,8 \%)$ & \multirow{2}{*}{$<0,0001$} & \multirow{2}{*}{$4,67(2,89-7,71)$} \\
\hline & $\mathrm{CC}+\mathrm{CG}$ & $63(55,3 \%)$ & $225(85,2 \%)$ & & \\
\hline & $C G+G G$ & $100(87,7 \%)$ & $154(58,3 \%)$ & \multirow{2}{*}{$<0,0001$} & \multirow{2}{*}{$5,10(2,77-9,39)$} \\
\hline & CC & $14(12,3 \%)$ & $110(41,7 \%)$ & & \\
\hline
\end{tabular}

Tabla 20. Análisis del gen ATG2B según el modelo dominante y recesivo

\subsection{2) Asociación entre polimorfismos y variables clínicas}

Sólo hemos analizado las posibles asociaciones entre distintas variables clínicas y el gen ATG2B, dado que es el único que ha mostrado diferencias significativas entre casos y controles. Si analizamos la asociación del gen ATG2B con el género encontramos los resultados descritos en la tabla 21.

\begin{tabular}{|c|c|c|c|}
\hline Grupos & Varón & Mujer & Total \\
\hline Casos N (\%) & $61(53,5)$ & $53(46,5 \%)$ & $114(100 \%)$ \\
\hline Controles N (\%) & $73(27,7 \%)$ & $191(72,3 \%)$ & $264(100 \%)$ \\
\hline Total & 134 & 244 & 378 \\
\hline
\end{tabular}

Tabla 21. Asociación entre el género y el gen ATG2B

Se observa que hay desequilibrios en los dos grupos en hombre y mujeres: mientras que en los casos está más equilibrada en la proporción hombre/mujer, los controles presentan un mayor porcentaje de mujeres que de hombres. 
A pesar de que puede haber cierta influencia del género en la asociación entre el genotipo y la presencia o no de Colitis Ulcerosa, el efecto no es tan grande porque los odds-ratios no varían tanto, tabla 22.

\begin{tabular}{|c|c|c|c|c|}
\hline ATG2B & Sig. & Exp(B) & $\begin{array}{c}\text { 95\% C.I. } \\
\text { inferior }\end{array}$ & $\begin{array}{c}\text { 95\% C.I. } \\
\text { superior }\end{array}$ \\
\hline CC & 0,000 & 9,178 & 4,524 & 18,621 \\
\hline CG & 0,000 & 2,882 & 1,665 & 4,989 \\
\hline GG & 0,000 & 1 & & \\
\hline Género & 0,000 & 0,382 & 0,235 & 0,623 \\
\hline
\end{tabular}

Tabla 22. Análisis del género y el gen ATG2B

Respecto a la asociación de este gen con el resto de variables analizadas, no hemos encontrado diferencias significativas. Los resultados se resumen en la tabla 23. 


\begin{tabular}{|c|c|c|c|c|c|}
\hline \multirow{2}{*}{\multicolumn{2}{|c|}{ Variables Clínicas }} & \multicolumn{3}{|c|}{ Genotipo ATG2B } & \multirow{2}{*}{ p-valor } \\
\hline & & \multirow{2}{*}{$\frac{\text { CC }}{2(15,4 \%)}$} & \multirow{2}{*}{$\frac{\text { CG }}{7(53,8 \%)}$} & \multirow{2}{*}{$\frac{\text { GG }}{4(30,8)}$} & \\
\hline \multirow{3}{*}{ Extensión } & E1 & & & & \multirow{3}{*}{0,828} \\
\hline & E2 & $7(513,7 \%)$ & $21(41,2)$ & $23(45,1 \%)$ & \\
\hline & E3 & 5 & 21 & 24 & \\
\hline \multirow{3}{*}{ Gravedad } & S1 & $7(12,7 \%)$ & $26(47,3 \%)$ & $22(40 \%)$ & \multirow{3}{*}{0,898} \\
\hline & S2 & $5(11,4 \%)$ & $17(38,6 \%)$ & $22(50 \%)$ & \\
\hline & S3 & $2(13,3 \%)$ & $6(40 \%)$ & $7(46,7 \%)$ & \\
\hline \multirow{2}{*}{ Uso GCs } & $\mathrm{Si}$ & $9(11,1 \%)$ & $33(40,7)$ & $39(48,1 \%)$ & \multirow{2}{*}{0,505} \\
\hline & No & $5(15,2 \%$ & $16(48,5 \%)$ & $12(36,4 \%)$ & \\
\hline \multirow{3}{*}{ Respuesta a GCs } & $C D$ & $5(13,5 \%)$ & $16(43,2 \%)$ & $16(43,2 \%)$ & \multirow{3}{*}{0,898} \\
\hline & CR & $1(11,1 \%)$ & $4(44,4 \%)$ & $4(44,4 \%)$ & \\
\hline & Ninguno & $3(8,6 \%)$ & $13(37,1)$ & $19(48,1 \%)$ & \\
\hline \multirow{2}{*}{ Uso AZA } & $\mathrm{Si}$ & $5(12,8 \%)$ & $16(41 \%)$ & $18(46,2)$ & \multirow{2}{*}{0,954} \\
\hline & No & $9(12 \%)$ & 33 (44\%) & $33(44 \%)$ & \\
\hline \multirow{2}{*}{ Uso IFX } & $\mathrm{Si}$ & 0 & $6(66,7 \%)$ & $3(33,3 \%)$ & \multirow{2}{*}{0,333} \\
\hline & No & $14(13,3 \%)$ & $43(41 \%)$ & $48(45,7 \%)$ & \\
\hline \multirow{2}{*}{ Uso CX } & $\mathrm{Si}$ & 0 & $3(37,5 \%$ & $5(62,5 \%)$ & \multirow{2}{*}{0,479} \\
\hline & No & $14(13,2 \%)$ & $46(43,4 \%)$ & $46(43,4 \%)$ & \\
\hline \multirow{2}{*}{ Cirugía } & $\mathrm{Si}$ & $1(8,3 \%)$ & $6(50 \%)$ & $5(41,7 \%)$ & \multirow{2}{*}{0,839} \\
\hline & No & $13(12,7 \%)$ & $43(42,2 \%)$ & $46(45,1 \%)$ & \\
\hline \multirow{2}{*}{ MEI } & $\mathrm{Si}$ & $2(10 \%)$ & 7 (35\%) & $11(55 \%)$ & \multirow{2}{*}{0,596} \\
\hline & No & $12(12,8 \%)$ & $42(44,7 \%)$ & $40(42,6 \%$ & \\
\hline \multirow{2}{*}{ Reservoritis } & $\mathrm{Si}$ & 0 & $2(50 \%)$ & $2(50 \%)$ & \multirow{2}{*}{$>0,99$} \\
\hline & No & 0 & $1(100 \%)$ & 0 & \\
\hline
\end{tabular}

Tabla 23. Asociación del gen ATG2B y las variables clínicas

Respecto a la asociación entre la aparición de complicaciones y el gen ATG2B, se observa que de los tres pacientes con CCR/displasia, los tres tenían al menos un alelo G, (2 eran homocigotos GG), aunque la muestra es muy pequeña para sacar conclusiones. 


\subsection{3) Asociación entre el genotipo ATG16L1, la variante alélica y} susceptibilidad a la enfermedad

Finalmente hemos comparado la frecuencia genotípica del ATG16L1 en pacientes con E. Crohn (gen analizado previamente en un trabajo previo de nuestro grupo llevado a cabo con 101 pacientes con EC) y los comparamos con los resultados obtenidos en nuestra población de pacientes con CU. Como se muestra en la tabla 23, el genotipo CC es discretamente más frecuente en los pacientes con EC que en los pacientes con CU $(39,6 \% \mathrm{vs}$ 33,3\%); sin embargo, estas diferencias no son estadísticamente significativas ( $p$-valor $=0,487$ ) (Tabla 24).

\begin{tabular}{|c|c|c|c|c|}
\hline \multirow{2}{*}{ Gen } & \multirow{2}{*}{ Genotipo } & \multicolumn{2}{|c|}{ Enfermedad } & \multirow{2}{*}{ p-valor } \\
\cline { 3 - 4 } & & EC & CU & \\
\hline \multirow{3}{*}{ ATG16L1 } & TT & $18(17,8 \%)$ & $27(23,7 \%)$ & \\
& TC & $43(42,6 \%)$ & $49(43 \%)$ & 0,487 \\
& CC & $40(39,6)$ & $38(33,3 \%)$ & \\
\hline
\end{tabular}

Tabla 24. Análisis del gen ATG16L1 entre pacientes con CU y EC 
10) DISCUSIÓN 
La etiopatogenia de la Ell sigue siendo desconocida, pero es casi con toda seguridad de naturaleza multifactorial, influyendo la predisposición genética, los factores ambientales y una respuesta inmune mal regulada a la microflora intestinal. Los estudios de asociación genómica (GWAS) han identificado genes que participan a través de diferentes mecanismos en la patogenia de la Ell; uno de estos mecanismos es el proceso de autofagia, involucrado en varias etapas de la respuesta inmunológica. De hecho un defecto en la autofagia se ha vinculado a la patogénesis de la Ell.

De los genes relacionados con la autofagia, disponemos de datos que relacionan determinados polimorfismos del gen ATG16L1 con la Enfermedad de Crohn [142, 166-168]; sin embargo, aunque algunos estudios describen una asociación modesta con la CU, ésta no ha sido confirmada de forma definitiva[156, 169]

Hasta el momento no existen estudios que analicen la asociación entre Ell y otros genes distintos a ATG16L1 que participan en el proceso de autofagia en la patogénesis de la CU, tales como ATG2B, ATG5 y ATG10.

En nuestro estudio hemos seleccionado los genes ATG5, ATG10 y ATG16L1 porque codifican proteínas que participan en la conjugación del complejo ATG5 - ATG12- ATG16L1, mientras que ATG2B es necesario en el aislamiento de membranas que forman el autofagosoma.

En este estudio hemos analizado si los polimorfismos ATG2B rs3759601, ATG10 rs1864183, ATG16L1 rs2241880 y ATG5 rs2245214 juegan algún papel en el desarrollo de la CU en nuestro medio. Tres de los cuatro polimorfismos estudiados son cambios "missense", que suponen cambios en la secuencia de aminoácidos de las respectivas proteínas (ATG2B rs3759601, ATG10 rs1864183 y ATG16L1 rs2241880), mientras que el polimorfismo ATG5 rs2245214 es intrónico. 
También analizamos si existía asociación entre el polimorfismo ATG2B y el riesgo de desarrollar CU; así como con distintas características clínicas estudiadas en nuestra cohorte de pacientes.

\section{1) ASPECTOS CLÍNICOS}

Las características demográficas y clínicas de los pacientes con CU incluidos en nuestro trabajo tienen un comportamiento similar a otras poblaciones. Nuestra cohorte está compuesta por pacientes relativamente jóvenes, con una edad media al diagnóstico de 37,7 años, similar a estudios epidemiológicos que describen un rango de edad entre 30-40 años [20]. La edad media de los pacientes en el momento de la inclusión en el estudio fue de 52,9 años, ligeramente superior a lo descrito en otras series; esto se debería a que el inicio de recoleción de muestras se realizó hace más de 20 años. Hay un discreto predominio del género masculino, sin diferencias significativas, similar a lo descrito en otros estudios [20]. Respecto a los antecedentes familiares, el $13 \%$ de nuestra población tenía algún familiar de primer o segundo grado con Ell, lo que concuerda con lo descrito en la literatura, donde se habla de una frecuencia del 8-14\% [4, 28], sin que ello tenga influencia en el fenotipo o curso de la enfermedad. Las MEI se presentaron en el $17,5 \%$, y han sido las manifestaciones músculo esqueléticas las más frecuentes, como se describe en otros estudios, donde la artropatía representa hasta el 75\% de las MEI [170]. La frecuencia de no fumadores supera a la de ex fumadores y a la de fumadores; el porcentaje de fumadores en nuestro estudio no superaba el $10 \%$, por lo cual la influencia del tabaco en esta muestra no se puede analizar. Hay un sesgo al incluir sólo pacientes con CU que podría explicar esta observación.

La extensión de la enfermedad se ajusta a lo descrito en otras poblaciones, con un predominio de colitis izquierda $(44,7 \%)$ y porcentaje ligeramente superior de pancolitis $(43,9 \%)[22,171]$. Éstos hallazgos 
podrían estar en relación con el tiempo transcurrido desde el diagnóstico hasta el momento de registro, en la mayoría de los pacientes (algunos más de 20 años), ya que durante el curso de la enfermedad, la extensión proximal de la inflamación progresa, y con el paso del tiempo alrededor del $50 \%$ de los pacientes tienen pancolitis [172]. El 13\% de los pacientes presentaron enfermedad grave y más del 50\% requirieron ingresos hospitalarios en algún momento de la enfermedad. El porcentaje de pacientes que precisaron colectomía fue del $11 \%$, bien por resistencia al tratamiento médico bien por la aparición de complicaciones, porcentaje que concuerda con series más extensas que describen un porcentaje de colectomía en 10 años de seguimiento de un 9,8\%[173]. El 80\% de pacientes que tenía reservorio, presentó reservoritis y uno de ellos tuvo que ser operado por imposibilidad de control médico con hemorragia grave. En la literatura se describe hasta un $10 \%$ de pacientes con reservoritis refractaria a antibióticos, necesidad de inmunosupresión o cirugía [93]. La prevalencia de displasia y/o CCR fue baja, del 2,6\%.

En nuestra población, el número de pacientes que necesitaron corticoides o inmunosupresores (azatioprina), así como el uso de corticoides en el primer brote ha sido similar al de otros estudios que incluyeron un mayor número de pacientes, como el de Riegler [174] con una "n" de 1705. No obstante, puede que la muestra estudiada tenga un sesgo de selección por inclusión de formas más agresivas que las que representaría el total de nuestra población con CU. El número de pacientes que desarrollaron corticodependencia o corticorrefractariedad también ha sido similar a lo descrito en otras series [175].

La extensión de la CU tiene influencia en el curso clínico y el pronóstico de la enfermedad. Como en las series analizadas, en nuestra muestra, los pacientes con colitis extensa han sido los más necesitados de terapias intensivas o incluso colectomía [176], con diferencias significativas en 
cuanto al uso de corticoides, inmunomoduladores y necesidad de cirugía. El uso de biológicos es poco valorable en este estudio por el bajo número de pacientes con estos fármacos.

Comprobamos en nuestro estudio que la presencia de MEI se asocia a un peor pronóstico y a una mayor extensión de la enfermedad[177]; el 32\% de los pacientes con pancolitis tenían MEI.

Como era de suponer, encontramos una asociación estadísticamente significativa entre la gravedad de la enfermedad y el uso de tratamiento corticoideo, inmunomodulador, biológico o la necesidad de cirugía. Sin embargo, a diferencia de otros estudios, no encontramos asociación entre el hábito tabáquico con el fenotipo de la enfermedad o con la respuesta a tratamientos, lo cual, como hemos señalado anteriormente, puede ser atribuible al escaso número de fumadores y al tamaño muestral.

\section{2) ESTUDIO DE POLIMORFISMOS}

\section{ATG5}

Este gen codifica una proteína que forma parte del complejo ATG5ATG16L1-ATG12, fundamental en la formación del autofagosoma. Su asociación con la Ell parece estar en relación con su acción a nivel de las células de Paneth, célula especializada, cuya función principal es liberar factores antimicrobianos contenidos en gránulos citoplasmáticos en el lumen intestinal; una alteración en el proceso de autofagia en las células de Paneth se asocia a un incremento en la respuesta inflamatoria [153]. Otra función a nivel intestinal está en relación con la regulación de los niveles de IgA. Se ha demostrado que linfocitos B carentes de ATG5 presentan niveles bajos de IgA en el lumen intestinal en respuesta a colitis inducida, lo que contribuiría a la inflamación intestinal [151]. Recientemente, se ha realizado un estudio en pacientes con EC que evalúa la función del gen ATG5 como potencial predictor de la respuesta a adalimumab. El análisis 
mostró que los polimorfismos SNPs rs9373839 y rs510432 del gen ATG5 se asociaron con la respuesta positiva a este fármaco [178].Este gen ha sido estudiado en una cohorte de pacientes con CCR. Tras el análisis inmunohistoquímico de tejidos con CCR se detectó que el aumento de la expresión ATG5 está asociada con la invasión linfovascular ( $p=0,035$ ) y según estos resultados, el gen ATG5 podría ser un potencial biomarcador de pronóstico o diagnóstico [179].

Hasta el momento aún no se han realizado estudios que analicen el rol del ATG5 en la CU. Nosotros analizamos el polimorfismo ATG5 rs2245214 y su asociación con la CU. Nuestros resultados no muestran diferencias significativas en la distribución de los genotipos del polimorfismo ATG5 rs2245214 entre pacientes con CU y controles. En nuestro estudio, el genotipo más frecuente en ambos grupos fue el heterocigoto $C G$, con un porcentaje de $48,2 \%$ en pacientes con CU y $48,1 \%$ en el grupo control respectivamente. Sin embargo; pensamos que su asociación con la Ell no debería ser descartada pues como hemos mencionado anteriormente, el gen ATG5 es un determinante en el funcionamiento de las células de Paneth que como sabemos es un punto clave en la patogenia de la EC; por ello podría ser de interés realizar nuevos estudios que analicen su asociación con la EC.

\section{ATG2B}

ATG2B es un gen esencial para la formación del autofagosoma e importante para la regulación del tamaño y la distribución de gotitas de lípidos y en el aislamiento de la membrana del autofagosoma. Se ha descrito la asociación de este gen con varios tipos de neoplasias malignas, entre ellos el cáncer gástrico, el CCR, el cáncer de pulmón y neoplasias mieloides [160-162, 180]. La sobreexpresión del mismo sería responsable de la progresión tumoral, de forma que sería un factor con valor pronóstico 
y pasaría a ser considerado como una diana terapéutica. Aún no se han realizado estudios que hayan analizado su asociación con la Ell; éste es el primer estudio que investiga el polimorfismo rs3759601 del gen ATG2B y su posible asociación con la CU.

Nuestros resultados muestran una significativa frecuencia del genotipo GG del gen ATG2B en pacientes con CU comparado con el grupo control (44.7\% vs $14,8 \% \%)$. El alelo $G$ fue más frecuente en los casos con un $43,9 \%$ y el alelo $\mathrm{C}$ en el grupo control con un $81,3 \%$. En el estudio de codominancia recesiva observamos que ser portador del alelo $G$ (genotipos CG+GG) del polimorfismo ATG2B rs3759601 es más frecuente en los pacientes que en los controles. Tener el genotipo GG aumenta más de 10 veces el riesgo de desarrollar CU que ser portador del genotipo CC y es 3 veces más que el genotipo CG. Sería interesante analizar la distribución del polimorfismo ATG2B en pacientes con EC $\mathrm{y}$ determinar si también constituye factor de riesgo en esta enfermedad.

\section{ATG16L1}

ATG16L1 es un gen que codifica una proteína relacionada a otras dos proteínas de la autofagia, ATG5 y ATG12, para formar un complejo esencial para el proceso de autofagia. La función específica de ATG16L1 en estos procesos sigue siendo poco claro. ATG16L1 se expresa no sólo en las células epiteliales del intestino, sino que también se expresa en los linfocitos y macrófagos. Desde que se identificó por primera la asociación del polimorfismo rs2241880 del gen ATG16L1 con la EC pero no con la CU (Hampe et al), muchos estudios han tratado de verificar esta asociación con resultados inconsistentes, especialmente en lo relativo a la relación entre ATG16L1 y CU.

En un metaanálisis que incluye 25 estudios, se demostró una asociación significativa entre el alelo G de ATG16L1 y la susceptibilidad de 
padecer EC (OR = 1,32; IC del $95 \%$ : 1,26 a 1,39; $p<0,00001)$, y también se detectó una asociación positiva con el riego de padecer $\mathrm{CU}$. $(\mathrm{OR}=1.06$, 95\% Cl: 1.01-1.10, $\mathrm{P}=0.02) \cdot[156]$

Otro metaanálisis mostró la fuerte asociación entre el polimorfismo rs2241889 del gen ATG16L1 con la EC, pero muy pequeña aunque estadísticamente significativa con la CU [169].

En nuestro estudio, el genotipo más frecuente en ambos grupos ha sido el heterocigoto TC, pero sin diferencias significativas. Este porcentaje ha sido discretamente mayor en el grupo control que en el grupo de pacientes con $\mathrm{CU}(53,3 \%$ vs $43 \%)$.

Podemos concluir que en nuestra serie no hemos encontrado diferencias significativas en la distribución de los genotipos del polimorfismo ATG16L1 rs2241880 entre pacientes con CU y controles, lo que confirma lo descrito en otros estudios.

\section{ATG10}

Este gen codifica una proteína ligasa de tipo E2 que es esencial para la formación del complejo Atg12-Atg5-Atg16L1. Las mutaciones de ATG7 y ATG10 evitarían la formación del conjugado ATG12-ATG5. Se han realizado estudios analizando su asociación en determinado tipo de tumores. Un estudio demostró la asociación de este gen con el CCR: la expresión ATG10 está fuertemente asociada a la invasión tumoral y al desarrollo de metástasis [163]. También se han realizado estudios en cohortes de pacientes con Enfermedad de Paget (EP), donde tendría un efecto protector[164]. Su asociación con la Ell aún no ha sido investigada.

En nuestro estudio, el genotipo heterocigoto CT es el más frecuente entre los pacientes con $\mathrm{CU}(51,8 \%)$ y en el grupo control $(57,2 \%)$, pero sin significación estadística $(p=0,4)$, por lo que el polimorfismo rs1864183 del gen ATG10 no se asocia a al desarrollo de la CU. 
Finalmente, Hemos analizado también las distribuciones del polimorfismo ATG16L1 rs2241880 entre la cohorte de pacientes con EC (estudio previo de nuestro grupo) y la cohorte de CU; se observa que el genotipo heterocigoto TC es el más frecuente en pacientes con CU y EC ( $43 \%$ VS 42,6\%); y el genotipo homocigoto CC es más frecuente en pacientes con EC $(39,6 \%)$ respecto a los pacientes con CU $(33,3 \%)$; a pesar de estas diferencias en porcentaje, no existen diferencias estadísticamente significativas en la distribución genotípica del polimorfismo en ambos grupos.

\section{3) ESTUDIO DE VARIABLES CLÍNICAS Y POLIMORFISMOS}

En el estudio de la distribución de los genotipos de los polimorfismos ATG2B rs3759601, ATG10 rs1864183, ATG16L1 rs2241880 y ATG5 rs2245214 respecto a las diferentes características clínicas (fenotipo de la enfermedad, tratamiento, respuesta al tratamiento y necesidad de cirugía) no se encontraron diferencias estadísticamente significativas. Estos resultados sugieren que las alteraciones en la autofagia pueden ser importantes en la patogenia de la CU pero probablemente no condicionan las manifestaciones clínicas, la respuesta a tratamientos o el comportamiento de la enfermedad.

Finalmente, como hemos comentado, se ha descrito en la literatura la asociación del gen ATG2B con tumores gastrointestinales. Hemos observado que de los 3 pacientes que desarrollaron displasia/CCR, 2 de ellos eran homocigotos GG y otro heterocigoto; es decir, que los tres pacientes tenían al menos un alelo $\mathrm{G}$ de este gen. Ésto abre una nueva área en el estudio del CCR y la Ell; son necesarios futuros estudio para evaluar el efecto causal del gen ATG2B en el desarrollo de CCR/displasia en pacientes con CU. 


\section{1) CONCLUSIONES}


Las características clínico-terapéuticas de nuestra serie son similares a las descritas en otras poblaciones con Colitis Ulcerosa.

En este trabajo hemos analizado por primera vez la implicación de los genes ATG2B, ATG5, ATG16L1 y ATG10, relacionados con la autofagia en la CU. Nuestros resultados describen por primera vez la implicación del gen ATG2B en la susceptibilidad para la CU:

Ser portador del alelo G del gen ATG2B (rs3759601) confiere susceptibilidad para el desarrollo de CU, lo cual confirma que la alteración de la autofagia desempeña un importante papel en el desarrollo de esta enfermedad y podría ser una posible diana terapéutica.

Los polimorfismos genéticos de genes ATG5, ATG10 y ATG16L1 no parecen estar asociados al desarrollo de CU.

No hemos encontrado asociación entre los distintos SNPs con el comportamiento de la enfermedad ni con la respuesta a las distintas terapias utilizadas.

Ponemos de manifiesto que, a pesar de que determinados polimorfismos del gen ATG2B se asocian con la susceptibilidad para padecer CU, no influyen en las características fenotípicas de la enfermedad o en la respuesta a tratamientos. Esto se debe confirmar en futuros estudios para precisar cuál es su verdadera influencia. 


\section{2) LIMITACIONES}


El tamaño limitado de la muestra podría haber sido insuficiente para revelar la relación genotipo-fenotipo, por lo que se deberían realizar estudios ampliando el tamaño de la muestra para que la asociación sea corroborada.

Finalmente, al ser un estudio de casos y controles hospitalario el sesgo de selección no se puede evitar y los sujetos pueden no ser representativos de la población general. 


\section{BIBLIOGRAFÍA}


1. Collins, F.S., et al., A vision for the future of genomics research. Nature, 2003. 422(6934): p. 835-47.

2. Barnes, M.R., Predictive Functional Analysis of Polymorphisms: An Overview, in Bioinformatics for Geneticists. 2003, John Wiley \& Sons, Ltd. p. 247-271.

3. Sripichai, O. and S. Fucharoen, Genetic polymorphisms and implications for human diseases. J Med Assoc Thai, 2007. 90(2): p. 394-8.

4. Ananthakrishnan, A.N., Epidemiology and risk factors for IBD. Nat Rev Gastroenterol Hepatol, 2015. 12(4): p. 205-217.

5. Abraham, C. and J.H. Cho, Inflammatory Bowel Disease. New England Journal of Medicine, 2009. 361(21): p. 2066-2078.

6. Feuerstein, J.D. and A.S. Cheifetz, Ulcerative colitis: epidemiology, diagnosis, and management. Mayo Clin Proc, 2014. 89(11): p. 1553-63.

7. Ek, W.E., M. D'Amato, and J. Halfvarson, The history of genetics in inflammatory bowel disease. Ann Gastroenterol, 2014. 27(4): p. 294-303.

8. Kabi, A., et al., Digesting the genetics of inflammatory bowel disease: insights from studies of autophagy risk genes. Inflamm Bowel Dis, 2012. 18(4): p. 78292.

9. Jiang, P. and N. Mizushima, Autophagy and human diseases. Cell Res, 2014. 24(1): p. 69-79.

10. Geremia, A., et al., Innate and adaptive immunity in inflammatory bowel disease. Autoimmun Rev, 2014. 13(1): p. 3-10.

11. Molodecky, N.A., et al., Increasing incidence and prevalence of the inflammatory bowel diseases with time, based on systematic review. Gastroenterology, 2012. 142(1): p. 46-54 e42; quiz e30.

12. Burisch, J. and P. Munkholm, Inflammatory bowel disease epidemiology. Curr Opin Gastroenterol, 2013. 29(4): p. 357-62.

13. Appleyard, C.B., G. Hernandez, and C.F. Rios-Bedoya, Basic epidemiology of inflammatory bowel disease in Puerto Rico. Inflamm Bowel Dis, 2004. 10(2): p. 106-11.

14. Thia, K.T., et al., An update on the epidemiology of inflammatory bowel disease in Asia. Am J Gastroenterol, 2008. 103(12): p. 3167-82.

15. Fernández, A., et al., Incidence and phenotype at diagnosis of inflammatory bowel disease. Results in Spain of the EpiCom study. Gastroenterología y Hepatología, 2015. Vol. 38(5).

16. Evans, J.G., Trends in mortality from ulcerative colitis in England and Wales. Gut, 1971. 12(2): p. 119-22.

17. Jess, T., M. Frisch, and J. Simonsen, Trends in overall and cause-specific mortality among patients with inflammatory bowel disease from 1982 to 2010. Clin Gastroenterol Hepatol, 2013. 11(1): p. 43-8.

18. Jess, T., et al., Overall and cause-specific mortality in ulcerative colitis: metaanalysis of population-based inception cohort studies. Am J Gastroenterol, 2007. 102(3): p. 609-17. 
19. Palli, D., et al., General and cancer specific mortality of a population based cohort of patients with inflammatory bowel disease: the Florence study. Gut, 1998. 42(2): p. 175-179.

20. Cosnes, J., et al., Epidemiology and natural history of inflammatory bowel diseases. Gastroenterology, 2011. 140(6): p. 1785-94.

21. Ng, S.C., Epidemiology of inflammatory bowel disease: focus on Asia. Best Pract Res Clin Gastroenterol, 2014. 28(3): p. 363-72.

22. Molinie, F., et al., Opposite evolution in incidence of Crohn's disease and ulcerative colitis in Northern France (1988-1999). Gut, 2004. 53(6): p. 843-8.

23. Sartor, R.B., Mechanisms of Disease: pathogenesis of Crohn's disease and ulcerative colitis. Nat Clin Pract Gastroenterol Hepatol, 2006. 3(7): p. 390407.

24. Tian, C., A. Kabi, and C. McDonald, Role of Autophagy-Related Genes in the Pathology of Inflammatory Bowel Disease, in eLS. 2001, John Wiley \& Sons, Ltd.

25. Moller, F.T., et al., Familial Risk of Inflammatory Bowel Disease: A PopulationBased Cohort Study 1977-2011. Am J Gastroenterol, 2015. 110(4): p. 564-571.

26. Peeters, M., et al., Familial and sporadic inflammatory bowel disease: different entities? Inflamm Bowel Dis, 2000. 6(4): p. 314-20.

27. Halme, L., et al., Familial and sporadic inflammatory bowel disease: comparison of clinical features and serological markers in a genetically homogeneous population. Scand J Gastroenterol, 2002. 37(6): p. 692-8.

28. Henriksen, M., et al., Are there any differences in phenotype or disease course between familial and sporadic cases of inflammatory bowel disease? Results of a population-based follow-up study. Am J Gastroenterol, 2007. 102(9): p. 1955-63.

29. Fiocchi, C., Inflammatory bowel disease pathogenesis: Where are we? J Gastroenterol Hepatol, 2015. 30 Suppl S1: p. 12-18.

30. Radon, K., et al., Contact with farm animals in early life and juvenile inflammatory bowel disease: a case-control study. Pediatrics, 2007. 120(2): p. 354-61.

31. Sood, A., et al., Low hygiene and exposure to infections may be associated with increased risk for ulcerative colitis in a North Indian population. Ann Gastroenterol, 2014. 27(3): p. 219-223.

32. Mahid, S.S., et al., Smoking and inflammatory bowel disease: a meta-analysis. Mayo Clin Proc, 2006. 81(11): p. 1462-71.

33. Cosnes, J., What is the link between the use of tobacco and IBD? Inflammatory Bowel Diseases, 2008. 14(S2): p. S14-S15.

34. Parkes, G.C., K. Whelan, and J.O. Lindsay, Smoking in inflammatory bowel disease: impact on disease course and insights into the aetiology of its effect. J Crohns Colitis, 2014. 8(8): p. 717-25. 
35. Domènech, E., et al., Smoking status and response to thiopurines in steroiddependent inflammatory bowel disease. Inflammatory Bowel Diseases, 2011. 17(4): p. 971-975.

36. Ananthakrishnan, A.N., Environmental Risk Factors for Inflammatory Bowel Disease. Gastroenterology \& Hepatology, 2013. 9(6): p. 367-374.

37. Biedermann, L., et al., Smoking cessation alters intestinal microbiota: insights from quantitative investigations on human fecal samples using FISH. Inflamm Bowel Dis, 2014. 20(9): p. 1496-501.

38. McGilligan, V.E., et al., Hypothesis about mechanisms through which nicotine might exert its effect on the interdependence of inflammation and gut barrier function in ulcerative colitis. Inflamm Bowel Dis, 2007. 13(1): p. 108-15.

39. Hatoum, O.A., J. Heidemann, and D.G. Binion, The intestinal microvasculature as a therapeutic target in inflammatory bowel disease. Ann N Y Acad Sci, 2006. 1072: p. 78-97.

40. Andersson, R.E., et al., Appendectomy and protection against ulcerative colitis. N Engl J Med, 2001. 344(11): p. 808-14.

41. Rutgeerts, P., et al., Appendectomy protects against ulcerative colitis. Gastroenterology, 1994. 106(5): p. 1251-3.

42. Koutroubakis, I.E., I.G. Vlachonikolis, and E.A. Kouroumalis, Role of appendicitis and appendectomy in the pathogenesis of ulcerative colitis: a critical review. Inflamm Bowel Dis, 2002. 8(4): p. 277-86.

43. Galvez, J., M.E. Rodriguez-Cabezas, and A. Zarzuelo, Effects of dietary fiber on inflammatory bowel disease. Mol Nutr Food Res, 2005. 49(6): p. 601-8.

44. Roberts, C.L., et al., Translocation of Crohn's disease Escherichia coli across M-cells: contrasting effects of soluble plant fibres and emulsifiers. Gut, 2010. 59(10): p. 1331-9.

45. Ananthakrishnan, A.N., et al., A prospective study of long-term intake of dietary fiber and risk of Crohn's disease and ulcerative colitis. Gastroenterology, 2013. 145(5): p. 970-7.

46. Costea, I., et al., Interactions between the dietary polyunsaturated fatty acid ratio and genetic factors determine susceptibility to pediatric Crohn's disease. Gastroenterology, 2014. 146(4): p. 929-31.

47. Mouli, V.P. and A.N. Ananthakrishnan, Review article: vitamin $D$ and inflammatory bowel diseases. Aliment Pharmacol Ther, 2014. 39(2): p. 12536.

48. Kostic, A.D., R.J. Xavier, and D. Gevers, The microbiome in inflammatory bowel disease: current status and the future ahead. Gastroenterology, 2014. 146(6): p. 1489-99.

49. Manichanh, C., et al., The gut microbiota in IBD. Nat Rev Gastroenterol Hepatol, 2012. 9(10): p. 599-608.

50. Sheehan, D., C. Moran, and F. Shanahan, The microbiota in inflammatory bowel disease. Journal of Gastroenterology, 2015. 50(5): p. 495-507. 
51. Martinez, C., et al., Unstable composition of the fecal microbiota in ulcerative colitis during clinical remission. Am J Gastroenterol, 2008. 103(3): p. 643-8.

52. Sasaki, M. and J.-M.A. Klapproth, The Role of Bacteria in the Pathogenesis of Ulcerative Colitis. Journal of Signal Transduction, 2012. 2012: p. 6.

53. Kernbauer, E., Y. Ding, and K. Cadwell, An enteric virus can replace the beneficial function of commensal bacteria. Nature, 2014. 516(7529): p. 94-8.

54. Ott, S.J., et al., Fungi and inflammatory bowel diseases: Alterations of composition and diversity. Scand J Gastroenterol, 2008. 43(7): p. 831-41.

55. Li, Q., et al., Dysbiosis of Gut Fungal Microbiota is Associated With Mucosal Inflammation in Crohn's Disease. Journal of Clinical Gastroenterology, 2014. 48(6): p. 513-523.

56. Ordás, I., et al., Ulcerative colitis. The Lancet, 2012. 380(9853): p. 1606-1619.

57. Frank, D.N., et al., Disease phenotype and genotype are associated with shifts in intestinal-associated microbiota in inflammatory bowel diseases. Inflamm Bowel Dis, 2011. 17(1): p. 179-84.

58. Ananthakrishnan, A.N., M. Issa, and D.G. Binion, Clostridium difficile and inflammatory bowel disease. Gastroenterol Clin North Am, 2009. 38(4): p. 711-28.

59. Garcia Rodriguez, L.A., A. Ruigomez, and J. Panes, Acute gastroenteritis is followed by an increased risk of inflammatory bowel disease. Gastroenterology, 2006. 130(6): p. 1588-94.

60. Wallace, K.L., et al., Immunopathology of inflammatory bowel disease. World J Gastroenterol, 2014. 20(1): p. 6-21.

61. Van Klinken, B.J., et al., Sulphation and secretion of the predominant secretory human colonic mucin MUC2 in ulcerative colitis. Gut, 1999. 44(3): p. 387-93.

62. Antoni, L., et al., Intestinal barrier in inflammatory bowel disease. World Journal of Gastroenterology: WJG, 2014. 20(5): p. 1165-1179.

63. Laukoetter, M.G., P. Nava, and A. Nusrat, Role of the intestinal barrier in inflammatory bowel disease. World J Gastroenterol, 2008. 14(3): p. 401-7.

64. Heller, F., et al., Interleukin-13 is the key effector Th2 cytokine in ulcerative colitis that affects epithelial tight junctions, apoptosis, and cell restitution. Gastroenterology, 2005. 129(2): p. 550-64.

65. Nunes, T., C. Bernardazzi, and H.S. de Souza, Cell death and inflammatory bowel diseases: apoptosis, necrosis, and autophagy in the intestinal epithelium. Biomed Res Int, 2014. 2014: p. 218493.

66. Rahman, A., et al., Beta-defensin production by human colonic plasma cells: a new look at plasma cells in ulcerative colitis. Inflamm Bowel Dis, 2007. 13(7): p. 847-55.

67. Cario, E. and D.K. Podolsky, Differential alteration in intestinal epithelial cell expression of toll-like receptor 3 (TLR3) and TLR4 in inflammatory bowel disease. Infect Immun, 2000. 68(12): p. 7010-7. 
68. Zhang, F.X., et al., Bacterial lipopolysaccharide activates nuclear factorkappaB through interleukin-1 signaling mediators in cultured human dermal endothelial cells and mononuclear phagocytes. J Biol Chem, 1999. 274(12): p. 7611-4.

69. Hart, A.L., et al., Characteristics of intestinal dendritic cells in inflammatory bowel diseases. Gastroenterology, 2005. 129(1): p. 50-65.

70. Shih, D., S. Targan, and D. McGovern, Recent advances in IBD pathogenesis: Genetics and immunobiology. Current Gastroenterology Reports, 2008. 10(6): p. 568-575.

71. Heller, F., et al., Epithelial apoptosis is a prominent feature of the epithelial barrier disturbance in intestinal inflammation: effect of pro-inflammatory interleukin-13 on epithelial cell function. Mucosal Immunol, 2008. 1(1s): p. S58-S61.

72. Danese, S. and C. Fiocchi, Ulcerative Colitis. New England Journal of Medicine, 2011. 365(18): p. 1713-1725.

73. Diaz Pena, R., et al., Th17 response and autophagy - main pathways implicated in the development of inflammatory bowel disease by genomewide association studies. Rev Esp Enferm Dig, 2015. 107(9): p. 560-566.

74. Lennard-Jones, J.E., Classification of inflammatory bowel disease. Scand J Gastroenterol Suppl, 1989. 170: p. 2-6; discussion 16-9.

75. Fakhoury, M., et al., Inflammatory bowel disease: clinical aspects and treatments. J Inflamm Res, 2014. 7: p. 113-20.

76. Dignass, A., et al., Second European evidence-based consensus on the diagnosis and management of ulcerative colitis Part 1: Definitions and diagnosis. Journal of Crohn's and Colitis, 2012. 6(10): p. 965-990.

77. Satsangi, J., et al., The Montreal classification of inflammatory bowel disease: controversies, consensus, and implications. Gut, 2006. 55(6): p. 749-753.

78. da Silva, B.C., et al., Epidemiology, demographic characteristics and prognostic predictors of ulcerative colitis. World Journal of Gastroenterology : WJG, 2014. 20(28): p. 9458-9467.

79. Truelove, S.C. and L.J. Witts, Cortisone in Ulcerative Colitis. British Medical Journal, 1955. 2(4947): p. 1041-1048.

80. Seo, M., et al., An index of disease activity in patients with ulcerative colitis. Am J Gastroenterol, 1992. 87(8): p. 971-6.

81. Walmsley, R.S., et al., A simple clinical colitis activity index. Gut, 1998. 43(1): p. 29-32.

82. Lichtiger, S., et al., Cyclosporine in severe ulcerative colitis refractory to steroid therapy. N Engl J Med, 1994. 330(26): p. 1841-5.

83. D'Haens, G., et al., A review of activity indices and efficacy end points for clinical trials of medical therapy in adults with ulcerative colitis. Gastroenterology, 2007. 132(2): p. 763-86. 
84. Travis, S.P., et al., European evidence-based Consensus on the management of ulcerative colitis: Current management. J Crohns Colitis, 2008. 2(1): p. 2462.

85. Gomollón, F., et al., Guía clínica GETECCU del tratamiento de la colitis ulcerosa elaborada con la metodología GRADE. Gastroenterología y Hepatología, 2013. 36(8): p. e1-e47.

86. Hooper, K.M., et al., Inflammatory bowel disease drugs: $A$ focus on autophagy. Journal of Crohn's and Colitis, 2016.

87. Sandborn, W.J. and S.B. Hanauer, Systematic review: the pharmacokinetic profiles of oral mesalazine formulations and mesalazine pro-drugs used in the management of ulcerative colitis. Aliment Pharmacol Ther, 2003. 17(1): p. 2942.

88. Safdi, M., et al., A double-blind comparison of oral versus rectal mesalamine versus combination therapy in the treatment of distal ulcerative colitis. Am J Gastroenterol, 1997. 92(10): p. 1867-71.

89. Langholz, E., et al., Course of ulcerative colitis: analysis of changes in disease activity over years. Gastroenterology, 1994. 107(1): p. 3-11.

90. Moss, A.C., Optimizing the use of biological therapy in patients with inflammatory bowel disease. Gastroenterol Rep (Oxf), 2015. 3(1): p. 63-8.

91. Randall, J., et al., Delayed surgery for acute severe colitis is associated with increased risk of postoperative complications. Br J Surg, 2010. 97(3): p. 404-9.

92. Moum, B., et al., Change in the extent of colonoscopic and histological involvement in ulcerative colitis over time. Am J Gastroenterol, 1999. 94(6): p. 1564-1569.

93. Shen, B., et al., Comprehensive Evaluation of Inflammatory and Noninflammatory Sequelae of Ileal Pouch-Anal Anastomoses. Am J Gastroenterol, 2005. 100(1): p. 93-101.

94. Jostins, L., et al., Host-microbe interactions have shaped the genetic architecture of inflammatory bowel disease. Nature, 2012. 491(7422): p. 119124.

95. Liu, J.Z., et al., Association analyses identify 38 susceptibility loci for inflammatory bowel disease and highlight shared genetic risk across populations. Nature genetics, 2015. 47(9): p. 979-986.

96. Cleynen, I., et al., Inherited determinants of Crohn's disease and ulcerative colitis phenotypes: a genetic association study. The Lancet.

97. Sarlos, P., et al., Genetic update on inflammatory factors in ulcerative colitis: Review of the current literature. World J Gastrointest Pathophysiol, 2014. 5(3): p. 304-21.

98. Ventham, N.T., et al., Beyond gene discovery in inflammatory bowel disease: the emerging role of epigenetics. Gastroenterology, 2013. 145(2): p. 293-308.

99. Ek, W.E., M. D'Amato, and J. Halfvarson, The history of genetics in inflammatory bowel disease. Ann Gastroenterol, 2014. 27(4): p. 294-303. 
100. Zhang, J.X., et al., JAK2 rs10758669 polymorphisms and susceptibility to ulcerative colitis and Crohn's disease: a meta-analysis. Inflammation, 2014. 37(3): p. 793-800.

101. Lakatos, P.L., et al., Current concept on the pathogenesis of inflammatory bowel disease-crosstalk between genetic and microbial factors: Pathogenic bacteria and altered bacterial sensing or changes in mucosal integrity take "toll". World Journal of Gastroenterology: WJG, 2006. 12(12): p. 1829-1841.

102. Noomen, C.G., D.W. Hommes, and H.H. Fidder, Update on genetics in inflammatory disease. Best Pract Res Clin Gastroenterol, 2009. 23(2): p. 23343.

103. Cario, E., Toll-like receptors in inflammatory bowel diseases: A decade later. Inflammatory Bowel Diseases, 2010. 16(9): p. 1583-1597.

104. Múzes, G., et al., Changes of the cytokine profile in inflammatory bowel diseases. World Journal of Gastroenterology: WJG, 2012. 18(41): p. 58485861.

105. Parkes, M., J. Satsangi, and D. Jewell, Contribution of the IL-2 and IL-10 genes to inflammatory bowel disease (IBD) susceptibility. Clinical and Experimental Immunology, 1998. 113(1): p. 28-32.

106. Takac, B., et al., Importance of interleukin 6 in pathogenesis of inflammatory bowel disease. Coll Antropol, 2014. 38(2): p. 659-64.

107. Mitsuyama, K., et al., IL-8 as an important chemoattractant for neutrophils in ulcerative colitis and Crohn's disease. Clin Exp Immunol, 1994. 96(3): p. 432-6.

108. Li, K., et al., Genetic polymorphisms of interleukin 8 and risk of ulcerative colitis in the Chinese population. Clin Chim Acta, 2009. 405(1-2): p. 30-4.

109. Franke, A., et al., Sequence variants in IL10, ARPC2 and multiple other loci contribute to ulcerative colitis susceptibility. Nat Genet, 2008. 40(11): p. 1319-23.

110. Thompson, A.I. and C.W. Lees, Genetics of ulcerative colitis. Inflamm Bowel Dis, 2011. 17(3): p. 831-48.

111. Vignali, D.A.A. and V.K. Kuchroo, IL-12 Family Cytokines: Immunological Playmakers. Nature immunology, 2012. 13(8): p. 722-728.

112. Glas, J., et al., Analysis of IL12B Gene Variants in Inflammatory Bowel Disease. PLoS ONE, 2012. 7(3): p. e34349.

113. Magyari, L., et al., Interleukin and interleukin receptor gene polymorphisms in inflammatory bowel diseases susceptibility. World J Gastroenterol, 2014. 20(12): p. 3208-22.

114. Arisawa, T., et al., The influence of polymorphisms of interleukin-17A and interleukin-17F genes on the susceptibility to ulcerative colitis. J Clin Immunol, 2008. 28(1): p. 44-9.

115. Aizawa, Y., et al., Association of interleukin-18 gene single-nucleotide polymorphisms with susceptibility to inflammatory bowel disease. Tissue Antigens, 2005. 65(1): p. 88-92. 
116. El-Bassat, H., et al., Interleukin-23p19 expression in patients with ulcerative colitis and its relation to disease severity. Advances in Digestive Medicine.

117. McCole, D.F., IBD candidate genes and intestinal barrier regulation. Inflamm Bowel Dis, 2014. 20(10): p. 1829-49.

118. van Sommeren, S., et al., HNF4alpha and $C D H 1$ are associated with ulcerative colitis in a Dutch cohort. Inflamm Bowel Dis, 2011. 17(8): p. 1714-8.

119. Zhang, Y.Z. and Y.Y. Li, Inflammatory bowel disease: pathogenesis. World J Gastroenterol, 2014. 20(1): p. 91-9.

120. Deretic, V., T. Saitoh, and S. Akira, Autophagy in infection, inflammation and immunity. Nat Rev Immunol, 2013. 13(10): p. 722-737.

121. Shibutani, S.T. and T. Yoshimori, A current perspective of autophagosome biogenesis. Cell Research, 2014. 24(1): p. 58-68.

122. Romanov, J., et al., Mechanism and functions of membrane binding by the Atg5-Atg12/Atg16 complex during autophagosome formation. EMBO J, 2012. 31(22): p. 4304-17.

123. Van Limbergen, J., et al., Autophagy: from basic science to clinical application. Mucosal Immunol, 2009. 2(4): p. 315-30.

124. Kaser, A. and R.S. Blumberg, Autophagy, microbial sensing, endoplasmic reticulum stress, and epithelial function in inflammatory bowel disease. Gastroenterology, 2011. 140(6): p. 1738-47.

125. Bestebroer, J., et al., Hidden Behind Autophagy: The Unconventional Roles of ATG Proteins. Traffic, 2013. 14(10): p. 1029-1041.

126. Choi, A.M.K., S.W. Ryter, and B. Levine, Autophagy in Human Health and Disease. New England Journal of Medicine, 2013. 368(7): p. 651-662.

127. Liu, G., et al., Self-eating and self-defense: autophagy controls innate immunity and adaptive immunity. J Leukoc Biol, 2013. 93(4): p. 511-9.

128. Mizushima, N. and M. Komatsu, Autophagy: renovation of cells and tissues. Cell, 2011. 147(4): p. 728-41.

129. Chen, Y. and D.J. Klionsky, The regulation of autophagy - unanswered questions. Journal of Cell Science, 2011. 124(2): p. 161-170.

130. Subramani, S. and V. Malhotra, Non-autophagic roles of autophagy-related proteins. EMBO Rep, 2013. 14(2): p. 143-51.

131. Patel, K.K. and T.S. Stappenbeck, Autophagy and Intestinal Homeostasis. Annual review of physiology, 2013. 75: p. 241-262.

132. Klionsky, D.J., Autophagy: from phenomenology to molecular understanding in less than a decade. Nat Rev Mol Cell Biol, 2007. 8(11): p. 931-7.

133. Jones, S.A., K.H.G. Mills, and J. Harris, Autophagy and inflammatory diseases. Immunol Cell Biol, 2013. 91(3): p. 250-258.

134. Virgin, H.W. and B. Levine, Autophagy genes in immunity. Nat Immunol, 2009. 10(5): p. 461-470. 
135. Gianchecchi, E., D.V. Delfino, and A. Fierabracci, Recent insights on the putative role of autophagy in autoimmune diseases. Autoimmun Rev, 2014. 13(3): p. 231-41.

136. Levine, B., N. Mizushima, and H.W. Virgin, Autophagy in immunity and inflammation. Nature, 2011. 469(7330): p. 323-335.

137. Choi, A.J.S. and S.W. Ryter, Autophagy in Inflammatory Diseases. International Journal of Cell Biology, 2011. 2011: p. 11.

138. Randall-Demllo, S., M. Chieppa, and R. Eri, Intestinal Epithelium and Autophagy: Partners in Gut Homeostasis. Frontiers in Immunology, 2013. 4: p. 301.

139. Nedelsky, N., et al., Inflammatory Bowel Disease at the Intersection of Autophagy and Immunity: Insights from Human Genetics, in Molecular Genetics of Inflammatory Bowel Disease, M. D'Amato and J.D. Rioux, Editors. 2013, Springer New York. p. 241-264.

140. Travassos, L.H., et al., Nod1 and Nod2 direct autophagy by recruiting ATG16L1 to the plasma membrane at the site of bacterial entry. Nat Immunol, 2010. 11(1): p. 55-62.

141. Saitoh, T., et al., Loss of the autophagy protein Atg16L1 enhances endotoxininduced IL-1 beta production. Nature, 2008. 456(7219): p. 264-8.

142. Plantinga, T.S., et al., Crohn's disease-associated ATG16L1 polymorphism modulates pro-inflammatory cytokine responses selectively upon activation of NOD2. Gut, 2011. 60(9): p. 1229-35.

143. Mostowy, S., Autophagy and bacterial clearance: a not so clear picture. Cell Microbiol, 2013. 15(3): p. 395-402.

144. Spalinger, M.R., G. Rogler, and M. Scharl, Crohn's disease: loss of tolerance or a disorder of autophagy? Dig Dis, 2014. 32(4): p. 370-7.

145. Cooney, R., et al., NOD2 stimulation induces autophagy in dendritic cells influencing bacterial handling and antigen presentation. Nat Med, 2010. 16(1): p. 90-7.

146. Saito, M., et al., Intestinal epithelial cells with impaired autophagy lose their adhesive capacity in the presence of TNF-alpha. Dig Dis Sci, 2012. 57(8): p. 2022-30.

147. Umeno, J., et al., Meta-analysis of published studies identified eight additional common susceptibility loci for Crohn's disease and ulcerative colitis. Inflamm Bowel Dis, 2011. 17(12): p. 2407-15.

148. Raine, T., Insights from immunology: new targets for new drugs? Best Pract Res Clin Gastroenterol, 2014. 28(3): p. 411-20.

149. Kim, J.H. and H.K. Song, Swapping of interaction partners with ATG5 for autophagosome maturation. BMB Rep, 2015. 48(3): p. 129-30.

150. Yousefi, S., et al., Calpain-mediated cleavage of Atg5 switches autophagy to apoptosis. Nat Cell Biol, 2006. 8(10): p. 1124-32. 
151. Conway, K.L., et al., ATG5 regulates plasma cell differentiation. Autophagy, 2013. 9(4): p. 528-537.

152. Nedjic, J., et al., Autophagy in thymic epithelium shapes the T-cell repertoire and is essential for tolerance. Nature, 2008. 455(7211): p. 396-400.

153. Cadwell, K., et al., A common role for Atg16L1, Atg5 and Atg7 in small intestinal Paneth cells and Crohn disease. Autophagy, 2009. 5(2): p. 250-2.

154. Hwang, S., et al., Non-degradative Role of Atg5-Atg12/Atg16L1 Autophagy Protein Complex in Antiviral Activity of Interferon gamma. Cell host \& microbe, 2012. 11(4): p. 397-409.

155. Prescott, N.J., et al., A Nonsynonymous SNP in ATG16L1 Predisposes to lleal Crohn's Disease and Is Independent of CARD15 and IBD5. Gastroenterology. 132(5): p. 1665-1671.

156. Cheng, J.-F., T300A polymorphism ofATG16L1and susceptibility to inflammatory bowel diseases: A meta-analysis. World Journal of Gastroenterology, 2010. 16(10): p. 1258.

157. Cadwell, K., et al., Virus-Plus-Susceptibility Gene Interaction Determines Crohn's Disease Gene Atg16L1 Phenotypes in Intestine. Cell, 2010. 141(7): p. 1135-1145.

158. Velikkakath, A.K.G., et al., Mammalian Atg2 proteins are essential for autophagosome formation and important for regulation of size and distribution of lipid droplets. Molecular Biology of the Cell, 2012. 23(5): p. 896-909.

159. Kishi-Itakura, C., et al., Ultrastructural analysis of autophagosome organization using mammalian autophagy-deficient cells. Journal of Cell Science, 2014. 127(18): p. 4089-4102.

160. Wei, J., et al., miR-143 inhibits cell proliferation by targeting autophagyrelated 2B in non-small cell lung cancer $H 1299$ cells. Mol Med Rep, 2015. 11(1): p. 571-6.

161. Saliba, J., et al., Germline duplication of ATG2B and GSKIP predisposes to familial myeloid malignancies. Nat Genet, 2015. 47(10): p. 1131-40.

162. Kang, M.R., et al., Frameshift mutations of autophagy-related genes ATG2B, ATG5, ATG9B and ATG12 in gastric and colorectal cancers with microsatellite instability. J Pathol, 2009. 217(5): p. 702-6.

163. Jo, Y.K., et al., Increased expression of ATG10 in colorectal cancer is associated with lymphovascular invasion and lymph node metastasis. PLoS One, 2012. 7(12): p. e52705.

164. Usategui-Martin, R., et al., Polymorphisms in autophagy genes are associated with paget disease of bone. PLoS One, 2015. 10(6): p. e0128984.

165. Schleinitz, D., J.K. Distefano, and P. Kovacs, Targeted SNP genotyping using the TaqMan(R) assay. Methods Mol Biol, 2011. 700: p. 77-87. 
166. Sadaghian Sadabad, M., et al., The ATG16L1-T300A allele impairs clearance of pathosymbionts in the inflamed ileal mucosa of Crohn's disease patients. Gut, 2015. 64(10): p. 1546-52.

167. Lassen, K.G. and R.J. Xavier, An alteration in ATG16L1 stability in Crohn disease. Autophagy, 2014. 10(10): p. 1858-60.

168. Wolfkamp, S.C., et al., ATG16L1 and NOD2 polymorphisms enhance phagocytosis in monocytes of Crohn's disease patients. World J Gastroenterol, 2014. 20(10): p. 2664-72.

169. Palomino-Morales, R.J., et al., Association of ATG16L1 and IRGM genes polymorphisms with inflammatory bowel disease: a meta-analysis approach. Genes \& Immunity, 2009. 10(4): p. 356-364.

170. Isaacs, K.L., How prevalent are extraintestinal manifestations at the initial diagnosis of IBD? Inflamm Bowel Dis, 2008. 14 Suppl 2: p. S198-9.

171. Portela, F., et al., Ulcerative colitis in a Southern European country: a national perspective. Inflamm Bowel Dis, 2010. 16(5): p. 822-9.

172. Langholz, E., et al., Changes in extent of ulcerative colitis: a study on the course and prognostic factors. Scand J Gastroenterol, 1996. 31(3): p. 260-6.

173. Solberg, I.C., et al., Clinical course during the first 10 years of ulcerative colitis: results from a population-based inception cohort (IBSEN Study). Scand J Gastroenterol, 2009. 44(4): p. 431-40.

174. Riegler, G., et al., Age-related clinical severity at diagnosis in 1705 patients with ulcerative colitis: a study by GISC (Italian Colon-Rectum Study Group). Dig Dis Sci, 2000. 45(3): p. 462-5.

175. Khan, N., et al., Prevalence of corticosteroids use and disease course after initial steroid exposure in ulcerative colitis. Dig Dis Sci, 2013. 58(10): p. 29639.

176. Kiss, L.S. and P.L. Lakatos, Natural history of ulcerative colitis: current knowledge. Curr Drug Targets, 2011. 12(10): p. 1390-5.

177. Farmer, R.G., K.A. Easley, and G.B. Rankin, Clinical patterns, natural history, and progression of ulcerative colitis. A long-term follow-up of 1116 patients. Dig Dis Sci, 1993. 38(6): p. 1137-46.

178. Dezelak, M., et al., A Prospective Pharmacogenomic Study of Crohn's Disease Patients during Routine Therapy with Anti-TNF-alpha Drug Adalimumab: Contribution of ATG5, NFKB1, and CRP Genes to Pharmacodynamic Variability. OMICS, 2016. 20(5): p. 296-309.

179. Cho, D.H., et al., Down-regulated expression of ATG5 in colorectal cancer. Anticancer Res, 2012. 32(9): p. 4091-6.

180. Kovaleva, V., et al., miRNA-130a targets ATG2B and DICER1 to inhibit autophagy and trigger killing of chronic lymphocytic leukemia cells. Cancer Res, 2012. 72(7): p. 1763-72. 
ANEXO 


\section{CONSENTIMIENTO INFORMADO/ESTUDIO GENÉTICO}

NOMBRE Y APELLIDOS

DNI

№ HISTORIA

MÉDICO QUE INFORMA

Ha recibido información verbal y escrita sobre el estudio genético que se va a realizar sobre Colitis ulcerosa.

De acuerdo con esta información he entendido que:

1. Se me va a extraer una muestra de sangre para realizar un estudio genético.

2. El objeto de dicho estudio es analizar genes que estén implicados en la Colitis Ulcerosa, que puedan tener relación con un peor curso de la enfermedad y con la respuesta a ciertos fármacos (biológicos).

3. Debido a la complejidad de estos genes, los estudios pueden demorarse más de un año.

4. Se me informará de los resultados del estudio a mí y/o a las personas por mí autorizadas.

5. Se guardará la confidencialidad de los resultados del estudio, pudiéndose utilizar los datos para estudios epidemiológicos.

6. Si es mi decisión, puedo ejercer el derecho de anular el consentimiento y/o decidir no saber el resultado, así como solicitar que se destruyan las muestras extraídas.

Leído el documento consiento que se me extraiga una muestra de sangre para realizar el Estudio Genético de los genes implicados en la Colitis ulcerosa

En Salamanca, a..........de de.

Firma del paciente

Firma del médico 